\section{Zwischen Physiokratie Und LANDSChaftsverschönerung: Die KulturLANDSCHAFt REINHARDTSGRIMMAS}

Tom Leukefeld

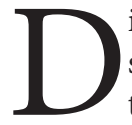

ie Gestaltung verschönerter Land- schaftung. Heute spricht man von einer Kulschaften im Umfeld von Rittergü- turlandschaft.

tern war im 18. und 19. Jahrhundert nichts Ungewöhnliches. Die Zeit nach dem Zur Begrifflichkeit der Kulturlandschaft Siebenjährigen Krieg und speziell das Jahr und der Landschaftsverschönerung 1770 gelten in Deutschland als Periodenum-

schlag im Wandel von barocken hin zu land- Um die Spannweite des Begriffs Kulturlandschaftlichen Gartenanlagen. ${ }^{1}$ Mit diesem schaft zu verstehen, sollen zwei verschieWandel breiteten sich die Parkanlagen in die dene Betrachtungsperspektiven angeführt Landschaft aus und immer weitläufigere werden: Einerseits bezeichnet der Begriff die Areale wurden in die Gestaltung mit einge- wirtschaftlich kultivierte Landschaft, andebunden. Dabei sind die bekanntesten ver- rerseits die nach ästhetischen Gesichtspunkschönerten Landschaften der Dresdner Um- ten gestaltete, gewidmete und sozial gegebung größtenteils zwischen 1770 und 1800 prägte Landschaft. Obschon der Begriff erst entstanden, wie der Röhrsdorfer Grund ( $a b$ in den letzten drei Jahrzehnten stärker in 1771) oder das Seifersdorfer Tal (ab 1781). Ei- den Fokus rückte, basiert er auf Vorstellun nige wurden aber auch erst im 19. Jahrhun- gen einer historischen, vom Menschen gedert geschaffen, wie die Anlagen des Schlos- stalteten Landschaft, die man lesen und aus ses Dittersbach samt Lieblingsthal (ab 1830) der man lernen kann. Der Begriff selbst oder die Maxener Spaziergänge (1819-1855). ${ }^{2}$ tauchte bereits im 19. Jahrhundert auf. ${ }^{3}$

Das ehemalige Rittergut Reinhardtsgrimma Die ästhetische Umgestaltung einer Landbietet als eines der Bindeglieder zwischen schaft kann als Fortführung einer Gartenöstlichem Erzgebirgsvorland und Dresden entwicklung angesehen werden. Die Enteine landschaftlich reizvolle Umgebung mit wicklung von einem formalen zu einem zahlreichen Feldfluren, Tälern und Waldflä- landschaftlichen Garten zog sich sowohl in chen. In der heutigen Landschaft springen Großbritannien als auch auf dem europäinoch einige markante Punkte ins Auge: schen Kontinent über Jahrzehnte hinweg mächtige Rotbuchenreihen, zwei bemer- hin, in denen nicht selten verschiedenste kenswerte klassizistische Gebäude mitten in Gartenformen gleichzeitig nebeneinander der Grimm'schen Heide, markante Felsvor- existierten. ${ }^{4}$ In Deutschland wurde dieser sprünge im Liebsteingrund, ein durch alte Wandel trotz Vorformen (wie im Bayreuther Lärchen gerahmter Ausblick am Feldrand, Sanspareil und im böhmischen Kukus Felsinschriften an der Ortsstraße, Obstal- (Kuks, Okres Trutnov)) erst nach dem Sieleen und alte Kirschgehölze in der Feldflur, benjährigen Krieg sichtbar, ${ }^{5}$ wobei man sich alte Gehöfte, ein markantes Schafstallge- an den verschiedensten Gärten in England bäude und zahlreiche Lesesteinhaufen - all orientierte, eigene Vorstellungen einbrachte, diese Spuren erzählen von einer Land- China als Vorbild ausmachte, die Literatur schaftsaneignung und einstigen Bewirt- einzubinden trachtete usw. ${ }^{6}$ Es war die Zeit des Experimentierens, die zu einer Reihe unterschiedlicher gestalterischer Lösungen führte, die - aufgrund ihrer Beliebigkeit mehr und mehr ins Kreuzfeuer der Kritik gerieten. Dabei schälten sich zwei Ansätze heraus, die sich rückblickend als zukunftsträchtig erweisen: zum einen entstand unter Friedrich Ludwig von Sckell (1750-1823) am Pfälzer Hof eine auf ästhetischen Kenntnissen beruhende Landschaftskunst, zum anderen eröffneten Persönlichkeiten wie der Sachse Wilhelm Gottlieb Becker (1753-1813) den Blick auf die Landschaft und die Möglichkeit diese zu verschönern.

Ausgehend vom formalen Garten wurde nun also ein Landschaftsgarten angestrebt und dabei auch versucht die umgebende Landschaft mehr und mehr einzubinden. Der Garten begann in die Landschaft überzugehen, sich auszubreiten und mit ihr zu verschmelzen. Folglich kann die Kulturlandschaft nicht losgelöst von der Entwicklung der Gartenkunst betrachtet werden. ${ }^{7}$ Das Bindeglied ist die Landschaftsverschönerung - wozu sich in Bezug auf die Verschönerung ganzer Länder durch eine Vielzahl von Gärten, Parks, Anpflanzungen und Gebäuden ab 1821 in Bayern auch der Begriff "Landesverschönerung " verbreitete. ${ }^{8}$ Diese Tendenz der Verschönerung manifestierte sich auch in Reinhardtsgrimma.

\section{Landschaftswandel in Sachsen im ausge-} henden 18. Jahrhundert

Ab 1750 wandelte sich im deutschen Kulturraum der Blick auf die Natur in vielfacher Weise: Zum einen hin zu einer wissenschaftlichen Methodik, wie sie bereits der Physiokratismus spiegelt, ${ }^{9}$ zum anderen änderte sich aber auch der Landschaftsbegriff unter sozialen und ästhetischen Gesichtspunkten - so sinnierte man plötzlichen in breiten Gesellschaftsschichten unabhängig vom Stand über Wert und Schönheit von Natur und Landschaft nach (Abb. 1).
Die im Entstehen begriffenen Naturwissenschaften fanden zunächst Interesse an verschiedenen Landschaftstypologien, d.h. geologischen Gegebenheiten, Flora und Fauna. Becker als einer ihrer Vordenker wurde 1799 zum Verfasser und Herausgeber einer Beschreibung des Plauischen Grundes im Süden Dresdens unter naturwissenschaftlichen und gartenkünstlerischen Darlegungen. Im Werk finden sich schriftliche Beschreibungen des Grundes, die stellenweise durch Ideen zur gärtnerischen Verschönerung der Landschaft ergänzt werden, sowie 25 aufwendige Kupferstiche, die neben malerischen Ansichten auch Tabellen, geologische Querschnitte, Schmetterlingsdarstellungen und Höhenprofile wiedergeben. $\mathrm{Zu}$ dem sind darin ein Aufsatz des Mineralogen Andreas Tauber, ebenso wie ein Pflanzenverzeichnis des Botanikers Friedrich Traugott Pursch (1774-1820) und ein Insektenverzeichnis des Entomologen Ludwig Heinrich von Block (1764-1834) enthalten. ${ }^{10}$

Becker wurde als Belletrist und Kunstschriftsteller bekannt, lehrte seit 1776 am Philanthropin Dessau, ${ }^{11}$ danach - von 1782 bis 1794 - als Professor an der Ritterakade mie zu Dresden und übernahm 1795 die Aufsicht über die Dresdner Antikengalerie und das Münzkabinett. ${ }^{12}$ Zudem veröffentlichte er Bücher zur Gestaltung und Ausstattung verschönerter Landschaften, wie etwa dem Seifersdorfer Tal (1792) oder dem Schlossgarten Teplitz $(1794,1813)$. Als Herausgeber des Werks »Taschenbuch für Gartenfreunde" (1795-1799) ist er gewissermaßen der Nachfolger des Gartentheoretikers Christian Cay Lorenz Hirschfeld (17421792) und dessen Gartenkalenders (17821789).

Stellt man Passagen aus Beckers Büchern in den zeitlichen Kontext, so wird deutlich, wie über Landschaft und ihre Verschönerung nachgedacht wurde:

»Hier lehnt sich ein Felsen neben ihm [dem Freund der Natur] empor, dessen 

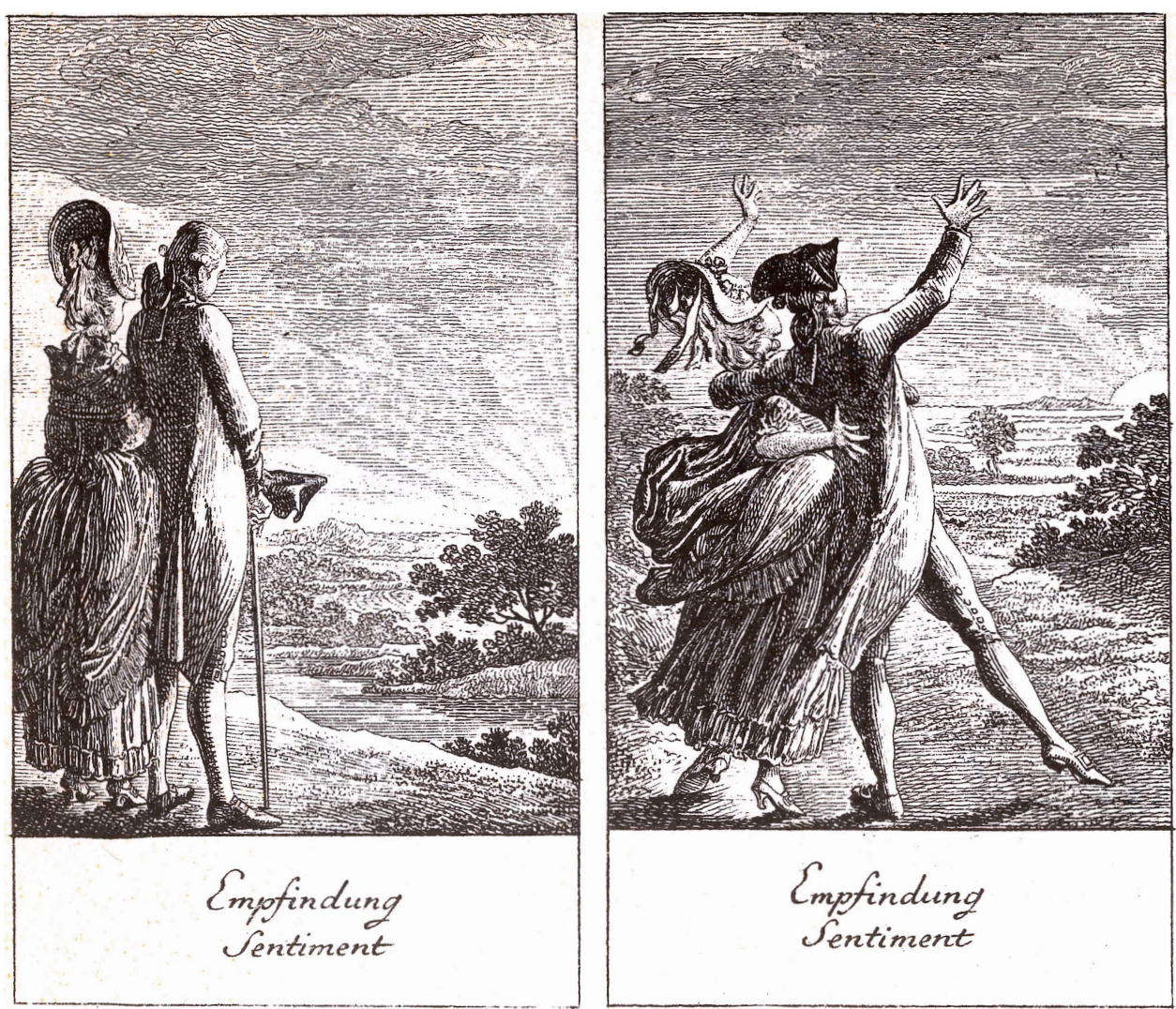

Empofindung

Sentiment

1 |»Empfindung, Sentiment«, Kupferstich, (aus Chodowieckis, Daniel `Natürliche und affektierte Handlungen des Lebens` (1799), in: Lichtenberg, Georg Cristoph: Handlungen des Lebens, Stuttgart 1971, S.50). Dort stellte Chodowiecki in semiotischer Weise die Unterschiedlichkeit der neuen bürgerlichen Lebenswelt gegenüber der, als künstlich betrachteten Adelswelt dar.

Nacktheit hie und da nur leichte Brom- Transparenz bestimmter Baumarten, die beersträucher bedecken; dort schmiege Textur verschieden großer Blätter, die Forsich ein spiegelnder Bach um eine blu- men der lokalen Topographie und außermichte Wiese, die schlanke durchsichte dem die Ästhetisierung der Landwirtschaft, Erlen umkränzen. Hier steigt ein bu- des weidenden Viehs und der arbeitenden schichtes Wäldchen den sanften Hügel hi- Landwirte selbst als Staffagefiguren. Diese nauf; dort strömen blühende Saaten in Landschaften sollten durch einzelne Bauhüpfenden Wellen. Schweigend sitzet der lichkeiten betont und verschönert werden, Hirt mit der tödlichen Angel am Bache, wie er am Beispiel des Seifersdorfer Tals 1792 indessen die bunte Heerde, unter dem beschreibt:

Schutze des wachsamen Hundes, zer-

streut am gegenüberliegenden Hügel weidet. $\ll^{13}$

Im Grunde beschreibt Becker hier eine bewirtschaftete >Naturlandschaft<. So dienen die Elemente der Naturlandschaft als eigentlicher Anreiz: natürliche Bachläufe, die

"Aber was dem Dichter und Maler diese Schönheiten der Natur noch reizender macht, sind die Denkmäler der Alten, und die Erinnerung vergangener Jahrtausende. Hier erblickt er die Trümmer eines Tempels, dort die ehrwürdigen Reste eines Grabmals, hier Triumphbogen von
Weltbezwingern, dort bewachsene Rui- dungsreisen in Italien kennenlernte, sonnen anmuthiger Bäder; hier die Spuren dern nordalpine Mittelgebirgsregionen. Feeines reizenden Landhauses, dort wieder derführend war Adrian Zingg (1734-1816), ans Licht gebrachte Gebäude versunkener der 1766 als einer der Wegbereiter der neuen Städte; hier den furchtbaren Orcus, und deutschen romantischen Landschaftsmaledort die elisaischen Felder. $\aleph^{14}$ rei nach Dresden kam. Als Schweizer hatte er eine Vorliebe für Landschaftsdarstellung Becker rekurriert dabei auf zwei Vorbild- en und flüchtete deshalb gerne aus der, landschaften: Helvetien, womit die rauen durch den Siebenjährigen Krieg zerstörten, Schweizer Landschaften gemeint sind, und Stadt Dresden in die Umgebung. Dort zeich das Welschland, das als sanfter beschrieben nete er unter anderem Partien in der Sächwird und bei Becker das Gebiet um den sisch-Böhmischen Schweiz sowie viele OrtsGenfer See bezeichnet. ${ }^{15}$ Als reizvoll be- ansichten, z.B. Liebethal, Rathen, Dohna, schreibt er die Kontraste dieser Gebiete. Ei- aber auch die erzgebirgischen Ortschaften nerseits die schroffen, steinigen und felsrei- Gießhübel bei Bad Gottleuba oder Frauenchen Gebirge der Schweiz mit farbig glän- stein und Wolkenstein. ${ }^{19}$ "Viele Motive erzendem Schnee und Eis, in denen die An- langten erst durch seine einschlägigen Wiemut ganz aus der Natur erwächst. Anderseits dergaben Berühmtheit. $\ll^{20}$ Er verwendete die die "holderen « Reize Norditaliens mit my- in der Heimat vorgefundenen idyllischen thischen, sagenumwobenen Landschaften Landschaftselemente, die dem klassischen voller Kulturdenkmale vergangener Zeiten - Kanon entsprachen: sanfte Berge, rauwobei er selbst sie noch nicht `Kulturdenk- schende Bäche, Hütten, Hirten, Herden. Die maler nennt. Diese Unterschiedlichkeit Sehnsuchtslandschaft Italien wurde plötzbringt ihn dazu, die Landschaft als zwiefa- lich in Sachsen gespiegelt. che Gattung zu bezeichnen. Die Landschaft ist demnach eine Medaille mit zwei Seiten. Aber auch die allgemeine LandschaftswahrEiner greifbaren, natürlichen, geologischen nehmung wandelte sich in gesellschaftlicher, und biologischen Seite (z.B. beeindru- religiöser, literarischer und künstlerischer ckende, schroffe Felsen) und einer assoziati- Hinsicht, wie Krepelin und Thränert in ihven, sentimentalen, unsichtbaren Seite mit rem Werk »Die gewidmete Landschaft « ausgeschichtsträchtigen Symbolen (z.B. mit führlich beschreiben. War das Spazieren dem Elysium oder den Nymphen in Verbin- und Lustwandeln in der Natur noch bis dung gebrachte Orte). Dabei lobt Becker die Ende des 18. Jahrhunderts dem Adel vorbeBildungsreisenden, die ihren Geist nähren halten ${ }^{21}$ so erlangte es mit der steigenden möchten und sich diesen Landschaften zu- Kaufkraft und einem erstmals ausreichenwenden. ${ }^{16}$

den Maß an Freizeit auch beim Bürgertum zunehmende Beliebtheit. ${ }^{22}$ Zugleich wurde Durch die Möglichkeit des Bereisens der das Naturempfinden von religiösen Konnokontrastreichen Schweizer Lande bekam tationen gelöst, durch wissenschaftliche soman ein neues Gefühl für die eigene Her- wie emotionale Bedeutungen (ja letztlich kunftsregion. Und sofort zog man Analo- durch die Empfindsamkeit) neu besetzt und gien und gab letztlich der Sächsischen damit einer quasireligiösen "metaphysiSchweiz ihren Namen. ${ }^{17}$ Dies geschah jedoch schen Schönheit « gleichgestellt. ${ }^{23}$ Im Konnicht plötzlich, sondern ist einem Prozess text dieser kulturhistorischen Entwicklung zuzuschreiben, in dem die Landschaftsmale- des Spaziergangs und dem Wunsch nach rei eine Leitkunst bildete. ${ }^{18}$ Dabei wurden eindrücklichen Naturerlebnissen entstaneben nicht mehr unbedingt die klassischen den vor allem ab 1770 landschaftliche Verlandschaftlichen Schönheiten jener Orte re- schönerungen, wobei man auf den vorhanzipiert, die man auf den traditionellen Bil- denen Feldern, Wiesen und Äckern mit Sitz- 
gelegenheiten, Kleinarchitekturen, Denk- Die ersten Landschaftsverschönerungen mälern und Felsinschriften landschaftlich in Reinhardtsgrimma

reizvolle Situationen betonte. ${ }^{24}$ Diese ver-

schönerten Landschaften wurden - insofern Obwohl der Commerzienrat Johann Chrissie zugänglich waren und nicht auf Privat- toph Lippold (gest. 1780) gerade in der Zeit grundstücken lagen - beim städtischen Pub- einer neuen Landschaftsästhetik 1767 das likum sehr beliebt, da sich dort schon im barocke Schloss in Reinhardtsgrimma erfrühen 18. Jahrhundert bauen ließ, zeigt der formale Lustgarten, dass das Rittergut zu diesem Zeitpunkt von "eine sozial erstaunlich breit verankerte den aktuellen landschaftlichen Impulsen städtische Ausflugskultur herausgebildet unberührt blieb. ${ }^{28}$

[hatte], die den sonn- und feiertäglichen

Spaziergang zur massenhaft ausgeübten Praxis machte. ${ }^{25}$

Dabei nahm die Residenzstadt Dresden gegenüber anderen deutschen Städten eine frühe Vorreiterrolle bei der Ausbildung einer Spaziergangstradition ein. ${ }^{26}$

Die Dualität von Natur- und Kulturlandschaft spiegelte sich auch in den Bezeichnungen, die man ihr gab. Noch bevor Landschaften im ausgehenden 18. Jahrhundert literarisch-sentimental oder in Bezug auf andere europäische Landschaften benannt und gewidmet wurden, erhielten sie zwecks einfacherer Orientierung und Bewirtschaftung differenzierte Bezeichnungen. Die Flurstücke der Rittergüter und Dörfer fanden ihren Ursprung in markanten geologischen Formationen, in bestimmter Vegetation oder Topografie, aber auch in Besitzverhältnissen. Die Gutskartierung Reinhardtsgrimmas von 1628 zeigt die Flurnamen "Martin Liebsteins Holz«, "Nieseldörners Wise", "des Schefers Grase randt" oder das »Pfarrfeldt « mit Besitzkonnotation. Schlichte Landnutzungen tauchen bei »Lehmgrube«, "Hopffberk « oder »Grummetwise der Dorffgrund « auf. Zudem sind die Namen oft mit topografischen Begriffen gekoppelt. ${ }^{27} \mathrm{Mi}$ dem Wandel der Landschaftswahrnehmung und der Landnutzung entwickelten auch sie sich unter den Gutsherren von Bülow, Ruschenbusch und Aster kontinuierlich weiter. Besonders unter der Gutsherrschaft der Asters zeigte sich eine Bandbreite verschiedener Widmungen.
Erste Hinweise auf die Verschönerung der Landschaft um Reinhardtsgrimma gibt es unter Carl Viktor August von Broitzem (1741-1812). Dieser ließ im Juli 1793 eine Promenade durch den Birk- und Teichbusch (später: Pfarrbusch) nördlich am Liebsteingrund anlegen und gab damit den Anstoß für die erste Gestaltungsphase. ${ }^{29}$ Obwohl es in Reinhardtsgrimma keine Hinweise auf ein durchgängiges Gestaltungskonzept uner von Broitzem gibt, lassen sich wiederum auf seinem Erbsitz Ebersbach bei Görlitz um 1800 großräumige Gestaltungen nachweisen, die - wie in Reinhardtsgrimma - architektonische Gartenelemente und Promenaden samt Baumgruppen in der Landschaft miteinander verbanden:

»Hinter dem Oberhof Gebäude auf der Abendseite ist ein weiter ofner Garten von dem ietzigen Lehnsherr von Broizem angelegt worden. Es ist derselbe in vier Theile getheilt, mit allerl. ausländischen Bäumen u. Gewächsen besetzt ingl. mit Alleen von Linden u. mit Buchen umgeben. [...] An den Seiten des Gartens sind außer den bedeckten Lindengängen auf den Tarrassen breite Gänge mit Buchenwänden. Auch sind Morgenwärts am Garten u. auf jeder Seite desselben Anlagen zu Fontainen. [...] An diesen Garten grenzt auf der Mittagsseite ein Spaziergang auf den Dämmen u. an den Wiesen der Lehnseite in Sträuchern u. hohen Birken welcher bis an den kleinen Steinberg u. hinter demselben bis an den Krahberg geht. Eben so hat auch der gedachte iet- zige Besitzer des Guths um den Wall her tung der sächsischen Forstvermessungsanden Weg durch Lindenalleen $u$. sofort auf stalt in Tharandt ab 1811 endlich zusammender Promenade am Wasser $u$. auf an den wuchsen, war man in Reinhardtsgrimma Wegen durch Papeln, Linden, Castanien- also auf dem neuesten Stand. ${ }^{33}$

Bäume zu Verschönerung der Gegend

beyzutragen gesucht. $\ll^{30}$

Als die von Bülows im Jahr 1800 Reinhardtsgrimma von den von Broitzems erwarben, kam es durch Hofbaumeister Christian Friedrich Schuricht (1753-1823) zur Umwandlung des formalen Gartens in eine sentimentale landschaftliche Anlage. ${ }^{31}$ Daraufhin muss auch der Wunsch entstanden sein, den angrenzenden Liebsteingrund entlang des Lockwitzbaches weiter auszugestalten, um so die Grenzen zwischen Schlossgarten und umgebender Landschaft aufzulösen. Der Liebsteingrund wird damit zu einer Fortsetzung des Landschaftsgartens. Neben Schuricht, der unter anderem Hirschfelds richtungsweisende »Theorie der Gartenkunst« illustrierte, muss im Zusammenhang mit diesen Bestrebungen der Blick auf Joseph Friedrich von Racknitz (1744-1818) den Schwiegersohn des Gutsherren Friedrich Ludwig Ernst von Bülow (1738-1811) fallen, der deutschlandweit als eine künstlerische Leitfigur galt und selber die Umgebung seines Gutes Ringethal verschönerte. Auf ihn werden wir am Ende noch einmal zurückkommen.

Eine der bildhaftesten und vollständigsten Darstellungen der verschönerten Landschaft unter von Bülow bietet die »Forstcharte vom Ritterguth Reinhardtsgrimme - aufgenommen im Jahr 1807 (Abb. 2). Mit der Darstelung von Grenzverläufen, Grenzsteinen samt Nummerierung, Wegen, Alleen, Baumarten, beigemischten Arten (»Melirung«), dem Alter der Bestände, von Wiesen, Feldern und Flurbezeichnungen war sie zur Zeit ihrer Entstehung fortschrittlich und ist vermutlich das Resultat einer Zusammenarbeit zwischen von Bülow und dem Förster Georg Konrad Ruschenbusch (1785-1866). Als Forstvermessung, -taxation und -kartierung unter Heinrich Cottas (1763-1844) Lei-
Über die genauere Entstehung der Forstkarte sind keine Hinweise bekannt, doch ist auffällig, dass zahlreiche Details benannt und eingezeichnet wurden, die nicht rein wirtschaftlich begründet, sondern gestalterischer Natur sind. Im Fokus liegt dabei der Liebsteingrund. Dort am Unterhof (B) sind eine Linde mit Rasenbank (x2), ein Pavillon (m), ein Parapluie (w2), steinerne Bänke (s2), eine Ruine (q2) und ein Portal (r2) eingetragen. ${ }^{34} \mathrm{Da}$ der $»$ melirte s sprich Mischwald sehr kleinteilig und detailliert aufgenommen wurde, ist anzunehmen, dass es sich um einen tatsächlichen Bestandsplan handelt. Zwar ist nicht jedes gestalterische Element in den Akten wiederzufinden, aber zum Beispiel sollte $1801 »[$ dem] Parapluis in der Promenade ein neuer Grund gegeben [werden] «35. Dieser stand im nördlich an den Liebsteingrund angrenzenden Pfarrbusch, den schon von Broitzem in die Promenade eingebunden haben soll (Abb. 3a). ${ }^{36}$ Dort befand sich laut Forstkarte ein Abzweig von der Tal-Promenade. Sie führte vorbei an einem kleinen Teich - in der Forstkarte als Tümpel (u2) bezeichnet -, der mittels eines Damms (v2) angestaut wurde. Am Tümpel konnte man bis zum Feld hinaufsteigen, von dort eröffnete sich der Blick auf den großen Wilisch (476m). Diese Strukturen sind bis auf den Parapluie auch heute ansatzweise noch vorhanden. Einen derartigen Aufgang zu den Feldern Niederfolgen (t2) und Folgen (n) mit Ausblick zum groBen Wilisch gab es auch am Pavillon (m) Den Aufgang aufs Feld markierten dort zudem zwei beiderseits des Weges gepflanzte archen. Mit ihrem goldfarbenen Herbstschmuck und der sonst hellgrünen Laubfärbung dürften sie sich vom restlichen Bestand abgehoben haben und eine Art natürliche Rahmung der Landschaft gebildet ha- 


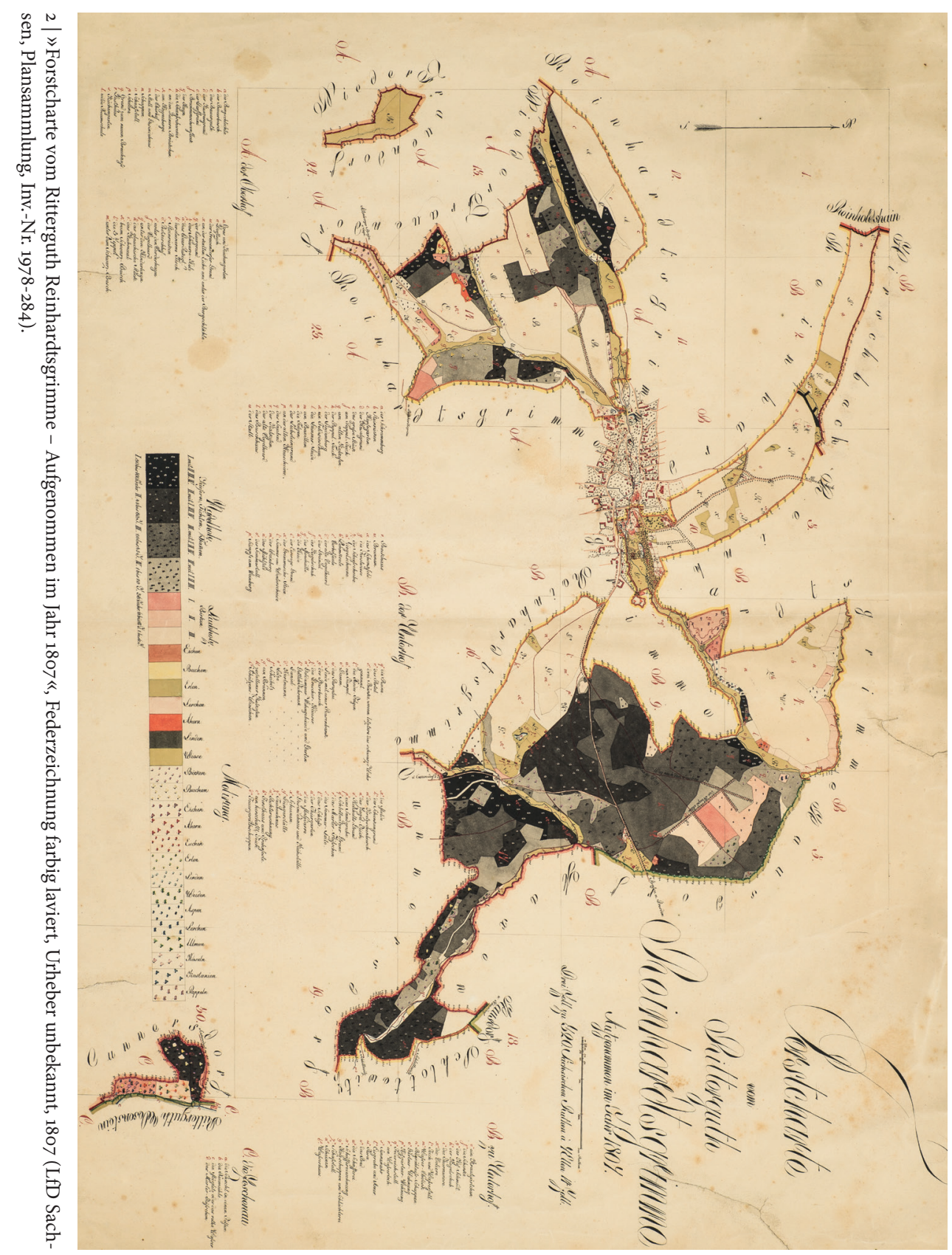

überliegenden Talseite, südlich des Lock- urkundlich erwähnt $1206^{39}$ - trieb laut Powitzbaches, hatte man zudem eine Hangpro- enicke sein Unwesen durch Raub und Wegemenade mit Ruine und Portal angelegt. Die lagerung. Zudem war er wohl in Konflikte Stellen, an denen besagte Ausschmückung- zwischen den Burggrafen von Dohna und en lagen, sind auf einer Flurkarte von 1809 den Markgrafen von Meißen verwickelt. im Foyer des Schlosses Reinhardtsgrimma Schließlich soll er unter Mithilfe eines Riteingetragen und nummeriert - nur fehlt ters Reinhardt von Bernstein besiegt worden dort die entsprechende Legende. Letztlich sein, wobei man wohl seine Bergfeste handelte es sich hier also um einen zwischen Gimmstein zerstörte. Zur Belohnung erhielt 1807 und 1809 angelegten Spaziergang durch Ritter Reinhardt Besitzungen an der Stelle den Liebsteingrund, der - ergänzt durch die des heutigen Schlosses..$^{40}$ Damit handelt es gegenüberliegende Hangpromenade - als sich quasi um den Gründungsmythos ReinRundweg begangen werden konnte. Ver- hardtsgrimmas, welcher durch den Bau eischönert war er mit >Verweilobjekten und ner kleinen Einsiedelei an dieser Stelle nochmit Ausblicken in die umgebende Land- mals besondere Wertschätzung erfuhr. Man schaft. Auch wurden einige geologische Be- ließ dort ein »liebliches mit Moos ausgekleisonderheiten, wie Vorsprünge am südlichen detes Lusthaus« - die "Mooshütte« - bauen Talhang durch Kleinarchitekturen, wie die (Abb. 3b), ${ }^{41}$ die dazu einlud vergangene Zeikünstliche Ruine, geschickt inszeniert. ten in einer rustikalen Architektur nachzuempfinden. Das genaue Aussehen und AusEin verlängerter Spaziergang führte von maß ist nicht bekannt, trotzdem handelte es dort Richtung Südosten in den Schlottwitz- sich um ein typisches Ausstattungselement grund, vorbei an der auf einem Felssporn der Zeit um 180o. Eine solche Hütte spielte gelegenen Ruine Grimmstein. Es wird wohl beispielsweise auch in Goethes Roman kein Zufall sein, dass man sie just in der Zeit "Wahlverwandtschaften " (1809) eine beder von Bülows als vermeintliche Feste des deutsame Rolle. Dort war die Mooshütte ein Raubritters Reinoldus de Grymme wieder- kleines Lusthaus, welches höchstens vier entdeckte und propagierte. Erstmals darge- Personen Platz bot, durch ihre Fenster gestellt wurde sie in der Forstkarte von 1807 rahmte Blicke in die Landschaft freigab, für und schriftlich erstmals 1816 erwähnt. ${ }^{38}$ Der persönlichste Gespräche diente und zurückRaubritter Reinoldus de Grymme - zuerst gezogene Momente ermöglichte. ${ }^{42}$
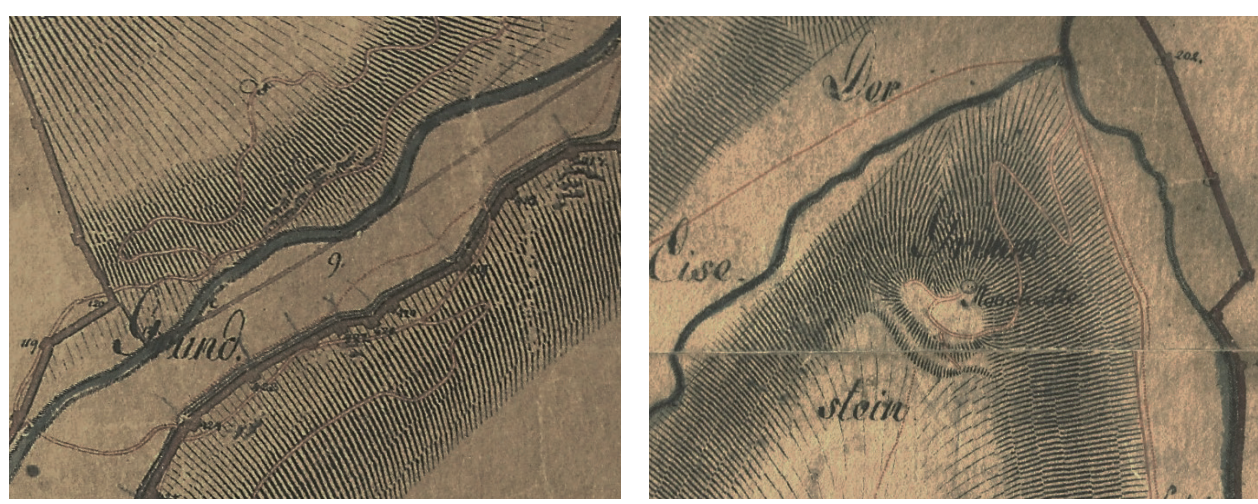

3a und b | Flurkarte des Rittergutes Reinhardtsgrimma (Ausschnitte), Federzeichnung farbig laviert, Urheber unbekannt, 1808/1809 (Originalplan im Foyer des Schlosses Reinhardtsgrimma). Ausschnitt links (3a) Liebsteingrund mit nördlicher Promenade im Pfarrbusch samt Parapluie am oberen Weg. Ausschnitt rechts (3b) Mooshütte mit Fußweg in den Schlottwitzgrund. 
Forst und Jagd Reinhardtsgrimma mit der Spazierenden mit zusätzlichen Baumreiseinen Feldern, der Heide und den Waldflä- hen einrahmte oder ob sie der Jagd dienten, chen sowie dem Talgrund umfasst seit Jahr- ist dabei nicht sicher. Das Forsthaus (b4) lag hunderten artenreiche Lebensräume, die vor 1807 noch südlich des Schlosses nah der allem für die Jagd bedeutend waren. Seit Schlossmühle..$^{52}$ Spätestens 1891 wurde es auf dem 16. Jahrhundert war diese nachweislich die Nordseite des Schlosses neben die ein wichtiger Faktor in Reinhardtsgrimma: Schlossgärtnerei verlegt (Abb. 5)..$^{53}$ erwarb 1571 zunächst Kurfürst August (1526-

1556) die Jagdgerechtigkeit, so folgte ihm Um 1807 finden sich in Reinhardtsgrimma gleich Kurfürst Johann Georg I. (1585-1656) zudem sogenannte Vogelherde (Forstkarte: nach. ${ }^{43} \mathrm{Ob}$ die Kurfürsten vor Ort selber $\mathrm{Af}_{2}$ und $\mathrm{Bd}_{2}$ ). Dies waren Einrichtungen Tiere erlegten oder diese einfangen und in zum Vogelfang mit Hügeln, Verstecken und ihre eigenen Wildgehege - wie etwa nach Fallen auf einem gerodeten Stück Wald. Im Moritzburg - überführen ließen, bleibt of- Fokus standen die als Delikatesse angesehefen. Ab 1806 ist zumindest ein »Rehgarten" nen Krametsvögel, womit Wacholderdrosnördlich des Schlosses belegt ${ }^{44}-1807$ auch seln gemeint waren (Abb. 6 und 7). ${ }^{54}$ Der "Thiergarten « genannt. ${ }^{45} \mathrm{Da}$ es sich um eine Vogelfang war in Sachsen und gerade im eher kleine Fläche handelte - die Empfeh- Erzgebirge und Vogtland weit verbreitet, da lung für einen Rehgarten bezog sich auf ein besagte Drosseln mit Vorliebe die dort heiAreal nicht kleiner als zehn Morgen (rund mischen Vogelbeeren verzehren und ihr $2,5$ ha $)^{46}$ - ging es sicher nur um die Pflege Fang nicht wenigen Familien einen winterlikranker Tiere oder die Aufzucht einzelner, chen Nebenverdienst einbrachte..$^{55} \mathrm{Ab} 1800$ um den Bestand zu unterstützen. ${ }^{47}$

begann zwar mit der Zuwendung zur Biologie, Ökologie und der nicht zuletzt romantisch induzierten Beschäftigung mit heimi-

Das lohnenswerte Jagdgebiet mag auch ein Grund dafür gewesen sein, warum von Bü-
low, der nach seiner Ausbildung auf der Lü-
phase des Naturschutzes,,$^{56}$ trotzdem gab es neburger Ritterakademie sogleich als Hof- maßgebliche Veränderungen und klar festund Jagdjunker in hannöversche Dienste geschriebene Fangverbote erst 1888 mit dem trat, Reinhardtsgrimma erwarb. ${ }^{48}$ Unter von Reichsvogelschutzgesetz. ${ }^{57}$

Bülow wird 1802 Georg Conrad Ruschen-

busch (1785-1866) als Förster angestellt. Dieser stammte aus einer kurhannoverschen Försterfamilie und war durch Familienbande an den ebenfalls von dort stammenden von Bülow empfohlen worden. ${ }^{49} \mathrm{Da}$ es wie u.a. eine Beschreibung von 1822 wieder gibt - nicht nur einen umfangreichen Waldbestand, sondern auch eine mittlere und niedere Jagd gab,,$^{50}$ muss sein Aufgabenfeld recht groß gewesen sein.

Der Grimm'sche Forst war zwischen 1807 und 1809 mittels der sogenannten Hauptallee und mehrerer kleiner Nebenalleen gegliedert. Die Wege- und Alleenstruktur mutet wie die Miniatur-Variante eines Jagd- Angreifen bringen und auf diese Weise aus sterns (Abb. 4) an. ${ }^{51} \mathrm{Ob}$ die Alleen eine Art der Nähe schießen. ${ }^{59}$ Nicht nur zum Schutz

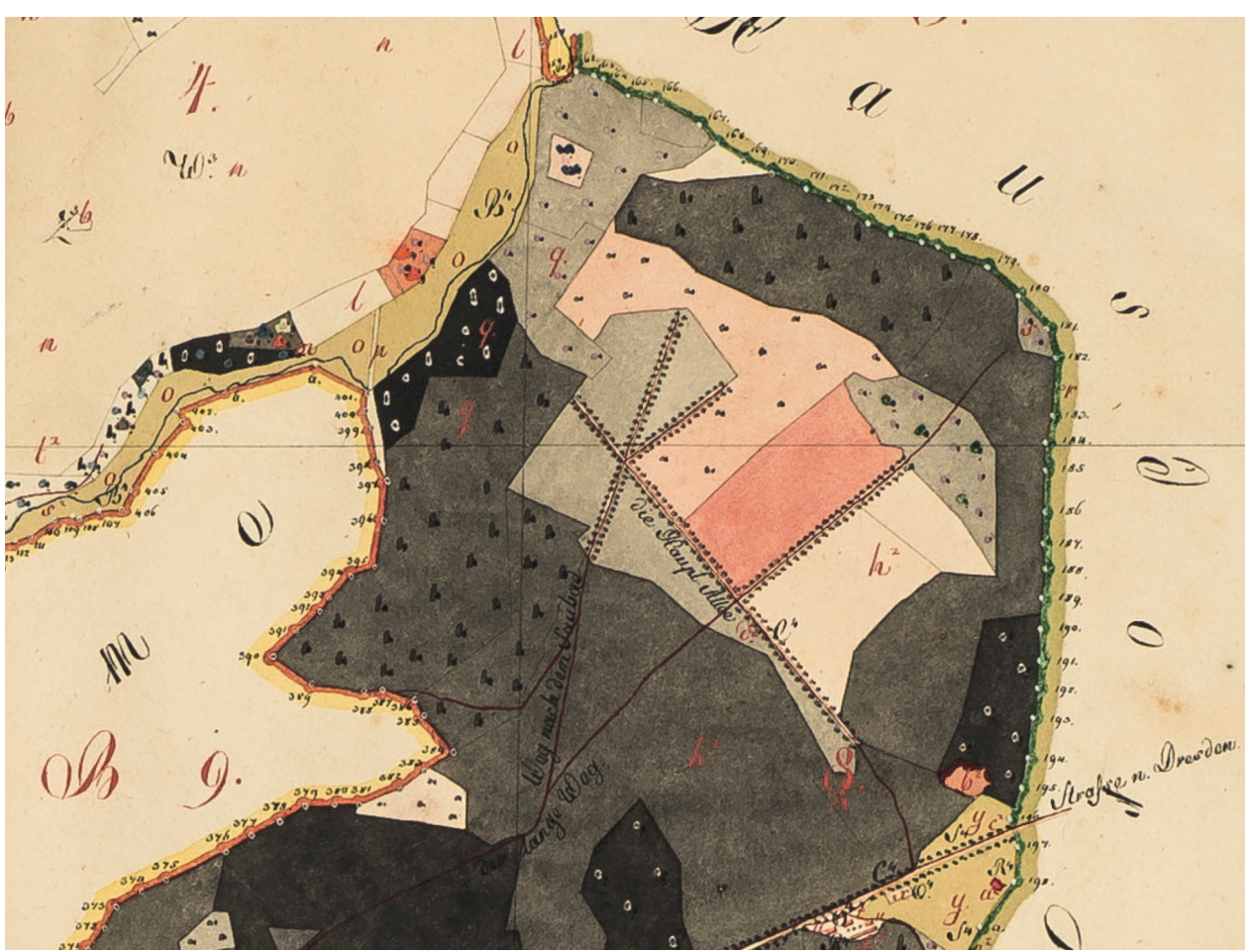

$4 \mid »$ Forstcharte vom Ritterguth Reinhardtsgrimme - Aufgenommen im Jahr 1807《 (Ausschnitt von der Grimmschen Heide), Federzeichnung farbig laviert, Urheber unbekannt, 1807. Am unteren Bildrand liegen die Forstwies (y) mit Ziegelscheune $\left(\mathrm{a}^{2}\right)$ und direkt westlich davon mehrere Gebäude samt Kegelschub $\left(\mathrm{f}^{2}-\right.$ schwer lesbar am Standort der späteren Buschhausschänke) (LfD Sachsen, Plansammlung, Inv.-Nr. 1978-284).

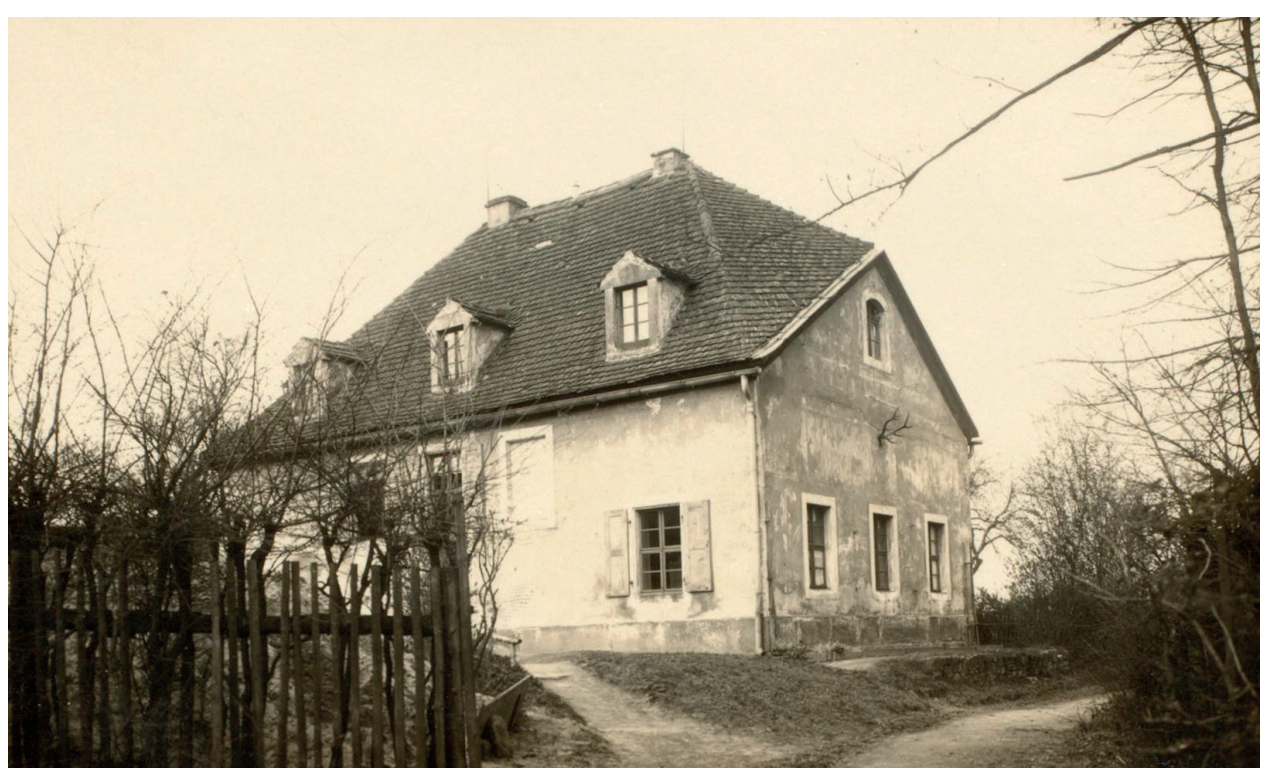

Forsthaus Reinhardtsgrimma auf der Nordseite des Schlosses an der Stelle des ehemaligen Gärtnerwohnhauses (B-04 auf Forstcharte 1807), Fotografie, Urheber unbekannt, 1927 (SächsHStA, 10505, Nr. 391, Baul. Veränderungen Forsthaus, 1927/28). 


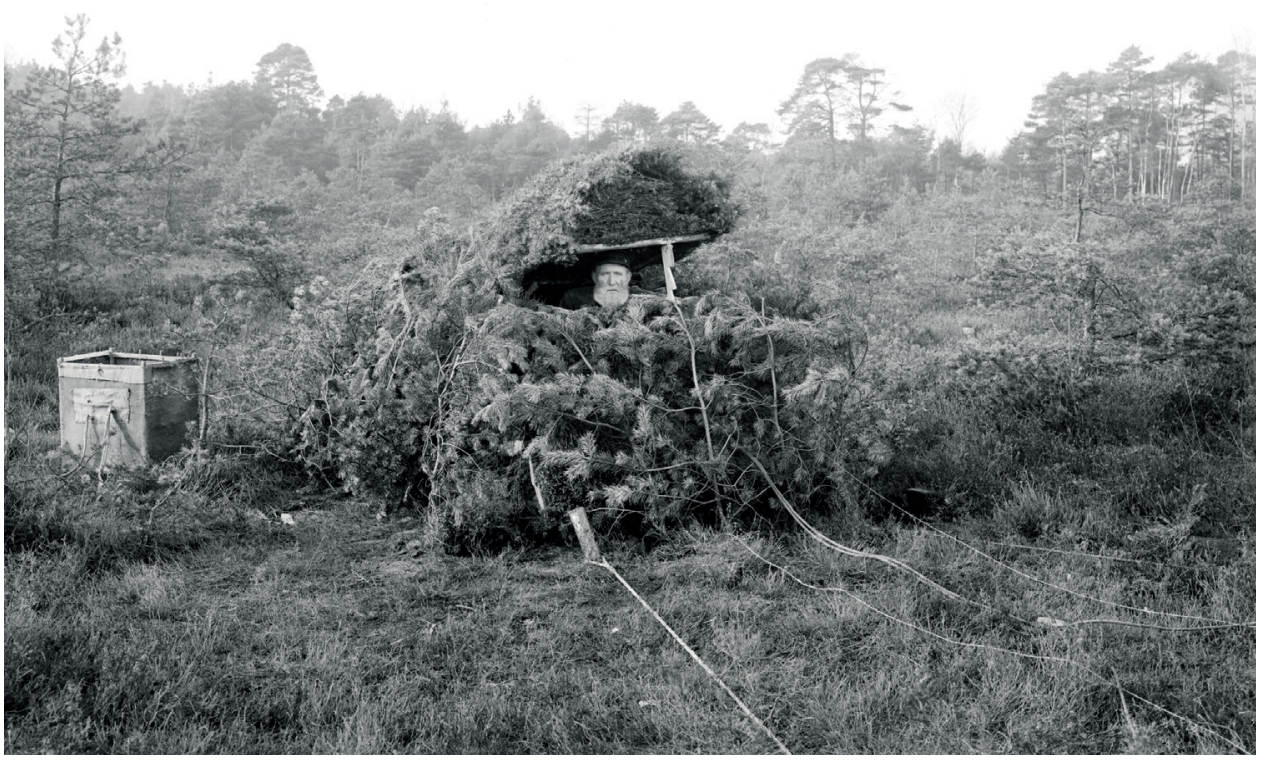

6 Krammetsvogelfang in Vadrup, Münsterland, 1916: Vogelfänger in seiner Tarnhütte hinter der Fangnetzanlage - Fotodokumentation des Ornithologen Dr. Hermann Reichling zum Massenfang der Wacholderdrossel als Speisevogel, Glas-Negativ, Urheber: Hermann Reichling, 1916 (LWL Medienzentrum für Westfalen, Archiv-Nr. 13_897 Ablage-Nr. HRo10_01).

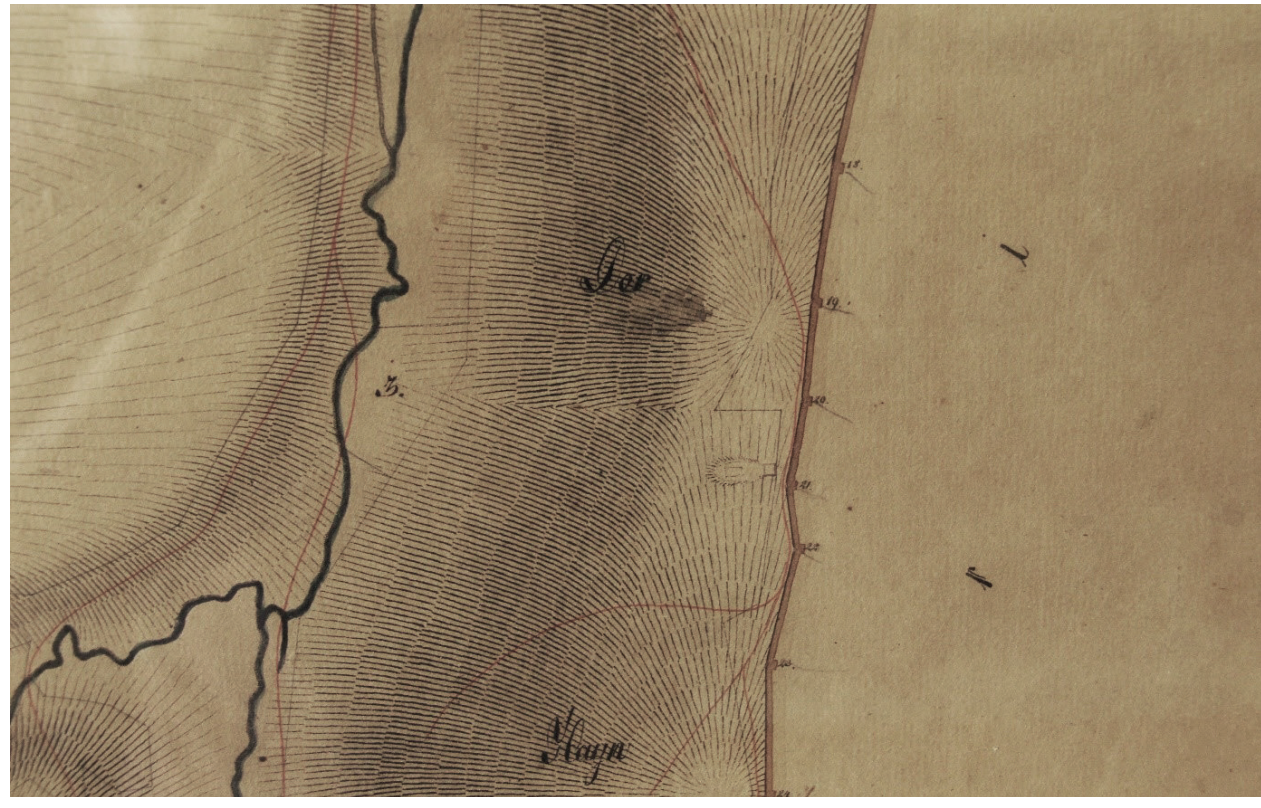

7 | Flurkarte des Rittergutes Reinhardtsgrimma (Ausschnitt Vogelherd im Waldstück `der Hayn`), Federzeichnung farbig laviert, Urheber unbekannt, 1808/1809 (Originalplan im Foyer des Schlosses Reinhardtsgrimma). von Saat, Obst und Hausvögeln, auch zum Die Buschhäuser

Vergnügen konnte man die Krähenhütte Zwischen 1810 und 1811 veranlasste von Bünutzen, waren doch solche Hütten häufig low die Errichtung der Buschhausschänke wie ein kleines Kabinett mit Sitzgarnitur (auch Buschhaus) an der Grimmschen und etwas Lichteinfall ausgestattet (Abb. 8). Hauptstraße (Abb. 9). Bei der Schänke hanDiesbezüglich sprach man sich selbst in der delte es sich um ein Ausflugslokal am OrtsZeitschrift der deutschen Ornithologischen eingang aus Richtung Hausdorf, das direkt Gesellschaft 1855 für Bau und Nutzung von an die Grimm'sche Heide und das sogeKrähenhütten aus. Neben dem Vergnü- nannte Gründel grenzte. ${ }^{61}$ Das heute als gungsaspekt drückt der Artikel den Zwie- klassizistisches Mustervorwerk anmutende spalt der Fachwelt während der Aufbruchs- Gebäudeensemble wird dem Dresdner Hofphase des Naturschutzes aus: baumeister Gottlob Friedrich Thormeyer (1775-1842) zugeschrieben..$^{62} 1811$ bestanden »Wenn wir uns die Mühe geben alle diese ersten Buschhäuser lediglich aus der Thiere zu überzählen, denen der Mensch Buschhausschänke, einem Kegelschub und nachstellt, so finden wir deren eine grosse eventuell einem weiteren Stall- oder WirtZahl; er stellt ihnen nach, einmal, weil es schaftsgebäude. Gegenüberliegend gab es ihm Vergnügen gewährt, dann, weil sie nach aktueller Quellenlage - das fast idenihm Nutzen oder Schaden bringen. [...] tisch anmutende Schießhaus noch nicht, ${ }^{6}$ Während er [Herr Dr. Gloger] spricht: aber vermutlich eine Art Jagdplatz mit ,Weg mit den Krähenhütten! ‘, rufe ich aus Schießscheibe. Ein solches Ensemble aus voller Ueberzeugung: >Bauet Krähenhüt- Kegelschub und Schießscheibe lässt sich beten, wo es nur angeht! « ${ }^{60}$ reits 1807 nachweisen. Zur 1811 ergänzten Buschhausschänke gehörte zudem ein Schankgarten, welcher durch Rosskastanien

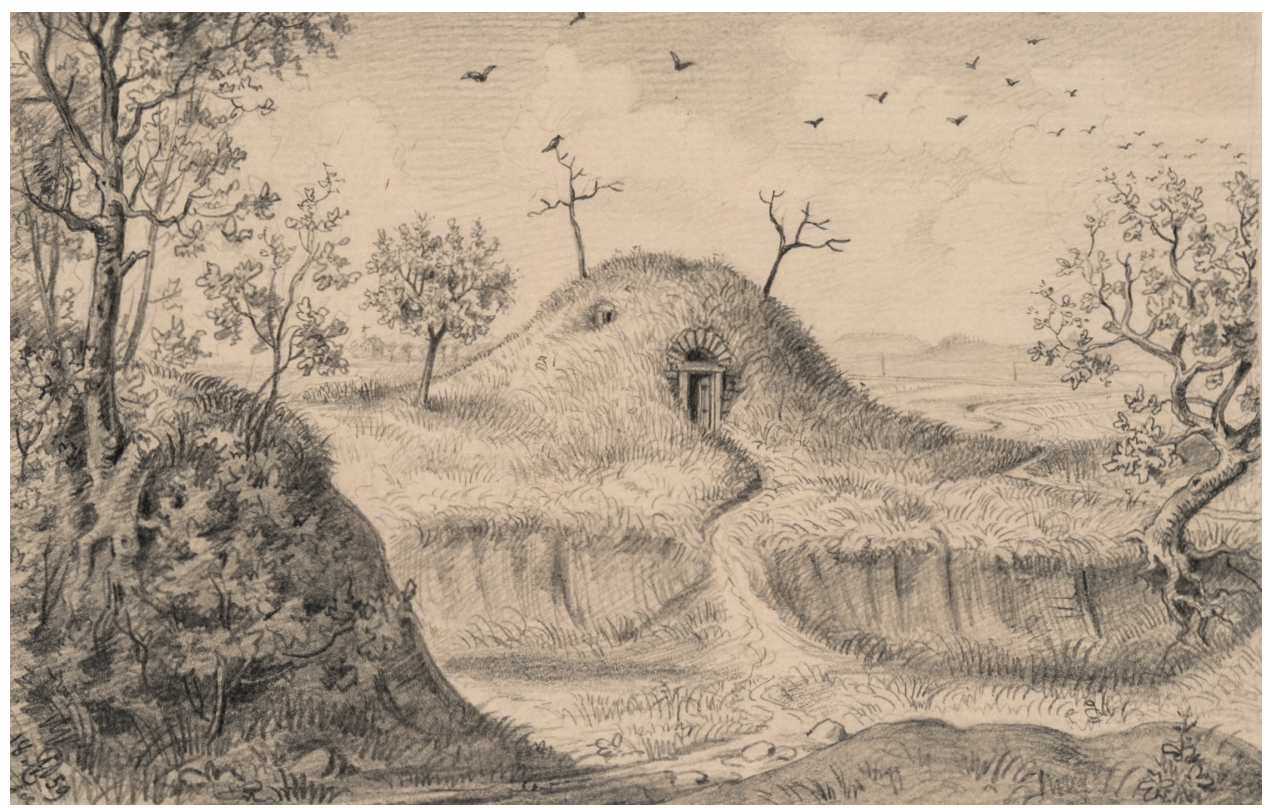

8 Alte Krähenhütte im Großen Garten zu Dresden, Bleistiftzeichnung, Hersteller: Max Eckart (SKD, Inv.-Nr. C 1995-1013). 


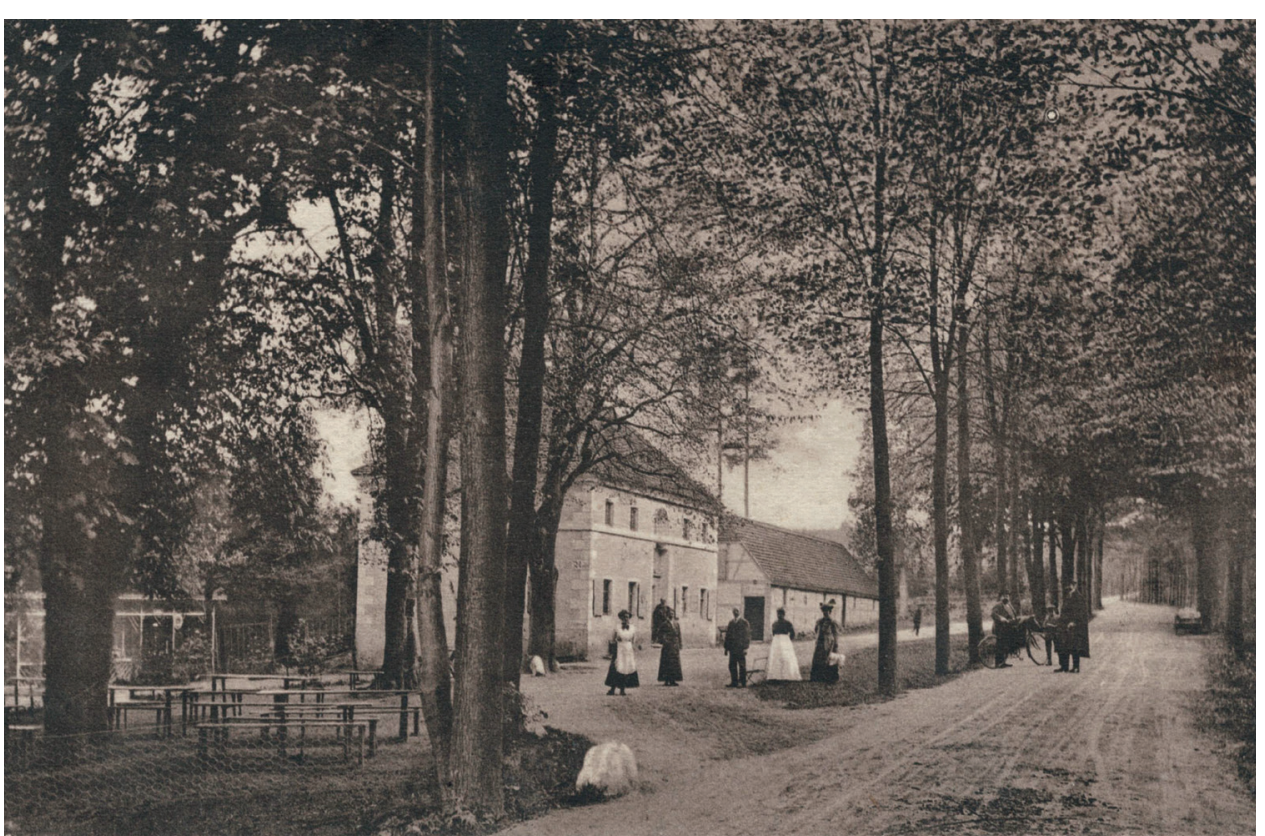

9 | Buschhausschänke Reinhardtsgrimma unter Inhaber Otto Röhringer (auf Rückseite bedruckt), Ansichtskarte um 1910 (Privatarchiv Köhler Dresden). Zu sehen sind anschaulich die Glashütter Straße mit Allee, die Buschhausschänke mit Kutsch-/Autovorfahrt, Biertischgarnituren unter einer Kastanie und eine Art Pavillon aus Lattenwerk im Hintergrund (linker Hand).

verschattet war. Darin befanden sich wohl ist. ${ }^{66}$ Solche Lehmgruben wurden häufig be ein mit Bänken und Tischen umgebener geplanten Neubauten angelegt, um die ZieBrunnen samt Pumpe, eine Laube mit Ti- gel vor Ort zu brennen. War genug Baustoff schen und Sitzplätzen sowie weitere Sitzge- hergestellt, wurden sie geschlossen und fülllegenheiten vor dem Eingang und unter den ten sich in der Regel schnell mit Wasser. Kastanien. Eine Beschreibung dieser Einrichtung findet sich erst in der Aufstellung Die »Buschhausschänke« aber auch die beides unbeweglichen Inventars von 1874. ${ }^{64}$ den im Dorf gelegenen Gaststätten (Erbgericht am Schloss und Brauhaus auf dem richt am Schloss und Brauhaus auf dem
Oberhof) lassen darauf schließen, dass beNordöstlich der Schießscheibe am Rande Oberhof) lassen darauf schließen, dass be der Grimm'schen Heide lag eine Lehmgrube reits Anfang des 19. Jahrhunderts mit Ausmit »Verbotssäule.$^{65}$ Sie gehörte zur neben flüglern gerechnet wurde. Obwohl die Verder Buschhausschänke befindlichen Ziegel- fasser von Reisebeschreibungen und auch scheune und verweist auf die Lehmherstel- die Künstler Reinhardtsgrimma nur wenig lung. Solche kulturlandschaftlichen Spuren Aufmerksamkeit schenkten und den Or wie spezielle Wirtschaftsgebäude, Berg- nur kursorisch streiften, findet die umgeschächte oder Teiche tauchen um Rein- bende Landschaft immer wieder Erwähhardtsgrimma häufiger auf. Beispielsweise nung. Eine dieser Beschreibungen beton der an die 1798 erbauten Drescherhäuser (ab bereits 1803 die romantischen Qualitäten des 1881: Neue Häuser/ Neuer Anbau) gren- an den Liebsteingrund angrenzenden Lockzende Ziegelteich, östlich vom Schloss zwi- witztals:

schen Ort und Buschhausschänke - wobei ein Ziegelteich mit Ziegelscheune schon im sogenannten »Ur-Öder« (1586-1634) belegt

"Von Borthen aus, wo wir ins Thal hinabstiegen, wandelt man ununterbrochen auf grünen Wiesenteppichen dahin, längs Lockwitzbach (damals Grimmsches Wasdem Faden eines kristallreinen Bächleins, ser), welcher sich in Reinhardtsgrimma so klein und unbedeutend, dass es, fast durch das Liebsteingrund genannte Ta unbemerkt hindurch rieselnd, sich unter schlängelt: „Erwähntes Thal hat einen etwas den Fusstritten des Spazierenden verlie- melancholischen Anstrich, gehört aber ohne ren zu wollen scheint. So ergiessen sich Zweifel zu den reizendsten der Gegend. « $^{71}$ mehrere kleine Berggewässer aus dem Reinhardsgrimmer Walde und von den Ähnlich liest sich die Ortsbeschreibung des ostwärts liegenden Dörfern, Wittgendorf Juristen und Übersetzers Wilhelm Adolph und Lungwitz, her in den Lockwitzer Lindau (1774-1849) von 1822. Auch dieser Grund, in dessen Hauptthale mehrere beschreibt den Garten als unmittelbar am kleine Mühlen und Seitenthäler sich be- Schloss liegend und den Park über die finden, die dasselbe mit jenen obenge- Mooshütte am Grimmstein und die Promenannten Dörfern vereinigen und dem naden in die Landschaft greifend. Der hinGanzen ein schönes romantisches Anse- tere Liebsteingrund wird auch hier eher mehen geben. $\ll^{67}$

lancholisch aufgefasst:

1822 findet auch die von Bülowsche Parkanlage im Lexikon des Albert Schumann (1773-1826) - Schriftsteller und Vater von Robert Schumann - und August Schiffner (1792-1873) - Geograph und Schriftsteller Erwähnung. Hier wird sie in ihrer Ausbreitung in die freie Landschaft bereits explizit vom Garten unterschieden:

»Im J. 1800 kaufte das Gut der dänische Gesandte von Bülow und bei dessen Familie ist es noch. Von ihm besonders rühren die schönen Parkanlagen hinterm Dorfe her, welche man vom Garten zu unterscheiden hat; $\left[\ldots . . . \ll^{68}\right.$

Die Autoren schlagen einen Ton an, der die ideellen Auseinandersetzungen um die Einbeziehung von Natur in die Gartengestaltung der Jahre um 1800 bereits rezipiert. Ganz im Sinne von Becker und von Racknitz fällt das Augenmerk auf die Parkanlagen (sprich Spaziergänge), die sich nahtlos an den Garten anschließen und die Natur weder nachahmen noch überladen, sondern sie vielmehr dem Durchstreifen öffnen ${ }^{69}$ Ergänzend nennen Schumann und Schiffner den Frauendorfer Grund sowie den Folgenbachgrund, welche zum Spaziergang genutzt wurden: » $\mathrm{Zu}$ dem Parke sind besonders die Thalgründe oberhalb des Ortes benutzt. « ${ }^{70}$ Ganz besondere Erwähnung findet der
»Auf der Höhe im Wald, unweit des Dorfes, liegt der Grimmstein mit den Trümmern einer Burg, [...]. Von der Anhöhe, wo eine Mooshütte uns einen Ruheplatz darbietet, läuft ein gebahnter Pfad ins Schlottwitzthal hinab. [...] Folgen wir von Reinhardtsgrimma dem Bache, der es durchfließt und das Grimm'sche Wasser heißt, so kommen wir in ein tiefes, ernstes Thal $[\ldots] .^{72}$

\section{Die Landschaftsverschönerung unter}

Ruschenbusch

Zwei Jahre vor ihrem Tod - also 1830 - übertrug Baron von Bülows Tochter Friederike Juliane Christiane von Bülow (1763-1832) das Gut ihrem Ehemann Georg Conrad Ruschenbusch..$^{73}$ Dieser war ab 1802 Förster, laut Überlieferung noch vor seiner Hochzeit 1820 mit Freifrau von Bülow als Gutsverwalter eingesetzt und schließlich der zweite bürgerliche Rittergutsbesitzer Reinhardtsgrimmas. ${ }^{74}$ Nach seinem Tod ging der gesamte Besitz an seine Tochter Friederike Conradine (1836-1910), die sich mit dem königlich-sächsischen Major Ludwig Emil Aster (1833-1907) vermählte. ${ }^{75}$ Sowohl Ruschenbusch als auch das Ehepaar Aster bauten den Wirtschaftsbetrieb aus, so habe sich das Rittergut zwischen 1843 und 1882 sehr 
Erneuerungen in der Landwirtschaft

in Sachsen und Deutschland zur vermehrIm 18. Jahrhundert wurden wirtschaftsphi- ten Kultivierung von Futterpflanzen wie losophische Konzepte entwickelt, in deren Klee. Dies führte zu einer besseren VersorFokus die Naturressourcen einer Gegend gung des Viehs, damit zu einem höheren standen. Denn die zur Zeit der Aufklärung Dunganfall und so wiederum zu einer eraufkommende Vorstellung einer »Herr- tragreicheren Folgeernte. Mit diesen und schaft der Natur« - einer »Physiokratie« wie weiteren Umstellungen gelang eine Abkehr es hieß - legte den Fokus auf die optimale von der klassischen Dreifelderwirtschaft hin Nutzung natürlicher Gegebenheiten zur zur variablen Fruchtwechselwirtschaft. ${ }^{84} \mathrm{Ru}-$ Schaffung eines gesunden und nachhaltigen schenbusch war Mitglied der oben benannStaatshaushalts. Dabei sollten Schönheit ten Ökonomischen Societät zu Leipzig, welund Nutzen der Agrarflächen in Einklang che solcherlei landwirtschaftliche Neuerun stehen. ${ }^{77}$ Wesentliche Impulse zu diesen gen förderte. Er trat spätestens 1830 der SoThemen gingen in Sachsen von der nach cietät bei, da er bereits im Kaufvertrag über dem Siebenjährigen Krieg 1764 gegründeten das Rittergut als deren Mitglied aufgeführt Okonomischen Societät zu Leipzig aus. Im wird. ${ }^{85}$

Rückgriff auf die Gedanken der Nachkriegs-

zeit wollte sie die allgemeinen Wirtschafts- Aufgrund der Anregungen durch die Sociebedingungen verbessern, die Staatsein- tät revolutionierte man auch in Reinhardtskünfte mehren und speziell auch die Land- grimma das Karten- und Flurbuchwesen sound Forstwirtschaft optimieren..$^{7}$ Auch auf wie die Landwirtschaft. Bereits 1822 baute sie werden wir noch einmal zurückkom- man hier Klee und verschiedene andere Futmen.

terkräuter an ${ }^{86} 1842$ kultivierte man ein breites Spektrum an Pflanzen, darunter Eine für diese Zwecke sinnvolle Erfassung Winter- und Sommerweizen, Winter- und der Gutsflächen (Flurkartierung) erlangte Staudenkorn, Gerste, Hafer, Erbsen, Somim Sächsischen Landtag 1766 durch die merrüben, Lein und Futterwicke. ${ }^{87}$ Bis 1875 Stände zunächst keine Mehrheit, aber das wurden all diese Neuerungen in einem FlurAnlegen von Flurbüchern verbreitete sich buch präzisiert und auf Flurkarten metergeim Leipziger Kreis nun rasch. Unter dem vo- nau verzeichnet. ${ }^{88}$ Für die folgenden Jahre ranschreitenden Aufklärungsgeist bildete bis 1900 differenzierte die Gutsherrschaft Sachsen im 19. Jahrhundert auf diese Weise die Futterpflanzen, wie Klee, Gras, Wicke ein umfangreiches Flurbuchwesen aus..$^{79}$ Bei sowie auch Hirse (meint Zuckerhirse) und diesen Flurbüchern handelte es sich zu- Futterkartoffeln, noch stärker. ${ }^{89}$ Zudem kulnächst nur um eine Aufzeichnung von Flur- tivierte man zahlreiche Obstsorten in einer nummern, Flurnamen, deren Nutzungen Baumschule, die sich nördlich des Niederund Flächengrößen. Später konnten auch hofes unterhalb der alten Schäferei befand Karten beigefügt und weitere Erklärungen Diese wurden in Tafel-, Wirtschafts-, Futund Details zur jeweiligen Gutswirtschaft ter-, Sommer-, Winter- und Herbstobst soaufgeschlüsselt sein.

Gleichzeitig erreichten zahlreiche Innovationen die Landwirtschaft. Unter dem wissenschaftlichen Einfluss von Vordenkern einer Agrarreform, wie Nathanael Gottfried Leske (1751-1786), ${ }^{80}$ Johann Riem (1739-1807), ${ }^{81}$ Albrecht Thaer $(1752-1828)^{82}$ und Christian Schubart Edler von Kleefeld (1734-1787), ${ }^{83}$ schaftlichen und sozialen Umbrüche der kam es schon ab Mitte des 18. Jahrhunderts Aufklärung auf die Landschaft ein.
Schafhaltung

, wie die von Merke aus statistischen Gesichtspunkten:

»Der schöne Viehstand aller Art besteh aus 34 Stück Kühen, 20 Ochsen, 6 Pferden, 10 Zuchtschweinen und 1000 Stück ganz veredelten Schafen, welche die Fluren sämmtlicher Unterthanen von Michaelis bis Walpurgis behüten. «11

Die Landschaft scheint zu dieser Zeit durch Viehwirtschaft geprägt zu sein, waren die Schafe doch in der Lage Grenzertragsflächen bewirtschaften zu können, Wegränder freizuhalten und die Felder nach der Ernte leer zu äsen.

Und Schafe begannen spätestens ab 176 eine essentiell neue Rolle im sächsischen Landschaftsbild einzunehmen. In diesem Jahr schenkte der spanische König Karl III. (1716-1788) dem sächsischen Königshaus auf dessen Anfrage eine Herde Merinoschafe, die in Sachsen weitergezüchtet und zur Veredelung der Landschafe genutz wurde. Für viele Rittergüter entwickelte sich die Schafzucht zu einem bedeutenden Wirtschaftsfaktor und verbreitete sich. ${ }^{22}$ Auch in Reinhardtsgrimma deuten die Beschreibungen in diese Richtung. Waren es 1624 noch 789 Schafe, ${ }^{93}$ belief sich ihre Zahl bis 1822 auf um die 11000 Stück [von] ganz veredelten Schafen ${ }^{94}$ Unterstrichen wird die Wichtigkeit der von den Zuchtschafen gewonnenen Wolle durch ein 1825 geführtes Buch mit Wollproben erster und zweiter Klasse. ${ }^{95}$ Wie aus Landschaftsdarstellungen der Zeit bekannt ist, spielte die Ästhetisierung der Landwirte und der Tiere als lebendige Staffagefiguren innerhalb der sächsischen Landschaften eine wichtige Rolle in der Rezeption des "Schönen " - auch wenn dies mit einer bürgerlichen, physiokratisch geprägten und moralisch verklärten Sich auf die ländliche Bevölkerung und ihr Leben einherging. ${ }^{96}$ Beispielsweise sind in Stichen von Zingg bereits um 1800 häufig Hirten mit Schafherden als Teil der Szenerie abgebil- det. ${ }^{97}$ Becker schreibt dazu aus ästhetischer

»[...] Spuren einer einfach ruhigen Lebensweise, von welcher die wirtschaftliche Benützung des umliegenden Bodens und anspruchslose Hütten von Pflügern und Hirten zeugen, den sanften und heitern Charakter des Ländlichen bestimmen. Die Schaafe, [...] mildern die natürliche Wildniss der schauerlichen romantischen Gegend und geben ihr einen lieblichen Reiz. ${ }^{98}$

1837 brannte die alte Schäferei am Niederhof herunter (Abb. 10). Da die Schafzucht ein bedeutsamer Faktor für die Gutsökonomie war, erhielt der von Ruschenbusch beauftragte Neubau eine besondere Gestalt. Noch im selben Jahr fertigte Johann Gottlieb Adam eine Zeichnung für einen klassizistischen Neubau mit Gewölbescheune an (Abb. 11). 1838 wurde dieser schließlich erbaut.99 Der Entwurf akzentuiert den Schafstall mit einem Mittelrisalit und setzt das Schäferwohnhaus, die Scheune und den Wagenschuppen in ihrer Gestaltung zurück. Auf diese Weise wurde dem Prestige der Schafzucht ein bauliches Andenken gesetzt. ${ }^{100}$ Ein maßgeblicher Grund für den schmuckvollen Aufbau war sicher auch, dass die Region um Reinhardtsgrimma und vor allem Maxen sehr gut ausgebaute Schafzuchten besaßen. Ein Artikel in der Allgemeinen Zeitung berichtet davon. 1836 - ein Jahr vor dem Brand - wurden aufgrund des »bedeutenden Rufs unsre[r] vaterländischen Schäfereien « zwei Transporte à 300 Schafe nach Buenos Aires verschifft, allesamt aus der Region um Dresden. Im zweiten Transport waren auch Schafe aus Reinhardtsgrimma dabei:

»Der größte Theil dieses Transports war aus der, zu einem hohen Grade der Vollkomenheit gediehenen Schäferei des Rittergutes Maxen, im Amtsbezirk Pirna, entnommen, nemlich 68 Stähre und 58 Mutterschafe; die übrigen waren von den 

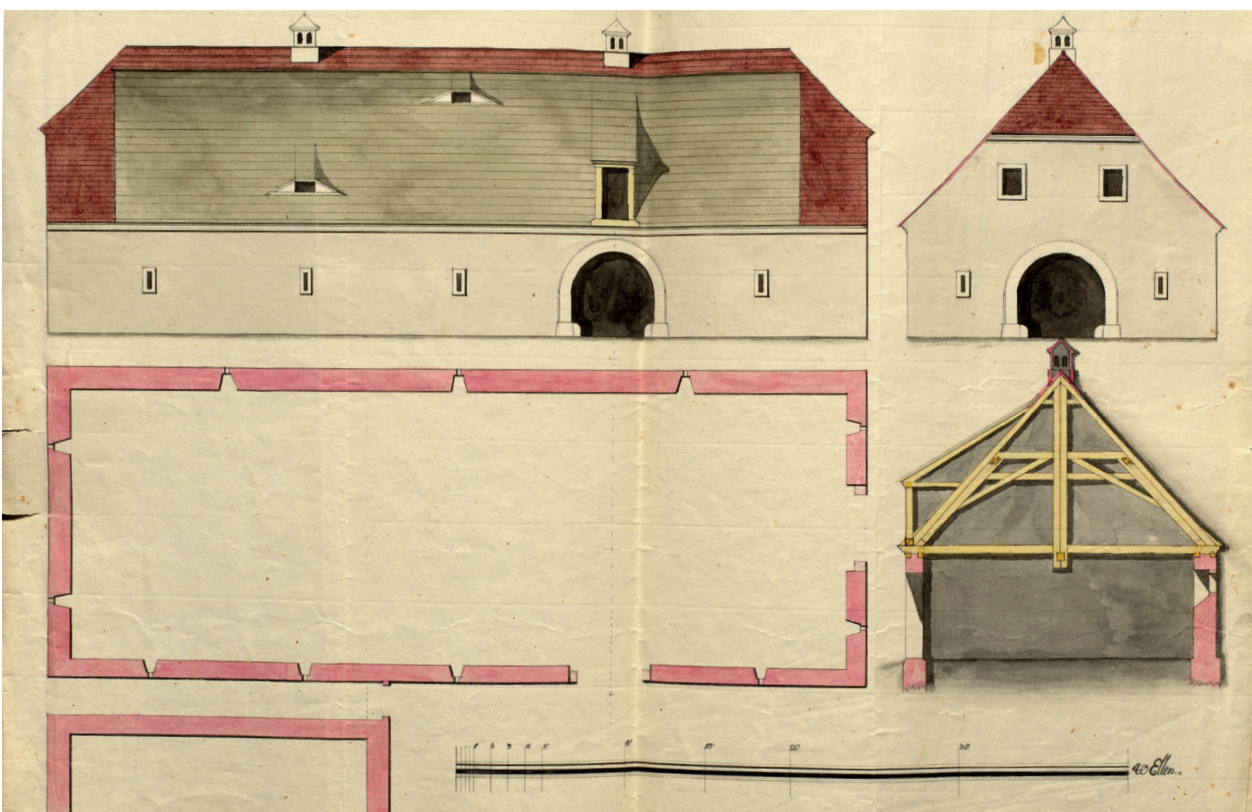

10 | Schafstall der Schäferei (vermutlich der alten Schäferei am Niederhof), kolorierte Federzeichnung, Autor unbekannt, um 1801 (SächsHStA, 10505, Nr. 253, unpaginiert). In den Akten geht es 1801 um die Erneuerung von Dachlatten, bretternen Wänden, den gebretterten Gesimsen und verfaulten Säulen im Schafstall. Die Markierungen an Dach und Gebälk passen dazu.

benachbarten Schäfereien der Kammergüter Groß-Sedlitz und Rennersdorf, so wie der Rittergüter Reinhardtsgrimma und Gamig, auf welchen Gütern die Schafzucht ebenfalls sehr kultivirt worden ist. ${ }^{101}$

mit Pflug und Hacke ausgestattet - zu erkennen (Abb. 12a). Die andere zeigt zwei Herren, von denen einer ein Gewehr trägt (eventuell ist damit Georg Conrad Ruschenbusch gemeint) (Abb. 12b). Durch den Blick von Süden zeigen die Stiche stets die auf dem Hügel liegende Reinhardtsgrimmaer Kirche Poenicke nannte zudem 1856 eine Schäferei sowie die typischen Drei- und Vierseithöfe. auf dem Oberhof, die aus einem Gebäude Auf der rechten Bildseite sind das im Tal liebestand "wie ein zweites in Sachsen nicht gende Schloss mit Schlossturm und angeleicht zu finden sein dürfte. ${ }^{102}$ Dies impli- deutetem Wirtschaftshof sowie die oberhalb ziert ein weiteres architektonisch bedeu- gelegene, neu erbaute Schäferei zu sehen. tungsvolles Schäfereigebäude in Reinhardts- Deutlich zu erkennen sind die unterschiedgrimma, welches heute allerdings nicht mehr vorhanden ist.

ichen Feldkulturen des Spätsommers, was die Umstellung auf die Fruchtwechselwirtschaft andeuten könnte. Die Staffagefiguren Einen künstlerischen Blick auf die von der zeugen zum einen von der Arbeit der LandLandwirtschaft geprägte Gegend gewähren bevölkerung und zeigen zum anderen eine zwei Lithographien, die 1840 in »Sachsens Feldbegehung durch Förster und vermutlich Kirchen-Galerie ${ }^{103}$ veröffentlich wurden. Gutsverwalter. Damit sind die Akteure darBeide zeigen einen größeren Ausschnitt der gestellt, welche die Landschaft ReinhardtsOrtslage Reinhardtsgrimma samt Feldflur. grimmas um 1840 bestimmten. Die bürgerliAuf einer der Darstellungen sind Bauern - chen Vertreter der Grundherrschaft und die

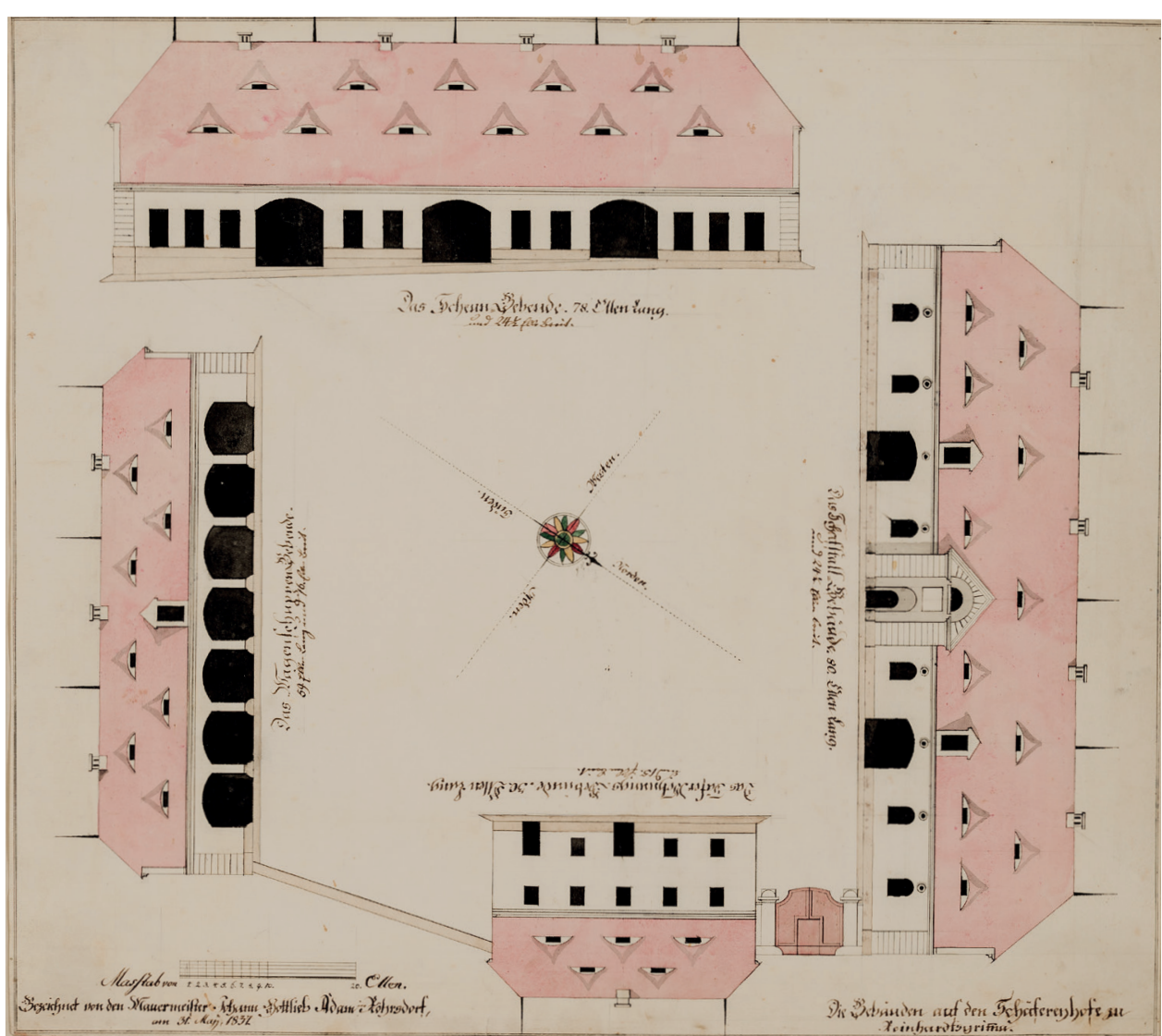

11 | Entwurf der neuen Schäfereigebäude am Niederhof Reinhardtsgrimma, Bleistift und Feder in schwarz sowie Pinsel in Wasserfarben auf Papier, Maurermeister Johann Gottlieb Adam (Röhrsdorf), 13. März 1837 (LfD Sachsen, Plansammlung, ohne Inv.-Nr.).

Bauern stehen in der Agrarlandschaft, die wirtschaftlichen Werk "Sylvicultura oecomalerisch das Dorf umgibt. Für ein gebildetes Publikum erstellt, stehen die Dorfdarstellungen der Kirchengalerie aus der Hand Gustav Täuberts (1817-1913) in der Tradition Zinggs, dem Lehrer seines Vaters Carl Gregor Täubert (1778-1861).

Fors nomica« (1713) Schönheitsaspekte im Wald an. In Kurhannover - Ruschenbuschs und von Bülows Heimat - ging man ähnlichen Konzepten nach. Otto von Münchhausen (1716-1774), Friedrich August von Veltheim (1709-1175) und Johann Philipp Du Ro (1741-1785) sind hier als niedersächsische Protagonisten zu nennen, die in der zweiten Der Wald oder Forst war durch die Jagd so- Hälfte des 18. Jahrhunderts durch Forstverwie durch die Gewinnung von Bau- und besserungen wichtige Grundlagen zur EntBrennmaterial nicht nur von wirtschaftli- stehung landschaftlicher Parkanlagen in cher Bedeutung, sondern wurde auch ästhe- Deutschland legten. ${ }^{104}$ Burchard Christian tisch rezipiert. So spricht bereits im Sachsen von Behr (1714-1771) war der Onkel von $\mathrm{Ru}-$ des 18. Jahrhunderts der erzgebirgische schenbuschs Dienstherren in Stellichte und Oberberghauptmann in Freiberg, Hans Carl diente als Minister bei der Deutschen Kanzvon Carlowitz (1645-1714), in seinem forst- lei in London ab 1762 als Ansprechpartner 

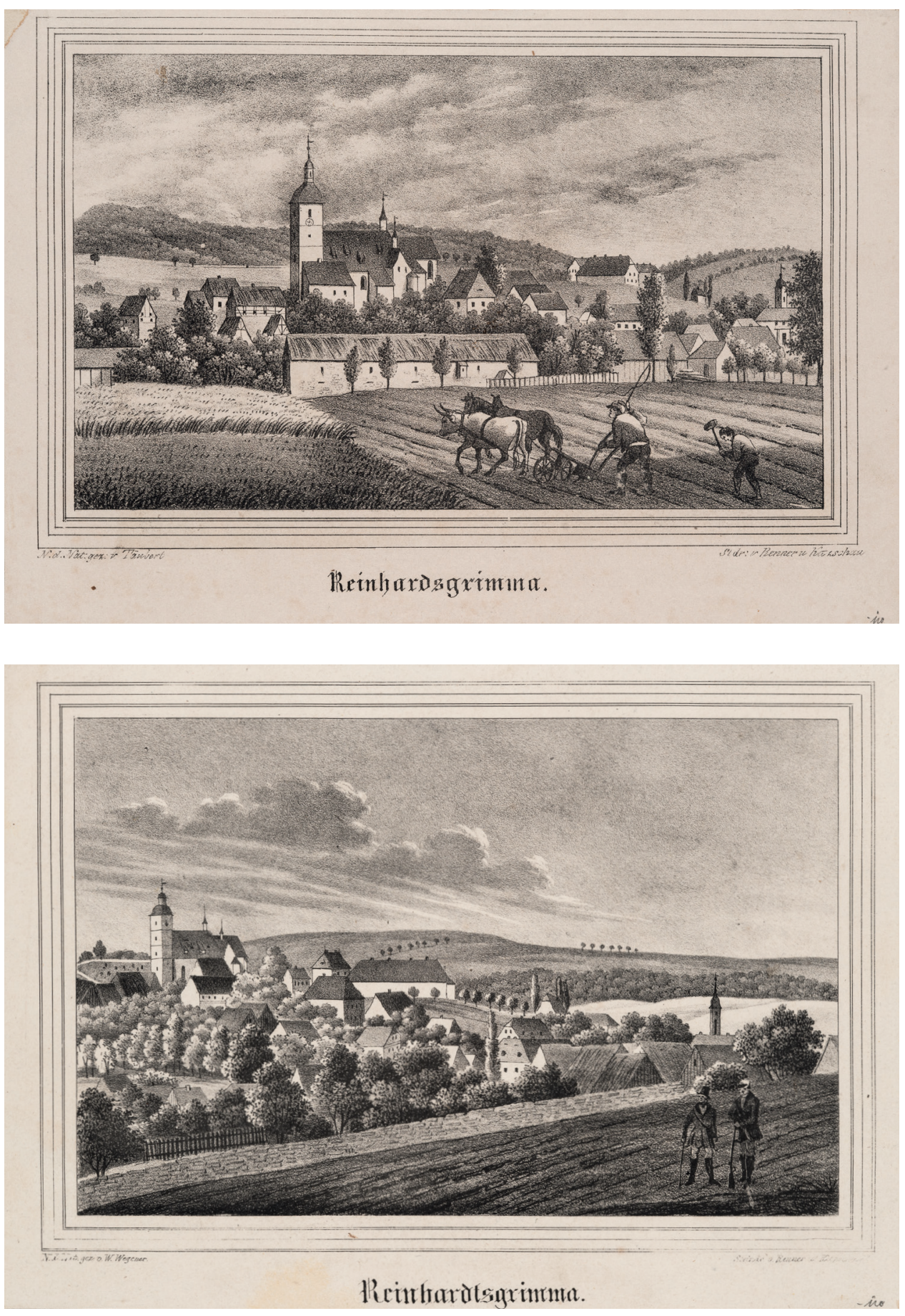

12a und b | Ortslage Reinhardtsgrimma mit Kirche, Schloss, Acker- und Waldfluren, Lithografien, um 1840, oben (12a): Gustav Täubert (Inventor), unten (12b): Johann F.W. Wegener (Inventor), aus Schmidt, Hermann: Sachsens Kirchen-Galerie, 1840 (SKD, Inv.-Nr. oben (12 a): A 1995-7715/ Inv.-Nr. unten (12 b): A 1995-7714). um die neuen Wirtschafts- und Gestaltungsideen der heimischen Verwandtschaft nahezubringen. Diese Vorschläge manifestierten sich zusehends: Im Jahr 1855 zum Beispiel schrieb Heinrich Christian Burckhardt (1811-1879) in seiner Monografie »Säen und Pflanzen« ein Schlusskapitel über die Waldverschönerung. Zudem hatte die Direktion der Forsten in der Herzoglichen Hannoverschen Kammer wohl schon 1859 den Schutz besonders schöner, alter Waldbestände verfügt. ${ }^{105}$ Außerhalb Niedersachsens publizierte Heinrich von Salisch (1846-1920) seine Bücher zur »Farbenlehre in der Landschaft» (1881), zur »Kiefer in ihrer forstästhetischen Bedeutung « (1883) und zur "Forstästhetik« (1885). Ob Ruschenbusch oder von Bülow bereits von diesen geistigen Strömungen beeinflusst waren, bleibt unklar. Belegt ist allerdings, dass um 1807 ein Forstwegesystem und bald darauf Lustpartien in der Grimm'schen Heide entstanden.

Ab 1830 musste Ruschenbusch - nun selbst Gutsbesitzer - seine Förstertätigkeit vermutlich einschränken und zuletzt gänzlich abgeben. 1842 taucht daher in den Akten ein Revierförster Müller auf. Dieser wird spätestens 1874 unter Aster durch den Revierförster Henke abgelöst.

In seiner neuen Position legte Ruschenbusch den Grundstein für eine neue Verschönerungsphase, führte den Ausbau der Buschhäuser, deren Bewirtung und die Pflege des Wegesystems fort. In einer Ortbeschreibung von 1840 liest man: "an der Glashütter Straße [liegt] 1 Gasthof nebst Ziegelei dabei beginnen die Lustpartien im Walde $\aleph^{106}$. Der Forst war also spätestens seit diesem Zeitpunkt tatsächlich Teil von Spaziergängen.

Erweiterung der Buschhäuser

Zwar starb von Bülow 1811 nach Fertigstellung der Buschhausschänke, jedoch entwickelte sich die Anlage unter seiner Tochter Friederike Juliane Christiane von Bülow und ihrem Gemahl Georg Conrad Ruschenbusch in den kommenden Jahren weiter.
Als gestalterisches Pendant ließ Ruschenbusch vis-à-vis zur Buschhausschänke ein klassizistisches Schießhaus errichten (Abb. 13), dessen Erscheinungsbild und Ausstattung nicht ohne eine geschichtliche und bildsprachliche Einordnung besprochen werden kann. In Kubatur und Fassadengestaltung war dieses der 1811 erbauten Schänke, trotz ungleich hoher Türnischen, weitestgehend angeglichen. So entstand das eindrucksvolle, heute noch als »Buschhäuser « bekannte Ensemble. Zwar lässt sich das genaue Baujahr des Schießhauses nich mehr nachvollziehen, jedoch weist ein Turmkugeldokument von 1843 darauf hin, dass es nicht, wie bisher angenommen, unte von Bülow, sondern von seinem Schwiegersohn errichtet wurde:

»Herr Georg Konrad Ruschenbusch, sei 1820 Gemahl der vorigen Besitzerin, Friederike Freiin von Bülow, seit dem Absterben, welches am gten November 1832 erfolgte wirklicher Besitzer von Reinhardtsgrimma, der unsere unvergeßlichen Bauten ausgeführt hat z.B. ein ganz neues Gasthaus, eine Schäferei [...], ein Schießhaus der sogenannten Buschschenke gegenüber, wo ein schöner Koncert- und Tanzsaal sich befindet - ließ [...] auch den Schloßturm erneuern und den Knopf desselben wieder vergolden. $\aleph^{107}$

Ein weiterer Beleg dafür, dass das Ensemble in zwei Bauetappen erschaffen wurde, ergibt sich aus der genaueren Betrachtung der beiden Tonreliefs, die - korrespondierend zum jeweiligen Zweck - oberhalb der straßenseitigen Gebäudeeingänge angebracht wurden. Während der Jäger in Tiroler Tracht (Abb. 14) über dem Eingang des Schießhauses in einer halbkreisförmigen Nische in die Fassade eingelassen ist, wurde der ruhende Wanderer (Abb. 15) über dem Eingang zur Buschhausschänke lediglich auf den Türsims aufgesetzt. So entsteht der Eindruck, dass man letzteres Relief nachträglich anbrachte und nicht von Beginn an als integralen Bestandteil des Gebäudes mitdachte. 


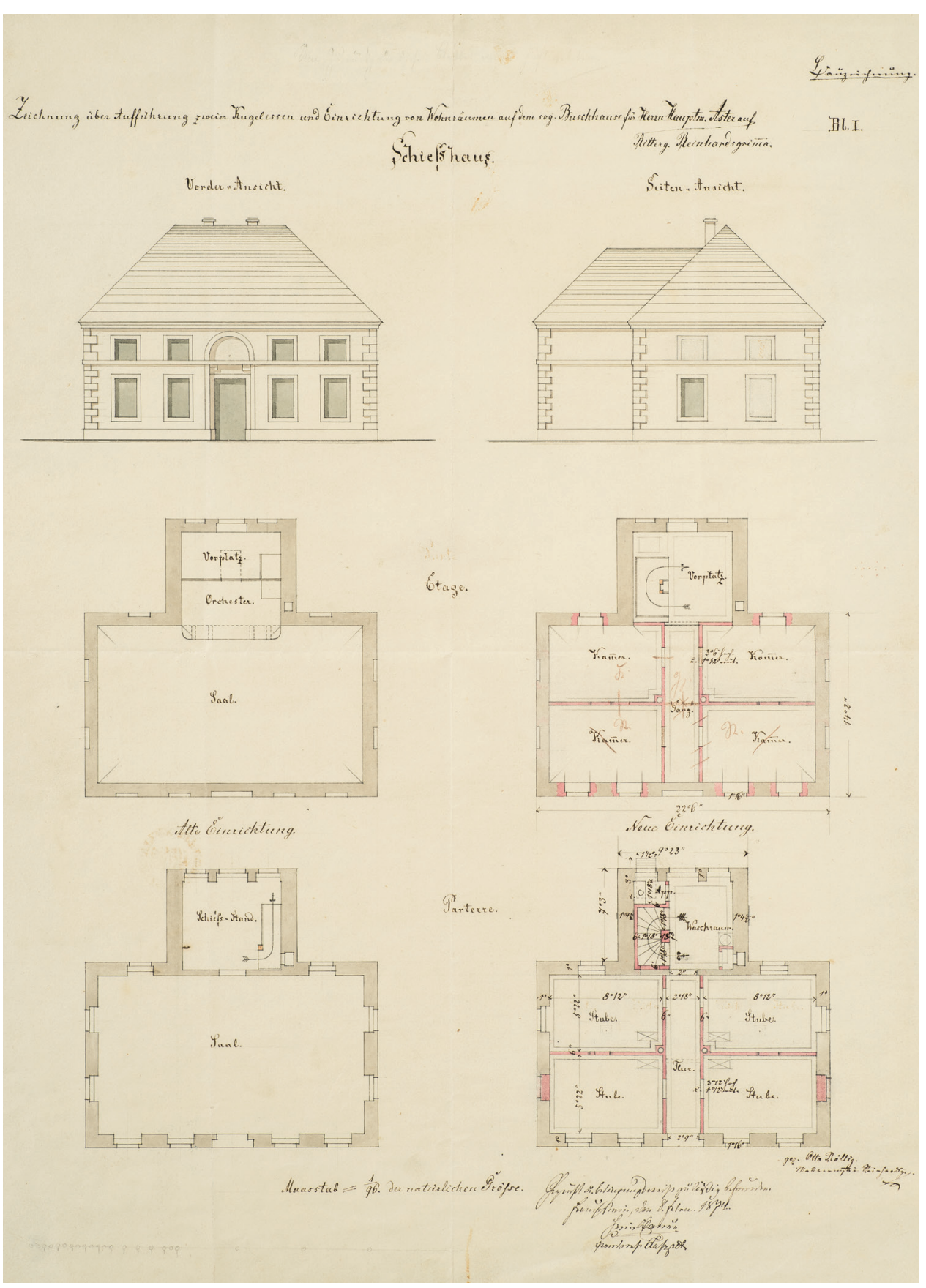

$13 \mid$ ZZeichnung über Ausführung zweier Kugelessen und Einrichtung von Wohnräumen auf dem sog. Buschhause für Herrn Hauptm. Aster auf Ritterg. Reinhardsgrimma«, Federzeichnung, Zeichner: Otto Röllig, 1874 (LfD Sachfur Herrn Hauptm. Aster auf Ritterg. Reinhardsgrimma«, Federzeichnung, Zeichner: Otto Rollig, 1874 (LfD Sach-
sen, Plansammlung, Inv.-Nr. 125-63). Auf der linken Seite sind die Grundrisse in der Fassung vor 1874 zu sehen, wie sie unter Ruschenbusch erbaut wurden.

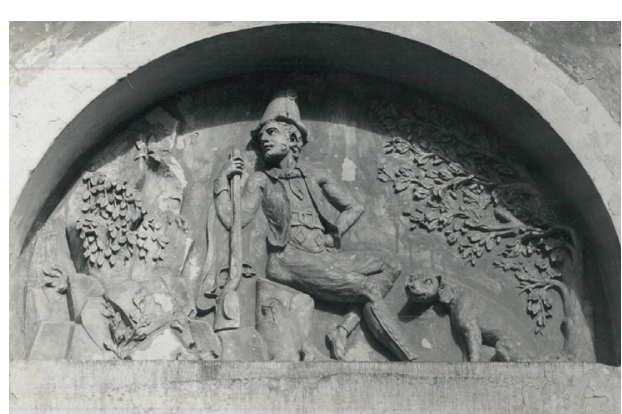

14 | Tonrelief eines Jägers in Tiroler Tracht über dem Eingang des Schießhauses zu Reinhardtsgrimma, Fotografie, Urheber unbekannt, ohne Jahr, wohl um 1950
(SLUB, Deutsche Fotothek, Datensatz-Nr. 33108632 (SLUB, Deutsche Fotothek, Datensatz-Nr. 3310863 Aufnahme-Nr. df_hauptkatalog_0100793).

Beide Reliefs schrieb man in der Fachliteratur bereits dem königlich-sächsischen Hof bildhauer Ferdinand Pettrich (1798-1872) $\mathrm{zu}^{108}$ Mit einer Entstehung der Reliefs nach 1811 erscheint diese Zuschreibung realistisch, denn zur ursprünglich vermuteten Entstehungszeit beider Buschhäuser samt Reliefs im Jahr 1811 war der junge Pettrich erst 13 Jahre alt. Daher stand die Vermutung im Raum, sein Vater Franz Pettrich hätte die Reliefs gefertigt. Doch dank der stilistischen Einordnung des Kunstschriftstellers Hans Helmut Geller (1894-1962) lässt sich dieser als Urheber weitestgehend ausschließen:

"Aber zwei weitere Reliefs, die wir dem jungen Pettrich wohl zuschreiben können, sind uns noch erhalten. Es handelt sich um die beiden über den Türen der zwei >Buschhäuser` bei Reinhardtsgrimma angebrachten Tonreliefs, [...]. Nun zeigen - zumal bei dem ruhenden Wanderer - diese Arbeiten gewisse Anklänge an Schöpfungen seines Vaters Franz Pettrich, wenngleich die ganze Auffassung und Darstellungsweise stark von dessen klassizistischer Art abweicht. Sie sind - wie wir feststellen, eine große Seltenheit - als wirklich >romantische` Bildwerke zu bezeichnen und weisen in vielem bei aller Originalität eine noch ungeübte und suchende Hand auf. Reichbelaubte Bäume im Relief sind sowohl bei

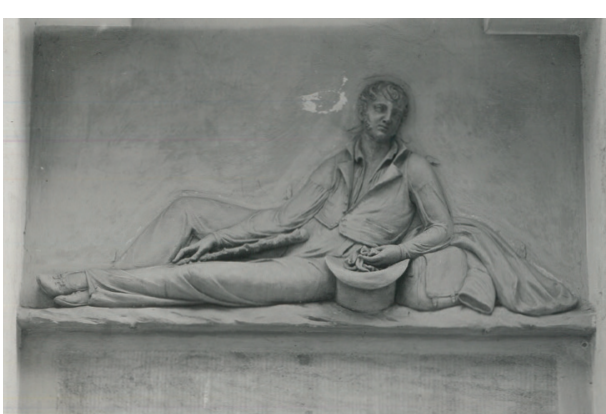

5 | Tonrelief eines liegenden Wanderers über dem Eingang der Buschhausschänke zu Reinhardtsgrimma Fotografie, Landesbildstelle Sachsen, 1948 (SLUB, Deutsche Fotothek, Datensatz-Nr. 33108634, Aufnahme-Nr. df_hauptkatalog_010079o).

Thorvaldsen, [...], als auch bei seinem Freunde und Zeitgenossen Pettrich senior sonst niemals vorkommende Darstellungen, die man aber bei dem rromantisch schaffenden Sohn Ferdinand auch später wiederfindet. $\ll^{109}$

Darüber hinaus formuliert Geller die Vermutung, dass Ferdinand Pettrich die Reliefs zwischen dem Antritt seines Studiums an der Dresdner Kunstakademie 1816 und seiner Abreise nach Rom in die Werkstätten Bertel Thorvaldsens 1819 als Frühwerk gefertigt haben könnte. ${ }^{110}$ Die Bildmotive unterstützen diese Vermutung. Sieht man sich diese genauer an, so ist die dargestellte, eigentlich hechtgraue Tiroler Jägeruniform mit den grünen Aufschlägen und einem aufgeschlagenen runden Hut - trotz ihrer Farblosigkeit - deutlich zu identifizieren. ${ }^{111} \mathrm{Di}$ Tiroler Jäger befanden sich während der Befreiungskriege (1813-1815) im Lützowschen Freikorps - einem Freiwilligenverband, der das preußische Heer, ähnlich den Schützenkompanien im Tiroler Aufstand (ab 1808), im Kampf gegen Napoleon unterstützen sollte. ${ }^{112}$ Den Jägerdetachements unter Leutnant Riedl, einem ehemaligen Adjutanten Andreas Hofers in Tirol, ${ }^{113}$ und weiteren Truppen des Lützowschen Korps gehörten neben zahlreichen Turnern wie Turnvater Friedrich Ludwig Jahn (1778-1852) und Karl 
nente Dichter und Romantiker wie Carl vervollständigen und den bewegten KriegsTheodor Körner (1791-1813) oder Joseph von zeiten ein romantisches Denkmal zu setzen Eichendorff (1788-1857) an. ${ }^{114}$ Bekannt - unter ähnlicher Besetzung wie beim Mowurde das von Carl Maria von Weber (1786 reaudenkmal auf der Dresdner Räcknitz-1826) vertonte Gedicht Körners »Lützows höhe, welches 1814 nach der Schlacht zu Wilde Jagd«. Aber auch Eichendorffs Ge- Dresden durch Thormeyer entworfen und dicht »Der Jäger Abschied « ist bezeichnend von Franz Pettrichs Schüler Christian Gottfür die patriotische Romantik dieser Zeit. lieb Kühn (1780-1828) geschaffen wurde. ${ }^{119}$ Die Befreiungskriege erzeugten unter der

Bevölkerung eine regelrechte Begeisterung, Im Parterre des Schießhauses befand sich dem Heer im Kampf um das Vaterland bei- ein Saal mit Schießstand - eine Art Jagdanzustehen - in einer Zeit, in der das deutsche stand - im rückwärtigen Gebäudeerker, was Heimatgebiet in literarischer und künstleri- darauf hindeutet, dass man bei Wind und schen Hinsicht immer bedeutsamer wurde. ${ }^{15}$ Wetter aus dem Gebäude herausschoss. DaSo blieben auch die Gegenden um Dresden ran anschließend befindet sich noch heute und Reinhardtsgrimma nicht unberührt im nordwestlichen Außenbereich eine Rotvon den Ausläufern der Kriegshandlungen, Eichen-Allee, die bereits damals die Schießbevor es zur Völkerschlacht bei Leipzig bahn markierte und sie zu beiden Seiten opkam. ${ }^{116}$ Mit der Erweiterung der Buschhaus- tisch abgegrenzte (Abb. 16). An ihrem nördschänke durch ein Schießhaus samt Tiroler lichen Ende ist eine circa zwei Meter hohe Jägerrelief wird demnach nicht zuletzt auf Bruchsteinmauer situiert, an der die Zieldie deutsche Romantik und den Sieg über scheibe beziehungsweise die Zielobjekte andie Napoleonische Herrschaft verwiesen; gebracht wurden. Seitlich davon liegt ein geauch sollten sich dort die Turner versam- mauerter Kugelfang, hinter dem sich die meln, die in den folgenden Jahrzehnten für Person, die die Zielobjekte ausrichtete, vereinen demokratischen Nationalstaat plä- stecken konnte (Abb. 17). Im Obergeschoss dierten ${ }^{117}$

befand sich ein Tanz- und Konzertsaal mi einer Aufstellfläche für eine Musikkapelle Bedenkt man dazu, dass das Schießhaus am im Erker - im Plan als »Orchester « bezeichStandort der vormals in der Forstkarte dar- net. Von dort konnte sich die Musik vermutgestellten Schießscheibe (Forstcharte 1807: lich optimal in den Raum ausbreiten und die B-z) entstand, lässt sich hieraus auch lesen, Musiker standen bei Tänzen gut geschützt dass Schänke und Jagd bereits vor der Er- (Abb. 13).120

richtung des Gebäudes im Zusammenhang

standen. Möglicherweise hatte von Bülows Trat man nun aus der Buschhausschenke Schwiegersohn von Racknitz nicht nur musste man den Blick zum Eingang des Schuricht zwecks der Gartengestaltung, son- Schießhauses sogar etwas nach oben richdern auch Thormeyer nach Reinhardts- ten, denn dessen Erdgeschoss war als Hochgrimma vermittelt - schließlich förderte von parterre ausgebildet. Der Wanderer über Racknitz beide Baumeister sowohl ideell als dem Schänkeneingang blickte zum Tiroler auch finanziell und beteiligte auch beide an Jäger auf - als Jagendem und sicherlich verder Gartengestaltung in Ringethal. ${ }^{118}$ Es wäre gnügtem Schützen, aber eben auch als Patridemnach möglich, dass bereits mit Errich- oten, der mit der Lokalgeschichte verbuntung der Buschhausschänke auch das den war. In den Jahren um 1820 scheint es Schießhaus nach Thormeyers Plan entste- sich bei einem Schießhaus mit Schießbahn hen sollte, das Vorhaben jedoch durch von sowie Tanz- und Konzertsaal um eine gänBülows Tod zunächst unterbrochen wurde. gige Kombination zu handeln. Ab $1823 \mathrm{gab}$ Nach den Befreiungskriegen entschloss man es ein weiteres Beispiel u.a. im Müglitztal bei sich unter Ruschenbusch das Ensemble zu Lauenstein. ${ }^{121}$

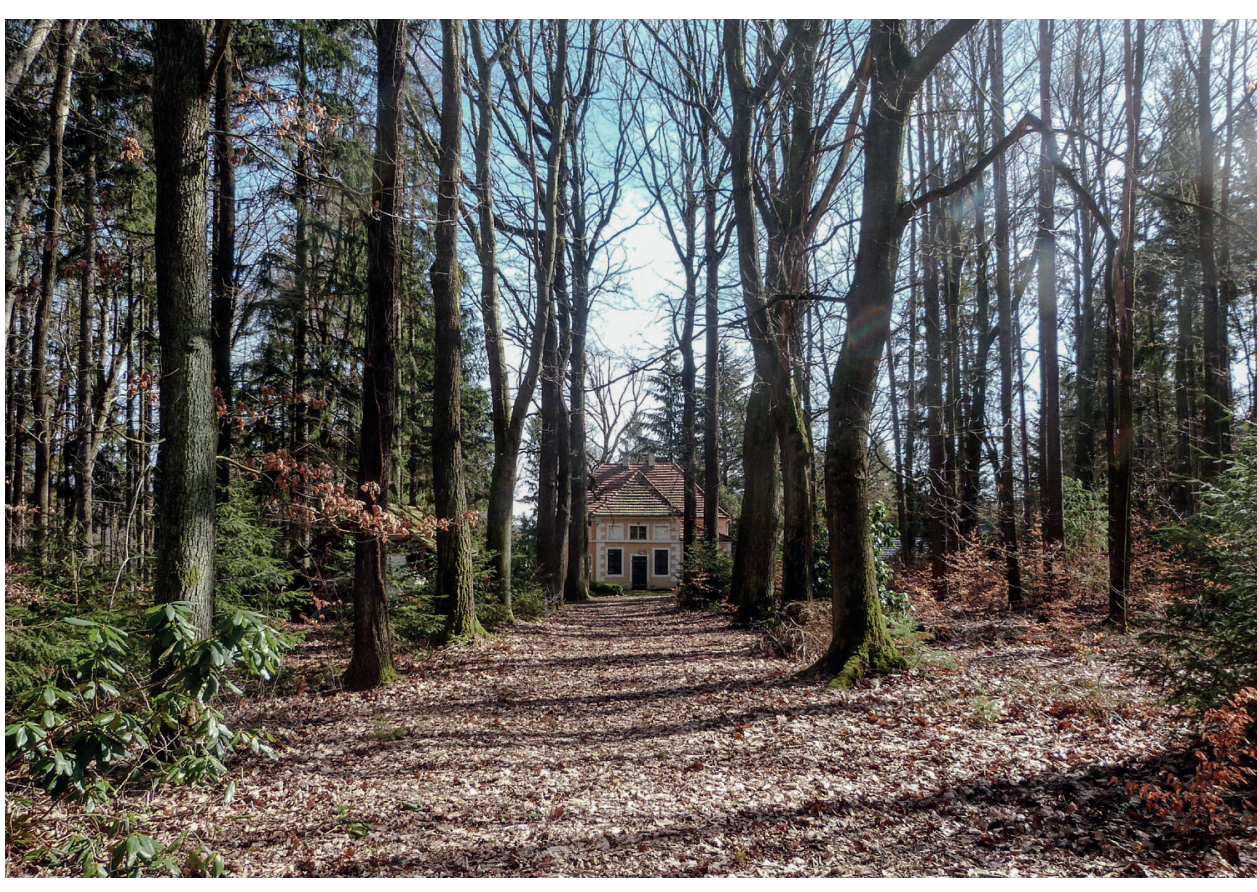

16 | Die Rot-Eichen-Allee entlang der Schießbahn am Schießhaus zu Reinhardtsgrimma, Fotografie: Anja Gottschalk, März 2019. Blick auf den rückwärtigen Erker, in dem sich unten der Schießanstand und oben das Orchester befand.

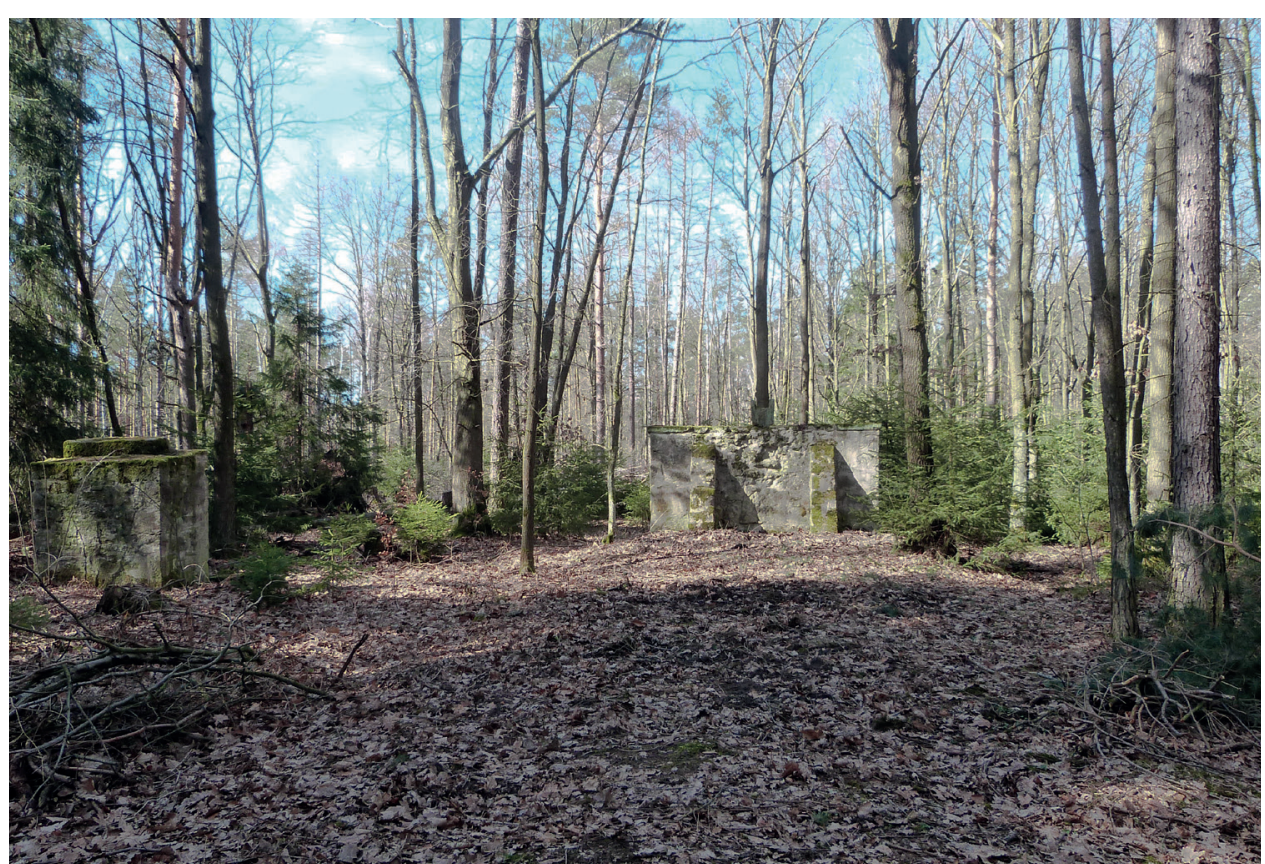

${ }_{17}$ | Die gemauerte Zielscheibe samt Kugelfang am Schießhaus zu Reinhardtsgrimma, Fotografie: Anja Gottschalk, März 2019. Mittig ist die gemauerte Zielscheibe zu sehen und am linken Rand der zur Schießscheibe halb geöffnete Kugelfang. 
Später sollte sich das Schießhaus unter Aster Fremdenverkehrs, der mit der Erweiterung zu einem Arbeiterwohnhaus mit Stuben der Buschhausschänke durch das Schießund kleineren Kammern entwickeln. ${ }^{122}$ In ei- haus anscheinend lohnenswert war, zumal nem Inventar von 1874 werden zwei davor auch schon vor 1840 regelmäßig Besucher stehende Gipslöwen genannt, die im Winter aus Maxen, wie Clara und Robert Schueingehaust wurden. ${ }^{123} \mathrm{Ob}$ es sich dabei um mann, zu Gast waren. ${ }^{129}$ Diese besuchten die heutigen Terrakotta-Sphingen handelte, auch später, zum Beispiel am 27. Mai und 12. bliebe zu untersuchen - feststeht, dass die Juni 1846 den Ort und hatten dort am 26. Terrakotta-Sphingen samt dem Terracotta- Juni 1846 laut Haushaltsbuch Forellen beWappen auf der Gebäuderückseite nicht zur stellt. ${ }^{130}$ Dies legt nahe, dass Fremde nun mit ursprünglichen Gestaltung gehören.

Unter Ruschenbusch sollten die Buschhäuser ein begehrter Ausflugsort bleiben, den nicht nur Wanderer und namhafte Künstler u.a. aus Maxen regelmäßig besuchten. Auch festliche und landwirtschaftliche Zusammenkünfte fanden im neuen klassizistischen Ensemble statt und ließen dieses zu einem Treffpunkt verschiedener Ortschaften und Parteien werden. So stattete zum Beispiel der dänische Bildhauer Bertel Thorvaldsen 1770-1844) dem Ort einen Besuch ab, als er im Alter von 71 Jahren (13.-22. Juni 1841) die befreundete Familie von Serre in Maxen besuchte. ${ }^{124}$ Ihn zog es aus mehreren Gründen in die Buschhausschänke und auf das Schloss Reinhardtsgrimma. Zum einen war er an der Buschhausschänke interessiert, da diese mutmaßlich eines der ersten klassizistischen Bauwerke Thormeyers darstellte und außerdem für den dänischen Gesandten am sächsischen Hof, von Bülow, errichtet worden war. Zum anderen war Reinhardtsgrimma der Geburtsort des ihm wohl bekannten Kunsthistorikers Carl Friedrich von Rumohr (1785-1843), der auch in Kopenhagen einen guten Ruf besaß.125

Auch die Brauereiwirtschaft florierte. Um 1840 galt die Reinhardtsgrimmaer Bierbrauerei am Oberhof als gemeinhin bekannt, später gar als berühmt. ${ }^{126}$ Schon vor 1628 besaß Reinhardtsgrimma einen »Hopfegarten " am Haselbach und damit das Braurecht, ${ }^{127}$ 1808-1811 wurde dann am Oberhof die neue Brauerei mit herrschaftlicher Stube sowie Brauteich erbaut. ${ }^{128}$ Denkbar ist ein weiterer Ausbau des Brauwesens aus Gründen des sich neu bildenden Vereinen diverser. Ihre Ziele waren jedoch wieder ein einheitliches demokratisches Deutschland und eine freiheitliche Verfassung. ${ }^{133}$ Leitfigur in Sachsen war nun der Turnvater und Abgeordnete der Nationalversammlung Otto Leonhard Heubner (1812-1893). Der politische Umbruchswille der Turner wurde so stark, dass sie im Mai 1848 den Zwingerwall in Dresden besetzten und am Zeughaus einen gewaltsamen Aufstand probten, ${ }^{134}$ was ab 1850 zum staatlichen Vorgehen gegen politische Vereine in Sachsen führte und eine Erholung des Vereinswesens erst wieder ab $1860 \mathrm{zu}-$ ließ. ${ }^{135}$

Vor dem Hintergrund dieser Entwicklungen stellte Ruschenbusch den Turnern im Jah 1862 Flächen hinter dem Schießhaus zur Verfügung und ließ auf Anraten des Turnlehrers Karl Viktor Thurm (1844-1904) aus Dippoldiswalde den ersten »deutschen Central-Turnplatz « einrichten. ${ }^{136}$ Das bereits 1861 zur Einrichtung bestimmte Komitee beschaffte sechs Recke, sechs Barren, sechs Sprungbretter, Holz für ein großes Klettergerüst mit mehreren Masten und weitere Geräte. ${ }^{137}$ Die feierliche Einweihung fand am 6. Juli 1862 statt:

"Das >Pirnaische Wochenblatt $<$ berichtet >Herr Rittergutsbesitzer Ruschenbusch auf Reinhardtsgrimma hat mitten im Walde einen Turnplatz errichten lassen, der allen deutschen Turnern gewidmet und am 6. Juli eingeweiht worden ist. $\ll^{138}$

Dabei waren nicht nur Turner aus den umliegenden Dörfern zugegen

»In den Abendstunden des vergangenen Sonnabends zog die Dresdner Turnerschaft, ca. 200 Mann stark, in der üblichen Turnerkleidung, mit ihrer Fahne an der Spitze, vom Schießhause aus durch die Stadt, um ihren Nachtmarsch nach Reinhardtsgrimma anzutreten, woselbst vorgestern in solenner [feierlicher] Weise die Einweihung des schönen neuen Cen- tralturnplatzes gefeiert wurde. Die Festrede hielt Herr Prof. D. Wigard. ${ }^{139}$

Auch im Schlosspark wurden bis 1874 Turn geräte aufgestellt, darunter eine Schaukel ein Schwebebaum und eine Kletterstange. ${ }^{140}$ Interessant ist hier die Verbindung von Landschaftsverschönerung, Ausflugskultur und Turnbewegung, da diese sich gegenseitig inspirierten, wie das Grimm'sche Wörterbuch von 1922 deutlich macht:

"Erst die neuere Zeit kennt Wandern als das frohe Durchstreifen der Natur, um Körper und Geist zu erfrischen. Nachdem durch die Romantik und die Turnerei die Wanderfreude erweckt war, ist das Wort in diesem Sinne beliebt. $\ll^{141}$

Resultat der neuen Verschönerungswelle Nach dem Tod von Bülows finden sich in den Archivalien keine Nachweise mehr auf Ausschmückungen des Liebsteingrundes, dennoch wird deutlich, dass sich auch die nachfolgende Generation die Landschaft um Reinhardtsgrimma - neben allen wirtschaftlichen Überlegungen - zunehmend ästhetisch aneignet und erschließt. Wie man zeitgenössischen Schilderungen entnehmen kann, handelt es sich dabei nicht um parkmäßig erschlossene Partien, sondern um die Landschaft per se, die als schön und besonders empfunden wird. So beschreibt es beispielsweise Moritz Grimmel in Poenickes (1807-1867) umfassendem »Album der Schlösser und Rittergüter des Königreichs Sachsen «:

"Vorzüglich ist es aber die Lage von Reinhardtsgrimma, welche so ungemein anzieht. Wohin sich auch der Naturfreund hinwenden mag, überall wird derselbe entzückt von den herrlichen Ansichten, von dem zauberischen Liebreiz der Natur. Die Bildung der tiefsten und schönsten Thäler der hiesigen Gegend wird erzeug durch die rings herum liegenden Gebirge. Das Ganze bildet eine der reizendsten Parthien in Sachsen und kann nicht so ge- 
schildert werden, als es der Beschauer tuierten Liebsteingrundes betrachtet. Die fühlen und geniessen muss. $\aleph^{142}$

um 1843 angefertigte Zeichnung Gottfried Traugott Fabers belegt, dass auch Künstler Die Landschaftswahrnehmung hatte sich die Qualität dieser Landschaft erkannten nun endgültig vom Sentimentalen und Auf- (Abb. 18).145 Folglich ließ auch Poenicke dieklärerischen zum Romantischen und Natür- sen Landschaftsausschnitt nicht aus und lichen gewendet. Schon Ende des 18. Jahr- schrieb, dass bei »Hausdorf und bei Schlothunderts werden die empfindsamen, arran- tewitz die tiefsten und schönsten Thäler der gierten Szenen mit Ruinen und klassizisti- hiesigen Gegend ${ }^{146}$ liegen. Später wird in schen Gebäuden als künstliche Nachahmung der Nähe des Schlottwitzer Grundes die der Natur kritisiert, zum Beispiel 1777 von Buschhausschänke als Ausflugslokal angeGoethe..$^{143}$ Deswegen werden nach 1800 >Na- legt. Vor diesem Hintergrund erscheint es tur` und >Verschönerung ‘ bereits stärker ge- allerdings merkwürdig, dass neben Faber trennt voneinander wahrgenommen, was Zeichnung keine weiteren Skizzen der Reinauch die Beschreibungen Reinhardtsgrim- hardtsgrimmaer Landschaft zu finden mas verdeutlicht haben. Was 1822 durch sind. ${ }^{147}$

Schiffner und Schuhmann durch die Tren-

nung von Garten und Park von der verschö- Die Weiterentwicklung der Kulturlandschaft nerten Landschaft und den Spaziergängen unter Ruschenbusch geschah nicht unter angedeutet wurde, wird zur Leitlinie land- dem Gesichtspunkt einer sentimentalen schaftlicher Rezeption.

Dabei steht nicht mehr der Gutsherr als Gestalter im Mittelpunkt der Betrachtung, sondern eine Landschaft per se. Dies erklärt auch, warum die Fortsetzung des Liebsteingrundes, nämlich der Schlottwitzgrund, um 1840 mit diesem in Zusammenhang gebracht und als Einheit betrachtet wird:

»Reinhardtsgrimma [...] hierzu noch die Hälfte von Schlottewitz, Schloitz mit 2 Mühlen im Schloitzgrunde, d. h. dem überaus reizend-schönen, tiefen und breieine Fortsetzung der Verănderungen als eine Fortsetzung der Ideale der Aufkläengen Seitenschlucht zwischen Achat- rung gelesen werden, die sich mit dem Wänden in das Thal hervor. Dieses kreuzt Landschaftsverständnis der Romantik verder Achatgang bei einer Mühle, und hier mischten. Die Bewirtung von Gästen in der wird der Stein von Zeit zu Zeit in einem Buschhausschänke, die Belieferung der Ausübrigens verkürzten Bruche gewonnen, flugsgaststätte mit lokalen Erzeugnissen sofindet sich auch trümmerweise in der wie die bauliche Ergänzung durch das Müglitz. Er besteht aus Hornstein, Quarz Schießhaus sprachen den Fremdenverkeh und Amethyst, enthält auch Jaspis, Chal- an. So begegnete man in Reinhardtsgrimma cedon und Carneol. Weiter hinab finden nicht zuletzt dem Spazierengehen als nun sich noch andere Halbedelsteine. ${ }^{144}$

breit im Bürgertum verankerte Praxis und der Dresdner Ausflugskultur. ${ }^{150}$ Die BuschDer Schlottwitzgrund wird also als naturhis- häuser waren gut in die Promenaden eingetorische Erweiterung des von Bülow akzen- bunden. Zudem waren sie an den Schlott-

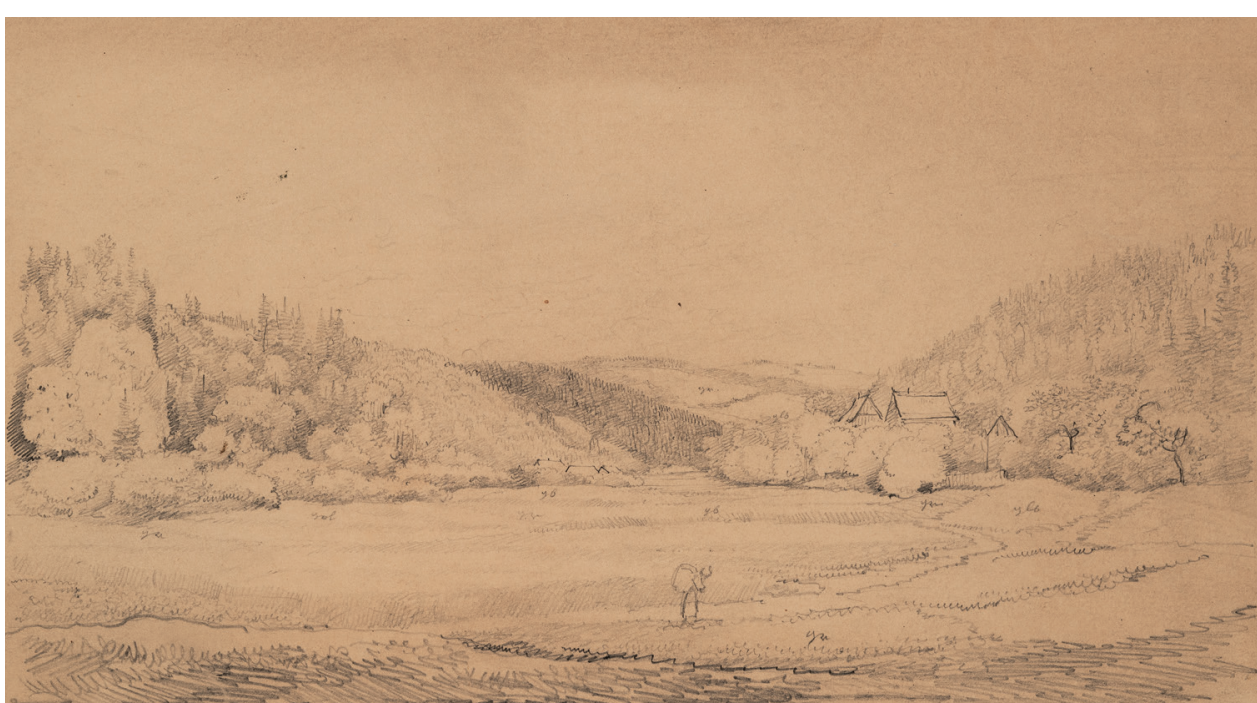

18 | Die Hütten im Schlottwitzgrund, Bleistiftzeichnung, Karl Gottlieb Traugott Faber, 1843 (SKD, Inv.-Nr. C 1995 1431).

witzgrund angeschlossen und belebten und Auch der Wiederaufbau einer Schäferei in betonten damit die Landschaft im repräsentativer Bauweise kann als eine geBecker'schen Sinne: widmete Architektur in der Landschaft verstanden werden - als eine Würdigung der "Sein [des Naturkünstlers] Zweck ist Schafe, die wirtschaftlich bedeutsam und nicht, in einem bestimmten Bezirke eine zudem durch die Landschaftsmalerei ästhe-

Natur im Kleinen zu schaffen; er unter- tisch mit der Landschaft verknüpft waren. nimmt die Natur zu verschönern, zu veredeln und noch mehr zu beleben. $\aleph^{151}$

\section{Unter den Asters: Von der Romantik zu} Realismus und Ökonomie

Die schauerlich romantischen Täler konnten den »wahren Freunden der Natur« - Nachdem Ruschenbusch im Jahr 1866 verganz nach Becker - leicht erreichbar ihre na- storben war, erbte dessen Tochter Friederike turwissenschaftlichen Aspekte offenbaren, Conradine mit ihrem Gatten Ludwig Emil wie zum Beispiel die teils offen liegenden Aster das Rittergut. Obwohl er einen militägeologischen Schichten oder die besondere rischen Hintergrund besaß, stürzte er sich Berglandvegetation mit einem mit großem Fleiß, Eifer und einem gewissen Geschick in die wirtschaftliche Leitung des

"Nebeneinanderseyn so mannichfaltiger Gutes. Dabei zeugen die Archivalien, z.B. Pflanzen und Bäume, welche nicht leicht das umfangreiche Flurbuch sowie die Bein der freien Natur einem gemeinschaftli- richte der Ökonomischen Gesellschaft zu chen Boden von selbst entspriessen; Dresden, von einer technischen und ökono$[\ldots] \cdot \ll^{152}$ mischen Aufbruchsstimmung.

Die außerdem neu aufflammende Turnbe- Vergleichbar mit den physiokratischen Bewegung war zwar politisch bedingt, aber strebungen im ausgehenden 18. Jahrhunauch im Sinne aufklärerischer Gesundheits- dert, besann man sich unter Aster stark auf prophylaxe zu verstehen. ${ }^{153}$ Schließlich be- die landwirtschaftliche Produktion und die feuerte sie sogar die Wanderbestrebungen. ${ }^{54}$ Naturwissenschaften. Dies war eine Ten- 
denz, die auch in den umliegenden Orten zu Für den Forst war spätestens seit 1874 Rebeobachten war. Beispielhaft dafür steht die vierförster Henke verantwortlich, ${ }^{159} \mathrm{der} \mathrm{ab}$ am 29. April 1866 - noch vor Ruschenbuschs 1877 auch Mitglied des sächsischen ForstverTod - erfolgte Gründung eines landwirt- eins war. ${ }^{160}$ Ziel dieses Forstvereins war es, schaftlichen Vereins auf dem Buschhaus zu Beobachtungen und Erfahrungen auszutauReinhardtsgrimma durch den Rittergutsbe- schen, allgemein die forstliche Erkenntnis sitzer Schulze zu Hausdorf. Zu dieser ersten zu erweitern, aber auch den Gemeinsinn zu konstituierenden Sitzung fanden sich Ver- stärken. ${ }^{161}$ Eine solche Beobachtung, die Astreter und Freunde der Landwirtschaft« aus ter im November 1875 mit der ÖkonomiReinhardtsgrimma, Cunnersdorf, Luchau, schen Gesellschaft teilte, betraf einen die BeHirschbach, Hausdorf und Maxen ein. stände zerstörenden Käfer, der vor allem Schulze bezeichnete die Landwirtschaft in Birken befiel. Ein weiterer Schädling (Curwa seführte Na- culio pini - Fichten-Rüsselkäfer) m turwissenschaft«. Letztendlich wurde

»noch ein Act der Pietät vollzogen, indem Rittergutsbesitzer Ruschenbusch auf Reinhardtsgrimma, als Senior der in hiesiger Gegend selbstthätigen Landwirthe, zum Ehrenmitglied einstimmig ernannt wurde. $\ll^{15}$

Spätestens 1872 wurde Aster Vorsitzender der Dresdner Ökonomischen Gesellschaft. ${ }^{156}$ Schon im Mai 1873 machte er für die Gesellschaft auf den Feldern Reinhardtsgrimmas Testversuche mit einem neuartigen amerikanischen Mouldbord Pflug. ${ }^{157}$ Zunehmend beschäftigten sich Aster und seine Kollegen auch mit der sozialen Frage in der Landwirtschaft und ihrer individuellen Lösung für die einfachen Bauern auf dem Land. Dazu stellte Aster im Dezember 1874 in seiner Position als Direktor der Ökonomischen Gesellschaft eine Abhandlung zur »Zucht des französischen Kaninchens und dessen Ver breitung in Deutschland « vor. Ziel war es:

"[...], bei den so gestiegenen Fleischpreisen dahin mitzuwirken, dass die nicht allein im Großen einträgliche, sondern auch dem kleinen Haushalte leicht mögliche und nutzbare Kaninchenzucht namentlich auch in Sachsen Verbreitung finde, für dessen Arbeiterbevölkerung dieselbe von hohem Werthe sein müßte. $\ll^{158}$ den Reinhardtsgrimmaer Kirschpflanzungen abgeschüttelt werden. Teilweise schien es also Schäden und Krankheiten in den Holzbeständen zu geben und man suchte be den Land- und Forstwirten in den Vereinen

Noch im gleichen Jahr 1875 legte Aster ein umfangreiches Flurbuch an und scheint sich unächst nicht mit Ausgestaltungen der Landschaft, sondern stark mit Feldwirt schaft, Viehzucht und Obstbau zu beschäftigen. ${ }^{163}$ Wie aber in einem Croquis zu den Obstgehölzen aus dem gleichen Jahr zu sehen ist, wurden zahlreiche sogenannte Hölzer außerhalb der Schläge aufgezählt (Gehölze, die nicht geschlagen wurden). Da es sich somit weder um Obst- noch um Nutzgehölze handelte, muss es sich um Ziergehölze, nicht schlagbare Gehölze oder Gehölze mit ökologischem Nutzen gehandel haben. Diese wurden am Oberhof zum Beispiel am Folgenbachgrund, am Gehweg nach Luchau, am Feldsaum vom Leichenweg zum Halsgericht, an Ruschenbuschs Ruhe und am steinernen Tisch verzeichnet. Neben den Gehölzen im Park und im Liebsteingrund wurden weitere entlang des Schlottwitzbaches und des Cunnersdorfer Baches gezeigt. 1875 werden sie erstmals dargestellt, ihre Anpflanzung und damit ihr Alter sind aber unklar. ${ }^{164}$ Das Wort Croquis deutet darauf hin, dass es sich um eine Entwurfszeichnung zur Vorbereitung der $\mathrm{Ge}$ hölzstrukturierung handelte. Damit erhalten wir unter dem Ehepaar Aster einen Hinund Gesellschaften um Rat. ${ }^{162}$ weis auf die Ausgestaltung bzw. Pflege wei- von Bülows Zeiten angelegten Pavillons, steterer Spazierwege, neben jenen im hen noch heute die Worte:

Liebstein- und Schlottwitzgrund. Im Fol genbachgrund stehen noch heute Rotbuchen mit großen Stammdurchmessern, die bis zurück in die Aster'sche Zeit datieren könnten.

Familiäre und politische Widmungen in der Landschaft unter den Asters

Parallel dazu wurde wieder ein stärkerer Bezug zu den bestehenden Promenaden und verschönerten Landschaften genommen, vor allem im Liebsteingrund. Eine Widmung erfuhren diese Landschaftsteile durch die Namen von Freunden, Angehörigen oder vereinzelt auch durch ein Zitat - wie nachfolgend dargelegt wird.

Als vormaliger Gutsbesitzer hatte Ruschenbusch in der Bevölkerung einen bleibenden Eindruck hinterlassen. Dass dieser im kollektiven Gedächtnis erhalten blieb, belegt ein Dokument in der Turmkugel des Schlosses. ${ }^{165}$ Im Jahr nach seinem Ableben und ganz im Sinne seines sozialen Engagements wurde 1867 die »Georg Conrad und Gotthold Ruschenbusch Stiftung « eingerichtet, welche eine Art Kranken-, Arbeitsunfähigkeits- und Rentenversicherung für Tagelöhner, Gesinde und Dienstboten des Rittergu tes darstellte. ${ }^{166} \mathrm{Zu}$ seinem Gedenken stellte man außerdem 1869 eine Bank »Ruschen buschs Ruh" mit Gedenkstein am Wiesenweg unterhalb des Bauernbuschs auf. ${ }^{167}$

1877 erfuhr zudem der Liebsteingrund eine Widmung. Am sschwarzen Wehr`, einer steinernen Bank im Liebsteingrund, wurde mit den Worten »von Bosses Ruh 1877 « dem Juristen und Kreishauptmann Hans Alexander von Bosse (1835-1898) ${ }^{168}$ ein Rastplatz gewidmet. In einen markanten Felsen gehauen, ist die Inschrift noch heute in goldenen Buchstaben zu lesen. Die gleichen goldenen Lettern verwendete man vermutlich im selben Jahr auch auf der gegenüberliegenden, südlichen Seite des Liebsteingrunds. Dort, in einer Sichtachse gegenüber des zu
»Es wirke jeder Geist und jede Hand belebend fördernd für des Ganzen Wohl

Dieser auf eine Art Gemeinwohl abzielende Spruch könnte als Bezug zur RuschenbuschStiftung und zur Gedenktafel an Ruschenbuschs Ruh verstanden werden. Die Inschrift ist jedoch einem anderen Zusammenhang entlehnt: Das Zitat findet sich in udwig Uhlands (1787-1862) Prolog zum Trauerspiel »Ernst, Herzog von Schwaben«. Diesen schrieb er zur Feier der württembergischen Verfassung am 29. Oktober 1819, als sein Stück uraufgeführt wurde. Das Trauerspiel beschreibt mit lyrischer Kraft das deutsche Mittelalter und Uhlands schwäbisches Heimatland. Der Prolog drückt dabei seine Euphorie über die neuen, geordneten politischen Verhältnisse aus. Im darauffolgenden ahr wurde Uhland Mitglied im ersten württembergischen Landtag. ${ }^{169}$ Die Inschrift kann also auch in diesem Zusammenhang gelesen werden. Zunächst in einem spätromantischen Kontext, wobei bereits damals in der Romantik zunehmend die Betrachtung nicht mehr der antiken, sondern vielmehr der eigenen Vergangenheit und $\mathrm{Ge}$ schichte - wie bei Uhland - in den Fokus rückte. ${ }^{170}$

Andererseits könnte der Spruch zudem die Freude über die deutsche Reichsgründung 1871 ausdrücken, die sich in gewisser Weise auch in der lokalen Turnerbewegung in Reinhardtsgrimma widerspiegelte. Denn auch die Turner strebten ein einiges deutsches Reich an. Die Turnsperre 1820 geschah aus Angst vor den vermuteten Bestrebungen zur Gründung eines solchen deutschen $\mathrm{Na}$ tionalstaats, die von Turnerschaften und Burschenschaften ausging - doch die Staatsgründung wurde durch die Karlsbader Beschlüsse im Jahr zuvor erst abgelehnt und so war die gewünschte Staatsgründung zunächst nicht erreichbar. ${ }^{171}$ 
Zudem passt auch Bosse ins Bild, nachdem Die topografischen Flurbezeichnungen waer seit 1874 die Landgemeinden Dippoldis- ren so allgemein, dass sie sich am längsten waldes im königlich sächsischen Landtag hielten - viele bis heute. Solche Bezeichnunvertrat und immer wieder kleine Handrei- gen sind z. B. das Waldstück »die Bergchungen für die Bevölkerung veröffent- schlüchte«, das Wiesenstück »Liebsteinlichte, z.B. »Die Selbstverwaltung in den grund « oder das Feldstück »Schrammberg«. Landgemeinden und die damit gemachten So wurden die Flurnamen seit jeher zu einer Erfahrungen « (1878). ${ }^{172}$ Damit galt er als klu- sprechenden Landschaftskomponente und ger Politiker und lokale Identifikationsfigur, tragen eine ganz eigene orientierungs- und gerade zu dem Zeitpunkt da - seit der wirtschaftsbedingte Komponente. ${ }^{174}$

Reichsgründung 1871 und mit der sächsischen $»$ Revidierten Landgemeindeordnung " vom 24. April 1873 - die Selbstverwaltung der Gemeinden entscheidend verstärk wurde und so vermutlich neue administrative Herausforderungen entstanden. ${ }^{17}$

Doch nicht nur Bänke, Felsformationen oder Stiftungen wurden gewidmet - auch Flurstücke erhielten die Namen von Angehörigen. So erhielt Ruschenbuschs Tochter Friederike Conradine spätestens 1875 ein nach ihr benanntes Friederikenfeld zwischen Quergrund und Frauendorfer Grund, ihre Mutter Ernestine Auguste (1816-1890), geb. von Brandenstein, ein Ernestinenfeld zwischen Quergrund und Luchauer Weg sowie Georg Conrad Ruschenbusch ein Feldstück namens Ruschenbusch-Dreieck unterhalb des Leichenweges. Unter der Gutsherrschaft Aster zeigte sich ein Flurnamenbestand, der ein Abbild voriger und aktueller Herrschaften darstellte. Einige Bezeichnungen waren so universell, dass sie seit 1628 unverändert blieben. Andere Orte erhielten neue Widmungen. Flurstücke wurden oft nach ihrer Nutzung benannt und wiesen noch 1875 auf eine alte Wirtschaftsweise hin, wie die Feldstücke »der Weinberg" oder »das Ziegelfeld«, beide an den Drescherhäusern. Auch wem die Flurstücke aktuell gehörten oder wer sie bewirtschaftete war namensgebend, wie bei dem Waldstück »Kretzschenbusch « oder bei den "Grummetwiesen «, dem »Schwenkengrund « oder dem "Eisrichsgrund « entlang des Cunnersdorfer Baches. Aber auch konstante Besitzverhält nisse spiegeln sich z.B. in Pfarrfeld, Pfarrwiese und Pfarrholz am Hirschbachgrund.
So hob man neue Straßen aus, wie die neue Schlottwitzer Straße um 1900, aber man erneuerte und verbreiterte auch zahlreich Straßen und bepflanzte sie mit Baumreihen, z.B. $1883 / 84$ an der Buschhausschänke. ${ }^{181}$ Die Gutsherrschaft pflegte vor allem den Obstbau - man verschnitt und pflanzte Obstbäume in den Jahren 1882 bis 1887 - sowie die Jagd. 1884 wurden Fuchsbaue gegraben vermutlich künstliche Bauten, um die Population besser regulieren zu können ${ }^{182}-$ und man bekam zahlreiche Jagdeinladungen, von denen wohl »nur« 16 besucht werden konnten. ${ }^{183}$ Mit der Renovierung der Brauerei im Jahr 1900 nahm Nitzsche Bezug auf die lange Tradition der Gastwirtschaft im Ort. ${ }^{184}$ Alles in allem schien er das Gut recht geschickt zu führen und die Landschaft auf eine Zunahme von Mobilität und Industrialisierung vorzubereiten. Nitzsche ereilte 1907 ein früher Tod. Seine Witwe nahm 1908 eine weitere Tradition auf und rief im Namen ihres Gatten eine Stiftung zur finanziel len Unterstützung für die Gemeinde ins Leben. ${ }^{185}$

Als Friedrich Hugo Maximilian Senfft von Pilsach (1855-1931) 1907 das Gut übernahm, zog eine eher konservative, auf Familienund Standesgrenzen achtende Kraft des oberpfälzischen Uradels in Reinhardtsgrimma ein. Darauf deutet bereits der innerfamiliäre Austausch von Gärtnern oder der Erwerb von Hunden samt Hundestammbäumen hin, ${ }^{186}$ aber auch die Ausstattung und Aufarbeitung des Schlosses ab 1907 mit luxuriösem Rokoko-Dekor, Skulpturen und Stuck sowie die Vergitterung der Fenster. ${ }^{187}$ Aufgrund des hohen finanziellen Aufwandes vernachlässigte Senfft von Pilsach zunächst die Kulturlandschaft und den Tourismus. Ob er den Fremdenverkehr aufgrund der Standesgrenzen ablehnte oder sein ländliches >Plaisir nicht teilen wollte, kann nur als Vermutung stehen bleiben. Dem Verkehrsverein für Kreischa und Umgebung begegnete man 1907 eher schroff, als dieser beim Bau eines Bismarckturmes auf dem Wilisch Unterstützung suchte:
"Zu meinem Bedauern muss ich [Maximilian Senfft von Pilsach] hierauf erwiedern, daß falls Angehörige von Reinhardtsgrimma mich in dieser Angelegenheit um eine Meinungsäußerung bitten sollten, ich ihnen raten werde ihr Geld für Unternehmungen aufzubewahren, die ihnen mehr [als] dieses Projekt tatsächlich Vorteil oder Annehmlichkeiten versprechen. $\ll^{188}$

Der Verkehrsverein wollte die Gegend für Wanderer und Fremdenverkehr attraktiver gestalten, besonders im Zuge der Eröffnung der Straßenbahn im Lockwitztal zwischen Niedersedlitz und Kreischa 1906. ${ }^{189}$ Man hätte auf diese Weise eine Verbindung beider Orte und, über die Teufelsmühle (und Wilischbaude ab 1909) hinaus, eine größere Attraktivität für den Besuch der Buschhäuser oder des Erbgerichts in Reinhardtsgrimma erreichen können.

Senfft von Pilsach setzte die Modernisie rungstendenzen vor allem in der Landwirtschaft fort und ließ zum Beispiel 1907-1913 Selbsttränkenanlagen und eine Acethylen gas-Heizanlage in den Kuhställen einbauen sowie landwirtschaftliche Maschinen lie fern. ${ }^{190}$ Zusätzlich ließ er 1927 eine Feld scheune umbauen und mit einem elektrischen Höhenförderer ausstatten. ${ }^{191}$

Verwunderlich ist, dass sich Senfft von Pilsach - als durch königliche Ernennung 1914 erwähltes Mitglied der ersten Kammer des Sächsischen Landtages - auf die Turntradition in Reinhardtsgrimma zurückbe sann und 1912 einen neuen Turnplatz südwestlich des Oberhofes zur Verfügung stellte sowie Übungsräume auf dem Malzboden des Brauhauses auf dem Oberhof. ${ }^{192}$ Mit dem zunehmenden Militarismus unter der ländlichen Bevölkerung, wie am 1872 in Reinhardtsgrimma gegründeten Militärverein zu sehen, ${ }^{193}$ wandelte sich der liberale Nationalismus der französischen Revolutionsideen mit der Reichsgründung 1871 wahrscheinlich eher zu einem konservativen Nationalismus des Kaisers und des Reichs. Die Frei- 
heitssymbole, die durch die Gestaltung der widmen sich Themen, die das Schloss, den Buschhäuser und die Errichtung des Cen- Schlossgarten, den Park, den Forst, Zeit tralturnplatzes in der ersten Hälfte des 19. zeugnisse, die Kulturlandschaft und aktuelle Jahrhunderts etabliert wurden, erfuhren Veränderungen in der Landschaft behanvermutlich eine Umwidmung im Sinne der deln. Das Schloss bietet nun in regelmäßiEinheit, unabhängig von Demokratie. Nach gen Abständen nicht nur Musikern und dem ersten Weltkrieg fasste der Deutsche Vorträgen einen Raum, sondern auch Turnverein 1924 den Beschluss, den zuvor Künstlern mit Ausstellungen zu wechselnbereitgestellten Turnplatz mit einer Turn- den Themen, wie im November 2019 mi halle zu versehen, ${ }^{194}$ deren Weihe schließlich Werken von Dresdner Künstlern zum im Jahr 1926 stattfand. ${ }^{195}$ Gutsbesitzer Senfft Thema "Garten und Landschaft». von Pilsach starb bereits 1931 - seine Witwe und sein Sohn lebten bis 1945 im Schloss Historische Spuren in der heutigen und wurden schließlich durch die sowjeti- Kulturlandschaft sche Bodenreform enteignet.

Die Deutsche Demokratische Republik entstand und die Zeiten tatsächlichen oder suggerierten Einklangs zwischen Gutsherrschaft und Dorf waren längst vergessen, als die Besonderheit der hiesigen Landschaft wiederentdeckt wurde. In den 1950er Jahren kamen Fotografen wie Walter Möbius (1900-1958), Fritz Adam (1914-1995) oder Erich Höhne (1912-1999) nach Reinhardtsgrimma (Abb. 19 und 20). Auch Künstler wie Richard Pusch (1912-1998), der in den 1950er/196oer Jahren teils detaillierte Tempera der Dorflandschaft in eindrucksvoller Lichtstimmung erschuf (Abb. 21) ${ }^{196}$, traten nun vermehrt an die Öffentlichkeit. Ganz allgemein wurden erst im 20. Jahrhundert lokale Künstler vermehrt sichtbar, zum Beispiel Herr Radochla, ${ }^{197}$ welcher um 1930 in Reinhardtsgrimma wirkte oder Erich Fraaß (1893-1974), der in Dresden lebte und besonders gern am Wilisch arbeitete.

Unterdessen widmete sich Heinz Tinius 1956 anlässlich der 750-Jahr-Feier einer Chronik der Ortsgeschichte. 1964 beschäftigte sich Gerhardt Müller in »Werte deutscher Heimat,Band 8 « mit der gesamten Kulturlandschaft zwischen Müglitz und Weißeritz. Seit seiner Gründung 2005 stellt sich der Heimatverein Reinhardtsgrimma in diese Tradition und gibt seit Februar 2009 im Internet zugänglich - die »Grimm'schen Heimatblätter« heraus. Zahlreiche Artikel
Was ist heute noch von der Blüte der Landschaftsverschönerung in Reinhardtsgrimma zu entdecken? Der überwiegende Teil der unter von Bülow zwischen 1800 und 1810 entstandenen Verschönerungen ist heute nicht mehr erkennbar. Als Baulichkeiten sind lediglich die Buschhausschänke und das gegenüberliegenden Jagdhaus erhalten. Zudem sind die Standorte einiger Elemente und deren Sichtbeziehungen zueinander noch nachvollziehbar: Felsplateaus auf beiden Hangseiten im Liebsteingrund weisen auf die Standorte der Ruine und des Pavillons hin. Des Weiteren existieren im Grund noch die Steinfundamente und die steinerne Sitzplatte einer 1807 verzeichneten Bank namens "schwarzes Wehr" (bei von >Bosses Ruh «). Der Standort der Mooshütte auf den verbliebenen Gemäuern der GrimmsteinFeste ist mit einer Infotafel und einer Bank ausgestattet worden, die eigentliche Mooshütte ist allerdings längst verfallen. Darüber hinaus sind in den Waldsäumen der Grimm'schen Heide und des "Hayns" am Oberhof immer wieder Grenzsteine zu finden, die in ihrer Nummerierung der Forstkarte von 1807 entsprechen. Dabei ist gut

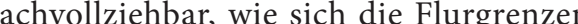
entlang der Forst-, Feld- und Wiesenflächen orientierten. Einige markante Altgehölze markieren den Grenzverlauf noch heute, wie die Linde am Feldsaum oberhalb der ehemaligen Gärtnerei. Entlang einprägsamer

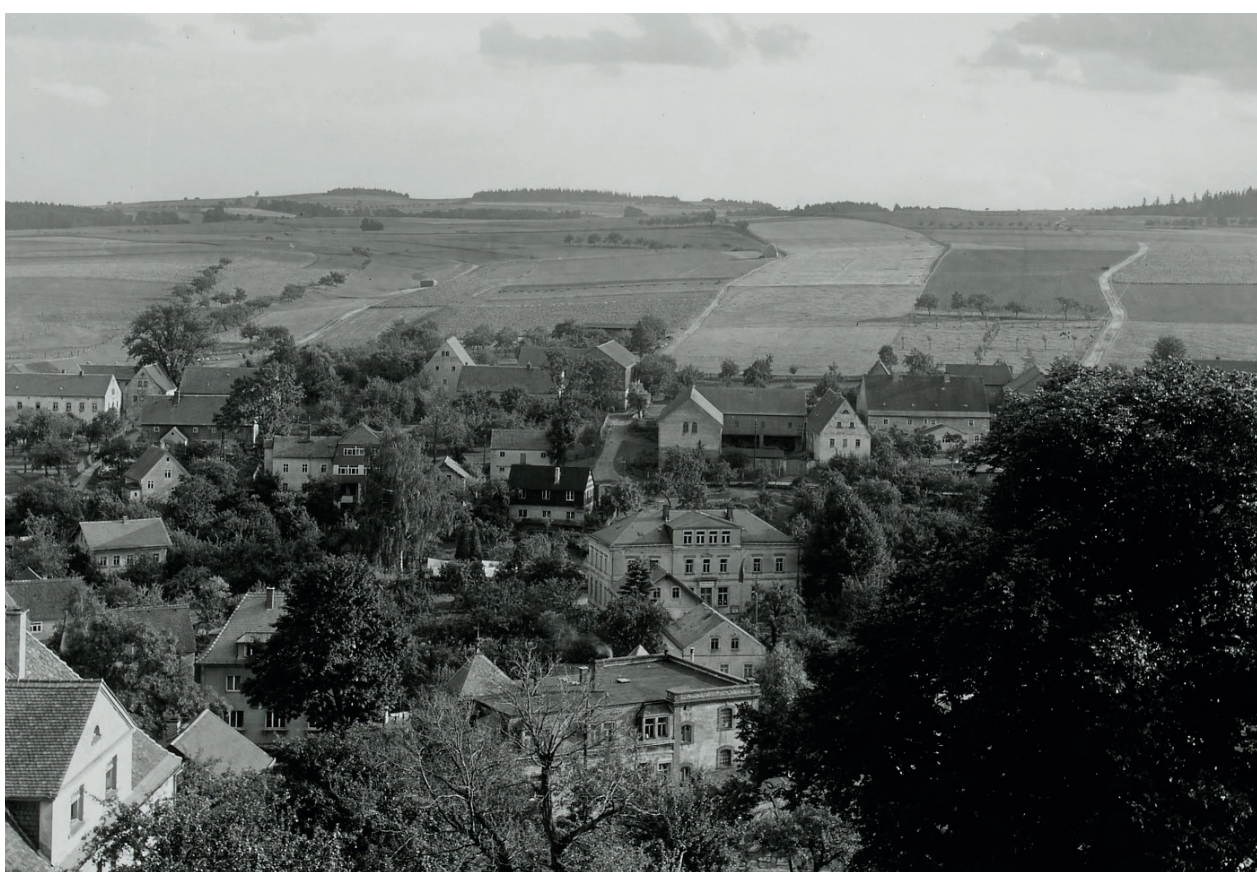

19 B Blick aus Nordwesten auf die Waldhufenstruktur Reinhardtsgrimmas (vermutlich vom Kirchturm aus), Fotografie: Fritz Adam, 1955 (SLUB, Deutsche Fotothek, Datensatz-Nr. 33108547, Aufnahme-Nr. df hauptkatalog_0354921).

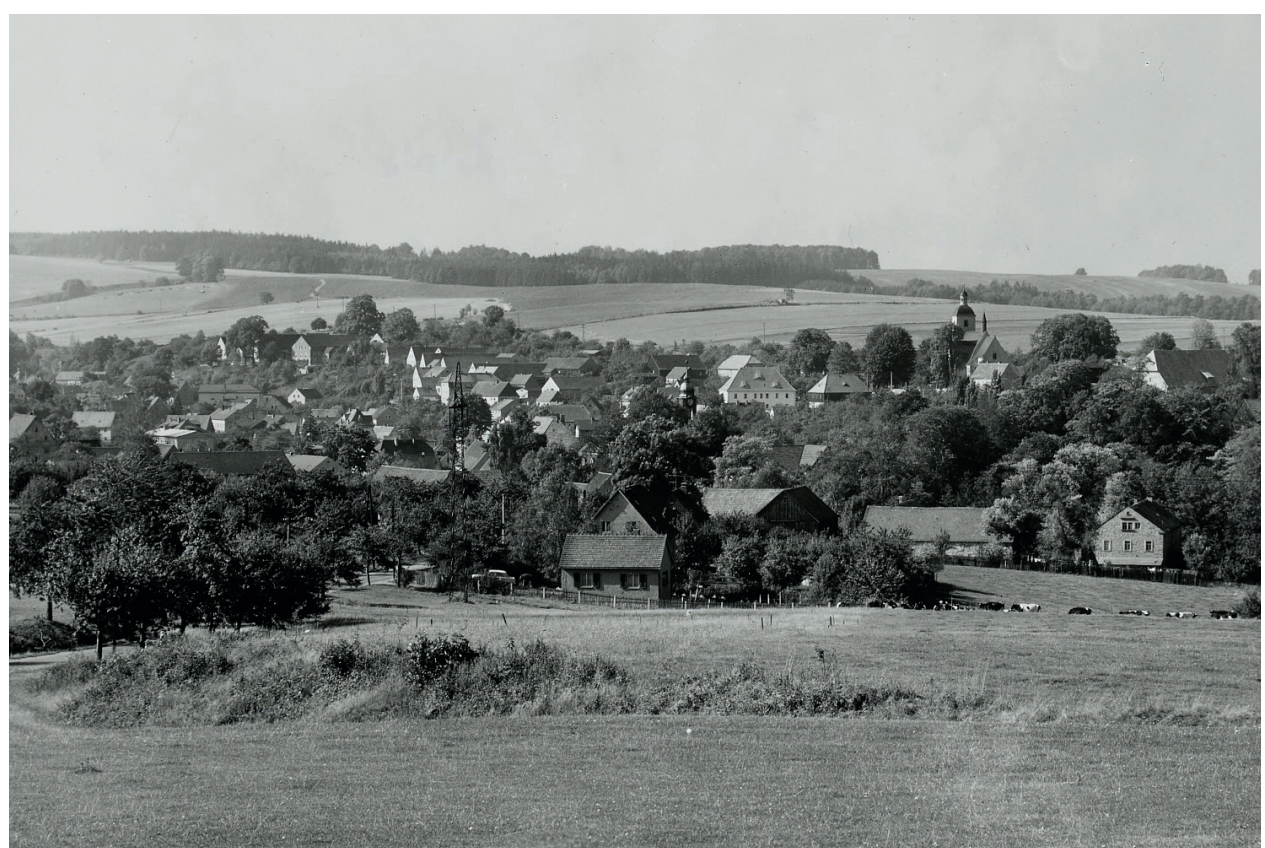

20 | Blick aus Osten von der Grimmschen Hauptstraße aus auf die Weiden und Obstbaumalleen Reinhardtsgrim mas, Fotografie: Fritz Adam, 1971 (SLUB, Deutsche Fotothek, Datensatz-Nr. 33108533, Aufnahme-Nr. df_hauptkatalog_0354918). 


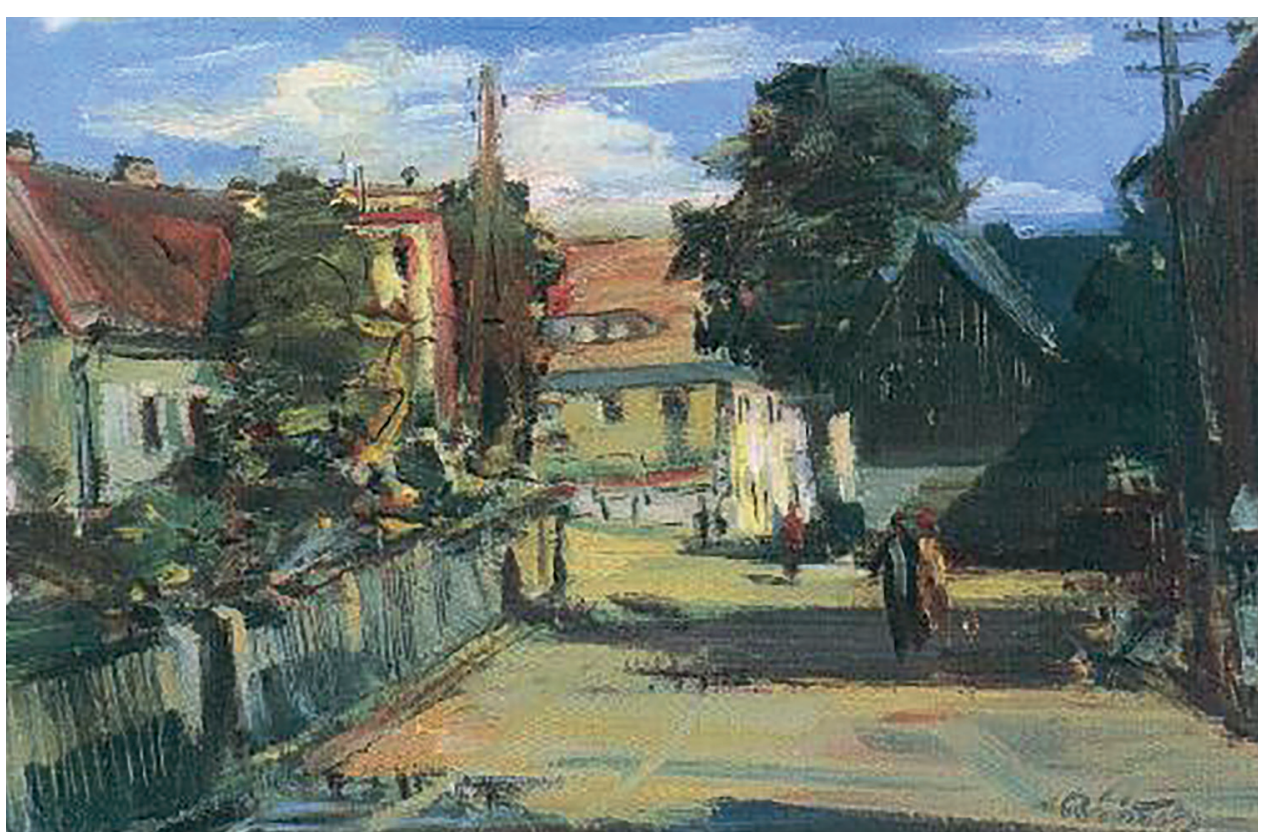

21 | Dorfstraße in Reinhardtsgrimma (vermutlich aus Osten in Richtung Oberhof), Tempera auf Pappe, Richard Pusch, 1960 (Museum Osterzgebirgsgalerie im Schloß Dippoldiswalde).

teilte bereits die Gutskartierung von 1628 Viele der Wege sind wohl im Zuge von Flurihre Flure ein. ${ }^{198}$ Das zur Zeit der Familie neuordnungen oder -bereinigungen in der von Bülow angelegte Wegesystem ist an eini- zweiten Hälfte des 20. Jahrhunderts vergen Stellen noch erhalten. Es existieren gut schwunden. So gibt es zum Beispiel am gepflegte Spazierwege im Folgenbachgrund Lockwitzbach unterhalb des Bauernbuschs am Oberhof und im Liebsteingrund am Un- kein solch ausgeprägtes Netz mehr wie 1807, terhof. Außerdem verlaufen nördlich des auch nicht im Schlottwitzgrund an der Ortes gut erhaltene Feldwege, die früher zur Mooshütte.

Krähenhütte und zum Hopfgarten am Ha- In den Tälern des Lockwitzbaches und selbach führten, heute allerdings durch die des Folgenbaches, am Heideberg oder an der Kreisstraße (Grimmsche Straße) zerschnit- Schafbrücke wurden 1926 einige Stellen unten werden. Weder Krähenhütte noch Hopf- ter Initiative von Alfred Herklotz und so lasgarten sind erhalten geblieben (Abb. 22).

sen Heimat- und Verkehrsvereins Reinhardtsgrimma wieder erschlossen und mit Ein Fußweg südlich des Ortes führt entlang Ruhebänken ausgestattet. Die seit $1869 \mathrm{er}-$ der ehemaligen Hufenstrukturen hinauf zur haltene Bank »Ruschenbuschs Ruh" ging Vorderen Höhe, vorbei an alten Kirschge- 1950 verloren und wurde in der Nähe des urhölzen, Lesesteinhaufen, Kopfweiden in sprünglichen Standorts am Frauendorfer Richtung Folgenbachgrund und Luchau. Er Grund neu aufgestellt. ${ }^{199}$

stammt aus der Zeit um 1875 unter der Fa-

milie Aster. In den Archivalien finden sich Die heute in Richtung Cunnersdorf (Cunviele Hinweise auf einen durch die Guts- nersdorfer Straße) oder am Luchauer Weg herrschaft finanzierten Wegebau, der eine zur Vorderen Höhe hinauf befindlichen, von Wetterverhältnissen weitgehend unab- teilweise abgängigen Obstgehölze stammen hängige Zuwegung der Felder sicherstellte. noch aus der Zeit intensiver Obstwirtschaft

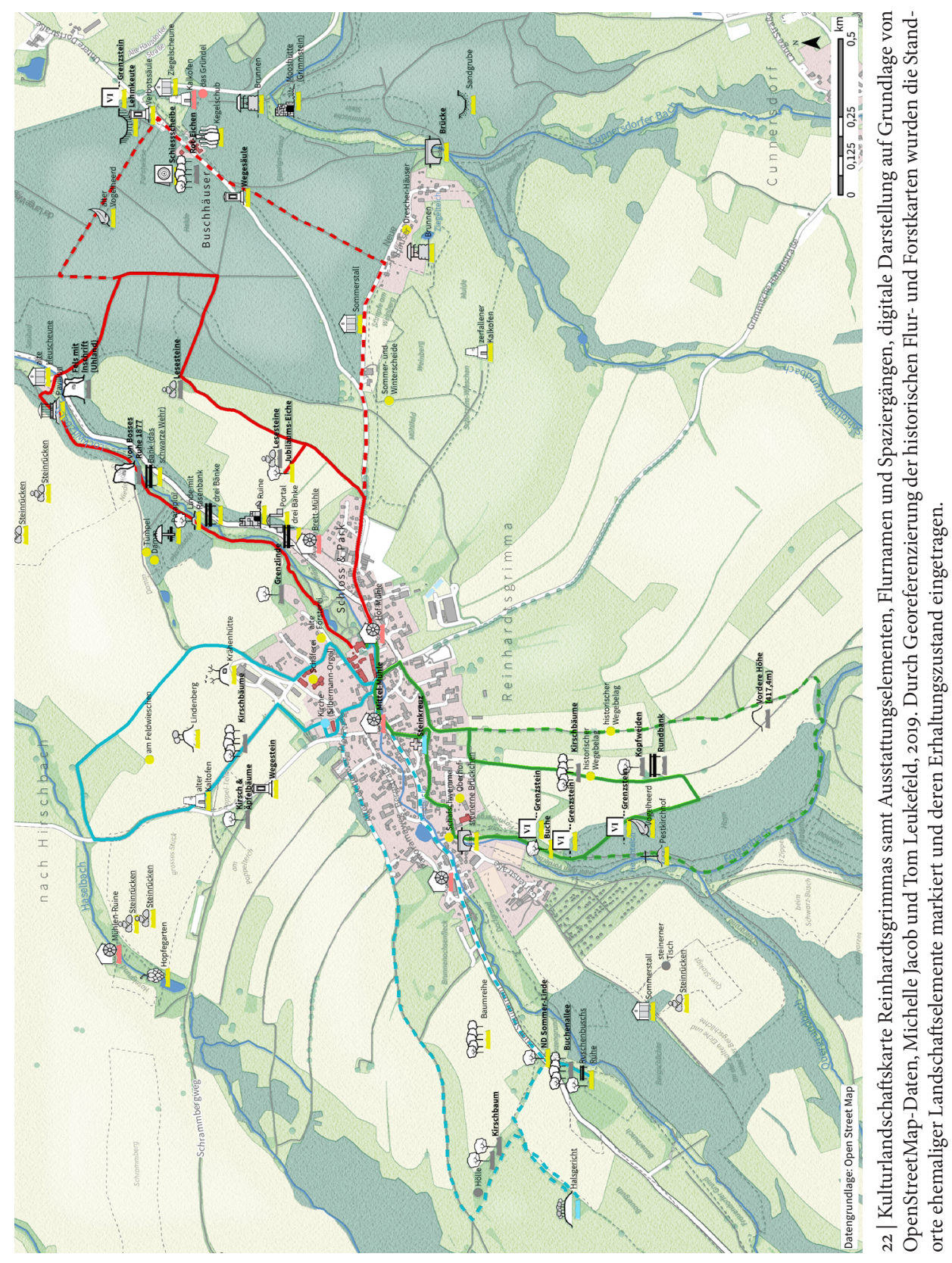


unter Aster. Auch einige Ziergehölze außer- später Vertreter unter den ersten Landhalb der Schläge, wie die große Buche im schaftsverschönerungen des 18. Jahrhun Folgenbachgrund, sind vermutlich Relikte derts. Die Promenaden und landschaftlidieser Zeit. Kapitale Rot-Buchen finden sich chen Inszenierungen bilden eine Überin einer Reihe an der neu gewidmeten Ru- gangsform zum aufkommenden romantischenbusch-Bank nahe des Bauernbuschs. schen Landschaftsverständnis des 19 . Markante Lindenreihen und alte Kirsch- Jahrhunderts. Unter den Ruschenbusch bäume stehen versteckt am Rande einer und Asters verstärkte sich dieses VerständMulde, dem »Hölle« genannten Gegenstück nis, das bald bürgerlich besetzt und stärker zum Halsgericht. 1875 lief auch dort, am touristisch interpretiert wurde. Damit wird nördlichen Rand der Mulde, ein Weg mit deutlich, dass Reinhardtsgrimma genau geZiergehölzen entlang. Kirschgehölze beglei- nommen kein Beispiel für eine landschaftliteten zudem die Hauptstraßen aus dem Ort. che Verschönerung mit Alleinstellungs"Himmel« beziehungsweise Halsgericht und merkmal ist. Vielmehr ging man mit der »Hölle« sind allerdings nur noch durch Um- Zeit wodurch man heute noch teils sehr dewege über das bearbeitete Feld zu erreichen. tailliert dem Zeitgeist nachspüren kann. Die späteren Eigentümer Nitzsche und Senfft Neben »Ruschenbuschs Ruh»sind als Über- von Pilsach führten diese Tradition einer reste gewidmeter Landschaft von Bosses Landschaftsverschönerung nicht bewuss Ruh mit Inschrift im Liebsteingrund und die fort, weil sie nicht mehr opportun war und Uhland-Felsinschrift von der Straße aus zu sich das soziale und wirtschaftliche Gesicht entdecken. Verlieren die Gehölze im Lieb- des Gutes und Dorfes wandelte. steingrund ihr Laub, ist sogar der Blickbezug vom Plateau des ehemaligen Pavillons Zum Zweck einer Einordnung muss also zuzur Inschrift ablesbar. Alles in allem sind die nächst der Blick auf jene Anlagen fallen, die landschaftlichen Reize der Kulturlandschaft in Sachsen um 1800 entstanden: Eine Kränoch erfahrbar. Zwar sind die sentimentalen henhütte, eine künstliche Ruine und eine Verschönerungen der ersten Gestaltungs- Schäferei mit Scheune in der Nähe der Prophase verloren, dafür tritt eine klassische menaden gab es zum Beispiel auch im ab Schönheit ohne Staffagen an ihre Stelle, die 1771 entstandenen Röhrsdorfer Grund. ${ }^{201}$ jedoch oft nicht mehr durch Spazierwege er- Hier erfuhr der Grund immer wieder theschlossen ist. Man muss dem Heimatverein matische Widmungen, indem freundschaft Reinhardtsgrimma zustimmen, der 2018 liche Motive (wie das Feuer der Freundfesthielt: »Ein Dilemma in Reinhardts- schaft) eingeführt und Freundschaftsbekungrimma ist, dass die meisten Wanderwege dungen in Stein gehauen wurden. Schließim >Nichts enden. ${ }^{200}$ Viele Wege führen lich wurde die Anlage auch Tal der über Privatgrund, werden untergepflügt und Freundschaft genannt und diente immer bestellt oder schließen nicht an Rundwege wieder für Treffen im kleinen Kreis. ${ }^{202}$

Auch im 1778-1786 entstandenen Fried richsgrund bei Pillnitz gab es Elemente wie Vogelherde, reale und künstliche Ruinen. Der Anreiz der Gestaltung war im Gegen satz zu Reinhardtsgrimma aber eher ein

\section{Zur Bedeutung der Kulturlandschaft} Reinhardtsgrimmas

In Reinhardtsgrimma wurde die Landschaft fürstliches Promenieren und umfasste weit erstmals 1793 unter Carl Victor August von aus ambitioniertere künstliche Fels- und Broitzem verschönert. Maßgeblich und Landschaftsveränderungen. ${ }^{203}$ Beide Anlaweitläufiger gestaltete sie schließlich zwi- gen eint die Einbeziehung realer Ruinen in schen 1800 und 1810 Friedrich Ludwig Ernst die Wegeführung und die Identifikation mit von Bülow. Reinhardtsgrimma ist damit ein diesen »Relikten des Alterums « ${ }^{204}$. Interes- sant ist dabei, dass die Ausdrucksformen der Gastfreundlichkeit. Vom Fürstenhaus eher Fürsten und des Hochadels dem Landadel misstrauisch beäugt, veranstaltete das Paar so ähnlich sind. Denn auch das Leben in be- auch Feste für die Armen der umliegenden scheideneren Verhältnissen brachte enga- Gemeinden. ${ }^{206}$ All dies war essentiell für die gierte Verschönerungen hervor. überregionale und internationale Reso-

Das Seifersdorfer Tal mag mit riesiger Re- nanz. ${ }^{20}$

sonanz wohl die bekannteste sächsische, Eine ähnliche kulturelle Bedeutsamkeit sentimentale Anlage gewesen sein. Dieser besaß das benachbarte Rittergut Maxen, das südwestlich von Seifersdorf liegende Talab- sich aufgrund historischer Fakten leicht als schnitt an der Größen Röder wurde 1781- »Musensitz« fassen lässt. Zwischen 1819 und 1792 unter Gräfin Christina von Brühl ange- 1873 war es im Besitz des Ehepaars Serre. ${ }^{208}$ legt. Durch sie als Gestalterin maßgeblich Dieses pflegte Kontakte zu namhaften geprägt, wurde es auch Tina-Tal genannt. Künstlern und Literaten der Zeit, darunter Man reicherte es mit rund 40 Ausstattungs- Robert (1810-1856) und Clara Schumann elementen an, darunter »Denkmäler, Tem- (1819-1896), Ottilie von Goethe (1796-1872), pel, Hütten, Grotten, Altäre, Brücken, In- Hans Christian Andersen (1805-1875), Berschriften und dergleichen, in der beliebten tel Thorvaldsen (1770-1844), Ernst Ferdienglischen Manier ${ }^{205}$. Die Dichte an An- nand Oehme (1797-1855) und Carl Gustav spielungen, Widmungen und Bezügen war Carus (1789-1869). Die Gäste verbrachten außerordentlich hoch, die 1792 erschienene regelmäßig Zeit auf Schloss Maxen, erkunBeschreibung Beckers erschloss die Anlage deten die Landschaft und zeichneten in der breiten Bevölkerungsschichten und das Umgebung (Abb. 23). ${ }^{209}$ Dabei gehörten zu Ehepaar von Brühl war bekannt für seine einer obligatorischen Spazierrunde oder

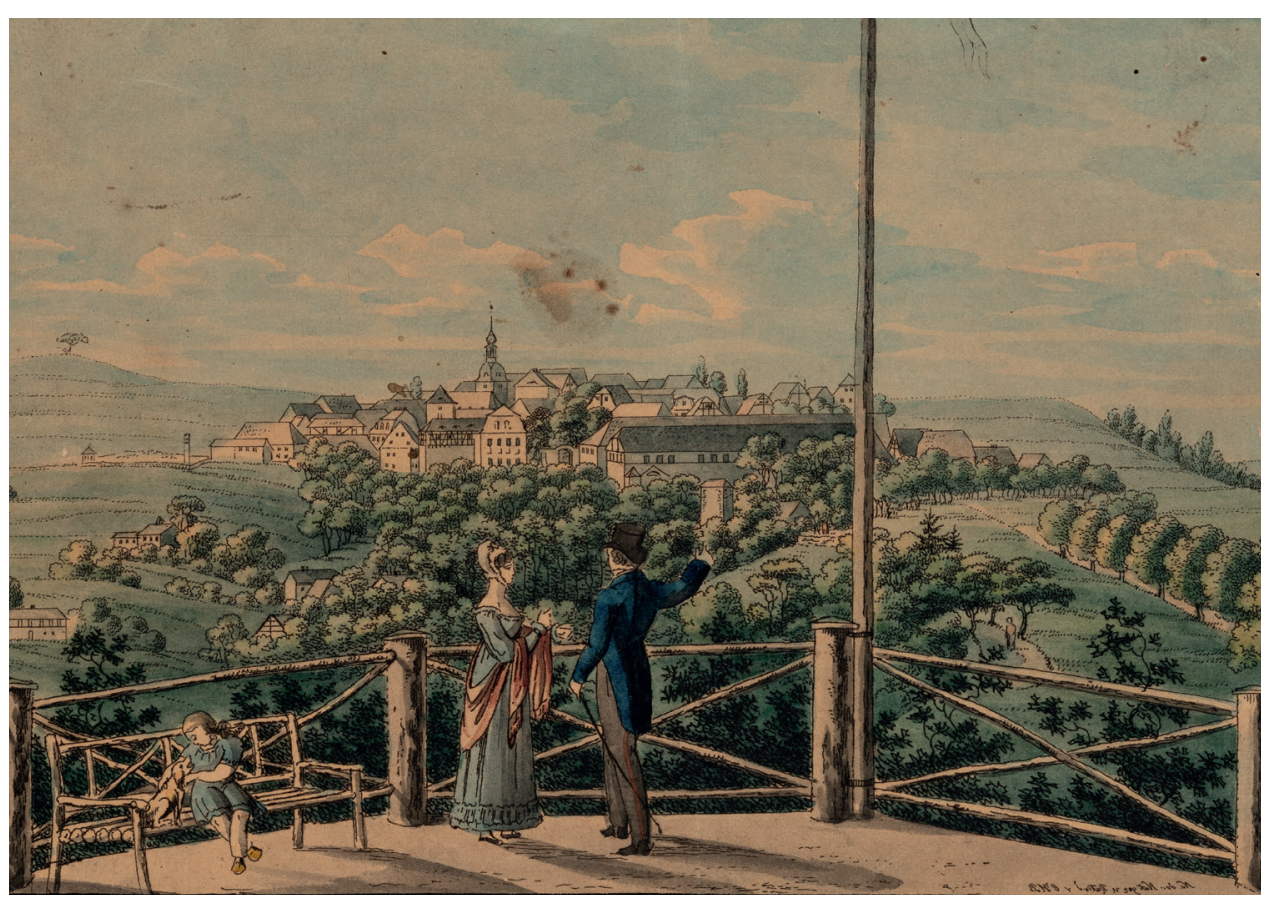

23 | Ortsansicht von Maxen, kolorierte Radierung, Stecher und Inventor: Carl Heinrich Beichling, um 1830. Blick von Osten auf den Ort mit dem Kirchturm von einer Aussichtsplattform. Der links gelegende Finckenfang war Schlachtfeld bei der Schlacht von Maxen am 20.11.1759 im Siebenjährigen Krieg (SKD, Inv.-Nr. A 1995-7716). 
Kutschfahrt der Besuch des Weesensteiner Ein weiterer wichtiger Bezugsort in der diSchlosses, der Buschhäuser oder des Schlos- rekten Umgebung sind die Lungkwitzer Anses in Reinhardtsgrimma. ${ }^{210}$ Dies deutet dar- lagen, zwischen Reinhardtsgrimma und auf hin, dass die Gutsherrschaften von Rein- Kreischa. Mit einer ähnlichen Topographie hardtsgrimma und Maxen mehr Kontakt und naturräumlichen Situation boten sie hatten, als man bisher anhand der Quellen- eine vergleichbare Ausgangslage. Sie wiesen lage rekonstruieren konnte. Vor allem besa- bereits in der zweiten Hälfte des 18. Jahrhunßen Ruschenbusch und Serre ähnliche Vor- derts unter dem bürgerlichen Hof- und Jusstellungen in Sachen fortschrittlicher Land- tizrat Johann Christian Benemann (gest. bzw. Forstwirtschaft, im Hinblick auf sozia- 1746) und seiner Frau Christiane Elisabeth les Engagement ${ }^{211}$ und vielleicht sogar beim (gest. 1772) einen Vorgänger verschönerter Natur- und Artenschutz - denn während Landschaften auf. ${ }^{214}$ An den Hängen, etwas Serre 1844 bis 1852 Vorsitzender des Dresd- weiter entfernt vom Lungkwitzer Schloss, ner Vereins für Tierschutz war, ist überlie- waren Promenaden angelegt, die zwar eher fert, dass Ruschenbusch vor Treibjagden achsialen Wegesystemen ähnelten, aber sein Wild aus dem Wald treiben ließ, um die auch Ausblicke in die Dorf- und NaturlandBestände zu schonen ${ }^{212}$

Da in dieser Hinsicht keine umfassenden Studien erstellt werden konnten, müssen Hypothesen versuchen zu erklären, warum Reinhardtsgrimma nicht so intensiv rezipiert wurde: Die maßgeblichen Landschaftsverschönerungen in der Zeit vor und nach 1800 nahmen vornehmlich adlige Familien vor, wobei die Anzahl der nichtsächsischen auffällig hoch ist. Das Heiratsverhalten zwischen von Bülow und Ruschenbusch war so außergewöhnlich, dass sie damit weder einer adligen noch einer bürgerlichen Distinktion entsprachen. Im Austausch mit benachbarten Adligen kulturbildend zu wirken, schloss sich damit aus. Gegenseitige Gesellschaften sind nicht bekannt. Einen großen Schnittpunkt scheint jedoch das Schützen- und Wirtshaus in der Grimm'schen Heide als `Sommerfrische $\mathrm{zu}$ bilden, das verschiedene Ortschaften, bürgerliche und vielleicht sogar adlige Gesellschaften zu verbinden vermochte, ähnlich wie die Kurhäuser um 180o. ${ }^{213}$ Dabei geschah die Verschönerung durch bürgerliche Hand und diese Art der Gestaltung wurde immer gängiger. So lassen sich weitere Vergleichsanlagen unter bürgerlicher Gestaltungsägide finden - zum Beispiel das bürgerliche Maxen.

ligatorisch in den Schulunterricht einfühen, was allerdings nicht erfolgreich war. $\mathrm{Zu}$ dem führte er eine ländliche Kommunalgarde ein, um die "schwerfälligen und gegeneinander unfreundlichen Bauern « aufzumuntern und einander anzunähern. ${ }^{21}$ Ebenso geschahen unter Quandt der Umbau und die Weiterentwicklung des Dorfes. Ähnlich wie in Reinhardtsgrimma wurde 1836 ein Gasthaus mit Tanzsaal, genann "schwäbisches Häuschen" errichtet. Ausge-

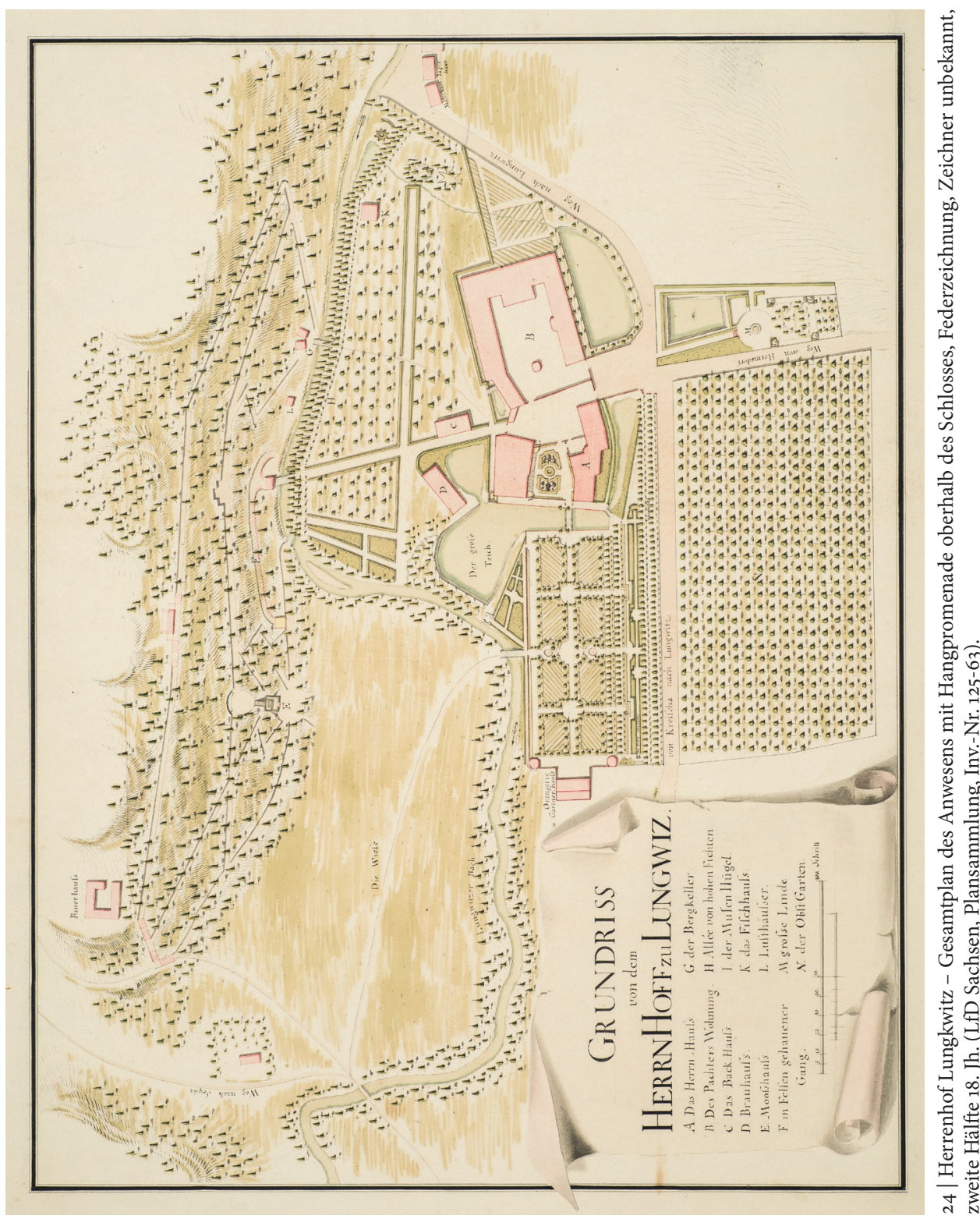
schmückt war es mit schweizerischen Landschaften $^{218}$ - einer mittlerweile in Sachsen 
typischen Bildsprache. Zwischen 1831 und tsgrimma die, zu dieser Zeit typischen spät1833 erbaute man ein turmförmiges Belve- sentimentalen Promenaden, mit teils histodere im Rundbogenstil auf der Erhebung risierenden klassizistischen Staffagebauten, ,Schöne Höheく. ${ }^{219}$ Das von Quandt auch teils auch der Inszenierung von natürlichen >Burg` genannte Belvedere als typisch ro- Felsformationen und Ruinen, einzurichten mantische Wertschätzung des deutschen Al- Über von Racknitz kamen Schuricht und tertums war Aussichtspunkt und wichtiger Thormeyer hinzu. Während Thormeyer verKnoten der Spaziergänge um Dittersbach mutlich die Pläne für die Buschhausschänke außerhalb von Gut und Park. In der Nähe und vielleicht auch für das Schießhaus zu der Schönen Höhe wurde zudem eine Zwer- verdanken sind, ist bei Schuricht unklar, ob genhöhle angelegt und bis in 1940er Jahre er für die Ruinen, Portale und Pavillons in bezog man die Täler der Weißeritz und des der Landschaft verantwortlich war. Zwar Schullwitzbaches mit ein, ähnlich wie den scheint dies aufgrund seiner Beteiligung an Liebstein- und Schlottwitzgrund in Rein- Hirschfelds maßgebender Theorie der Garhardtsgrimma. Im als »Lieblingstal« be- tenkunst und an Grohmanns Ideenmagazin zeichneten Grund des Schullwitzbaches er- nahezuliegen, sicher nachvollziehbar ist es richtete man zudem eine König-Anton- allerdings nicht. Die Beziehung zu von Büste, eine Konstitutionssäule als Racknitz, der zusammen mit Schuricht und Erinnerung an die erste sächsische Verfas- Thormeyer maßgeblich die landschaftliche sung von 1831 und eine neogotische Huber- Umgebung Ringethals gestaltete, legt jedoch tuskapelle. ${ }^{20}$ Solche teils politischen Wid- noch einmal die Beteiligung oder zumindest mungen finden sich auch in Reinhardts- Ideengebung an Reinhardtsgrimmas landgrimma mit "von Bosses Ruh«, dem Uh- schaftlichen Ausschmückungen nah. Auch land-Zitat, dem Turnplatz und dem Relief in diesem Bereich fehlen weitergehende >Jäger in Tiroler Tracht` am Eingang des Forschungen.

Schießhauses. Insgesamt sind der Natur-

raum und die in der Gestaltung adressierten Als direkter Vergleich zu den Promenaden Themen sowie die Art der Bewirtschaftung Reinhardtsgrimmas - quasi als Parallelanzu Reinhardtsgrimma sehr ähnlich, auch lage - sind diejenigen Ringethals anzusehen wenn die gestalterischen Ausführungen Ab 1799 gehörte besagtes Rittergut Joseph weitaus schmuckvoller, sentimentaler und Friedrich von Racknitz. ${ }^{221}$ Neben dem Rinaufwendiger sind.

Diese Einordnung darf nicht darüber hinwegtäuschen, dass die in Verbindung mit pau gestaltet:

Reinhardtsgrimma eruierten Namen wie Schuricht, Thormeyer, Giese, Pettrich und von Racknitz wesentliche Protagonisten der sächsischen Kunstgeschichte um 1800 waren, wie auch die von Bülows sich einem international agierenden Geflecht von Familien- und Interessenszugehörigkeiten verbunden fühlten. Verwandtschaftlich sind sie nicht nur mit den Protagonisten des frühen deutschen Landschaftsgartens verbunden, sondern lassen sich muhelos in den norddeutsch-dänischen Bezugsrahmen Hirschfelds einordnen. Die von Bülows verfügten über die finanziellen Mittel um in Reinhard- nießbar gemacht, und schon Mancher zog den umringten Felsen errichtet und diente die hiesigen Anlagen den sogenannten dem Ausblick in die Umgebung. ${ }^{225}$ Von englischen bei Lichtenwalde vor. Am inte- Racknitz war schon 1792 prominenter Kritiressantesten ist - am weitesten in Norden ker der überall entstandenen sentimentalen - die alte Burg oder das Raubschloß, eine Parkanlagen mit ihren Anhäufungen kleiner künstliche Ruine, die dennoch von histo- Einzelszenen. ${ }^{226}$ Die Mooshütte in Reinrischem Interesse ist, weil hier höchst hardtsgrimma, die eine reale Ruine besetzt wahrscheinlich die kleine Gottesburg und eine topografisch erhabene Stelle nutzt, stand. [...] Weiter südwärts kommt man, ist als Verschönerung der Landschaft im von in viel größrer Höhe, an eine Stelle, wo Racknitz'schen Sinne zu interpretieren - so man den Strom vollkommen in Gestalt ei- auch der Pavillon auf einer Anhöhe des nes Hufeisens fließen sieht; eine Bank be- Liebsteingrundes und die Promenade im zeichnet dieselbe, und ladet zum Genuß Pfarrbusch, die den Blick auf den Basaltkeder schönen Aussicht. Auf einer gel des Wilisch freigibt.

Felsklippe, da wo das von der Zschopau

halb umflossene Gelände am weitesten $\mathrm{Als} 18 \mathrm{o} 2$ der versierte und junge Förster $\mathrm{Ru}$ vorspringt, steht eine Einsiedelei. Nahe schenbusch an von Bülow empfohlen wurde beim Rittergut enthält der Berg eine und nach Reinhardtsgrimma kam, konnte er Grotte, und in deren Nähe ein Hüttchen, die teils sentimentalen, teils romantischen wo man die Zschopau aus Südost her gerade auf sich zu fließen sieht, und wo Schloß, Mühle, Wehr u. s. w. mit dem felBigen Hintergrunde bei Weinsdorf eine herrliche Wirkung thuen. Mehrere Alleen, zum Theil aus Ahorn bestehend, durchziehen den Wald, [...]..123

Das 1799 bis 1818 unter von Racknitz, Schuricht und Thormeyer entstandene Ringethal mit seinen gestalteten Landschaftszügen inszeniert die Natur ohne sie künstlich zu überformen. Grotten und Aussichtspunkte entstehen nicht um ihrer selbst willen, sondern in Korrespondenz mit den Ausblicken in die Landschaft. Bewusst grenzten Schuhmann und Schiffner in ihrer Beschreibung die dortigen Spaziergänge von typisch sentimentalen Anlagen wie etwa der in Machern ab. Besagter Schlosspark war um 1800 durch Vegetation in Einzelszenen unterteilt worden, die beim Beschauer jeweils andere Empfindungen auslösen sollten und mit künstlichen Ruinen, Tempeln und Bauernhäusern geschmückt waren. ${ }^{224}$ Die künstliche Ruine des Raubschlosses in Ringethal hingegen nahm einen historischen Burgstandort auf und wurde in "natürlicher", vermutlich das Mittelalter nachahmender Bauweise auf einem von Wällen und Waffenfun-
Ausschmückungen in ihrer Bauphase beobachten. Der Bau der Buschhausschänke mi Kegelbahn fungierte als Einladung an das reisende Bürgertum, den Ort und die Umgebung zu durchwandern. Ruschenbusch vermählte sich mit von Bülows Tochter, die zunächst das Rittergut erbte. 1830 übernahm er das Gut und erweiterte die Buschhausschänke um das Schießhaus mit "Concertund Tanzsaal«, was die wachsende Bedeutung der Ausflugskultur unterstreicht. Die in den Beschreibungen zwischen 1822 und 1840 auftauchenden "reizenden Thäler «, »Lustparthien " und »schönen Waldungen « stehen in engem Zusammenhang mit diesem Ausflugsziel. Der daran angebundene Schlottwitzgrund mit seinen naturkundlichen Reizen vermochte die Interessierten oder die nach Becker »wahren Freunde der Natur" - anzuziehen. Einige Reisende sind sicher bis in den Ort gewandert, da sich dort das zweite von Ruschenbusch eingerichtete Gasthaus (Erbgericht) befand. Außer Treibjagden gab es darüber hinaus keine öffentlichen Veranstaltungen im reich geschmückten Liebsteingrund, die sich in der Literatur niedergeschlagen hätten. Dennoch hätte $\mathrm{Ru}-$ schenbusch Park und Dorf sicher allen Wandernden geöffnet. Mit seiner bescheidenen Art war er bei Arbeitern, Dorfleuten 
und Nachbarn sehr beliebt. ${ }^{227}$ "Sein Name Denkmälern im Angesicht von Wirtschaft hat heute [1926] hier noch einen guten und Gesellschaft umgehen möchte, kann es Klang. «28 $^{228}$ hilfreich sein, in die Vergangenheit zu schauen. Die Romantik war die Geburtsstunde des Natur- und Artenschutzes ${ }^{230}$ Das passt ins Bild, da im alten Ständesystem stunde des Nalur- und Artenschutzes seit dem 18. Jahrhundert Förster wie Ru- heute so aktuell wie nie zuvor. Man beschăfnissen zwischen dörflichen und gutsherrli- fangs wollte man Philosophie, Kunst, chen Interessen zu agieren, wenn nicht zu Religion, Literatur, das Rationale und das vermitteln hatte. Durch seine Heirat 1820 Emotionale zusammenbringen, ${ }^{231}$ und setzte mit Friederike Juliane Christiane von Bülow sich auch mit einer mechanischen, zu rasanbegingen beide im Grunde eine Mesalliance ten und wissenschaftlichen Welt auseinan- eine nicht standesgemäße Heirat. Es zeich- der, ${ }^{232}$ die poetisiert werden sollte. Später benete sich ab, dass sich die Standesgrenzen wirkte die Romantik auch Ausgrenzung. Letztlich aber beschäftigte man sich sehr stark damit, was Natur ist und was deren Gestaltung bedeutet, wie man möglichs "natürlich" gestaltete und wie viel Verschö-

\section{Abschließend - Romantik 2.0?}

Auch wenn Aufklärung, Empfindsamkeit nerung eigentlich zu viel war - dieses Nachund Romantik gut 200 Jahre zurückliegen, denken ist durchaus zukunftstauglich. Nicht einige Themen der Romantik werden längst umsonst liest man hier und da von einer Roneu verhandelt. Um sich zu vergewissern mantik 2.0. ${ }^{233}$ wie man mit Natur, Kulturlandschaft und schenbusch zu einer standesherrlichen »Lei- tigte sich damit, was Heimat bedeutet, sam-
tungsebene« gehörten, die mit ihren Kenntdeutschen Philanthropismus. Dieser war eine aufkonnte gewonnen werden diese Ideen zu illustrie-

21 Krepelin;

22 Ebd., S. 37.

Maier-Solgk, Frank; Greuter, Andreas: Landschaftsgärten in Deutschland, München 2009, S. 18.

tergeschmack Frankreichs und Englands« beschrieben

Krepelin, Kirsten, Thränert, Thomas: Die gewidLandschaften um Dresden, Worms 2011, S. 237-239.

3 Zur Spannweite des Begriffs Kulturlandschaft: Hei- 6 land, Stefan: Kulturlandschaft, in: Kühne, Olaf; Weber, Florian; Berr, Karsten; Jenal, Corinna (Hg.): Handbuch Landschaft, Wiesbaden 2019, S. 653-655.

4 Carlson, Johann: Malerischen Darstellungen aus gen des Schlosses Weesenstein als »Garten im Zwit- tenkunst des Klassizismus und der Romantik, Köln 1989, S. 132-136.

Gothein, Marie-Luise: Geschichte der Deutschen Gartenkunst, 1914, S. 365-367.

Buttlar 1989, S. 36.

Vgl. Gesellschaft für nützliche Verschönerung des bairischen Landes (Hg.): Monatsblätter für Bauwesen und Landesverschönerung in Bayern, München 1821-1830. Zum Begriff auch: Pierer, Heinrich
August: Pierer's Universal-LexikonBand 10, Altenburg 1860, S. 79-80. Außerdem: Meyers Große Konversations-Lexikon, Band 12, Leipzig 1908, 103-104.

9 Krepelin; Thränert 2011, S. 58.

1o Becker, Wilhelm Gottlieb: Der Plauische Grund Be Dresden. Mit Hinsicht Auf Naturgeschichte Un Schöne Gartenkunst, Nürnberg 1799. Besondere Dank für hilfreiche Hinweise gilt an dieser Stelle Anja Gottschalk - wissenschaftliche Mitarbeiterin in dem Forschungsprojekt "Wilhelm Gottlieb Beckers Werk "Der Plauische Grund (1799) un sein Beitrag zur deutschen Gartenhistoriografie am Lehrgebiet Geschichte der Landschaftsarchitektur und Gartendenkmalpflege der TU Dresden.

11 Das Philanthropin (auch: Philanthropinum) in Dessau war wohl eine der wichtigsten Institutionen des klärerische Pädagogik Mitte des 18. Jh., bei der die Erziehung zu vermeintlicher Natürlichkeit, Vernunft und Menschenfreundschaft im Mittelpunkt stand (siehe dazu: Garber, Jörn: Das Dessauer Philanthropinum und der deutsche Philanthropismus 1774-1793, Tübingen 2008). Daniel Chodowiecki ren (siehe dazu: Schmitt, Hanno: Bilder als Quelle der Erziehungsgeschichte, Bad Heilbrunn 1997). Chodowiecki illustrierte 1799 auch die Affektiertheit des Adels, siehe Abb. 1

12 Becker (Schriftsteller, Dichter und Maler), in: Meyers Konversations-Lexikon. 4. Auflage,Band 2, Leipzig/ Wien 1885-1892, S. 590-592.

13 Becker, Wilhelm Gottlieb: Das Seifersdorfer Thal, Leipzig 1792, S. 1

14 Ebd., S. 6-7.

15 Ebd., S. 4-6 und S. 11 .

16 Ebd.

17 Koch, Hugo: Sächsische Gartenkunst, Beucha 1999 S. 300 .

8 Kuhlmann-Hodick, Petra; Schnitzer, Claudi Waldkirch, Bernhard von: Adrian Zingr. Wegbereter der Romantik, Dresden 2012, S. 125.

Ebd., S. 139.

20 Ebd.

sowie Sedlmayr Hans: Verlust der Mitte. Die bildende Kunst des 19. und 20. Jh. als Symptom und Symbol der Zeit, Frankfurt am Main 1985, zit. in: Krepelin; Thränert 2011, S. 57.

hardtsgrüm. f. Fritz Mangolts [Erben], 1614/ 1628. Steche, Richard: Beschreibende Darstellung de älteren Bau- und Kunstdenkmäler des Königreich Sachsen,Band 2 - Amtshauptmannschaft Dippoldiswalde, Dresden 1883, S. 71-72; sowie Poenicke, Gustav Adolf: Album der Rittergüter und Schlösse im Königreiche Sachsen. Section II - Meißne Kreis, Leipzig 1856, S. 163.

29 Matrikelbuch der Kirche zu Reinhardtsgrimma: Eintragung des Pfarrers Johann Gottlieb Holfert (1785-1818) vom 11.07.1793, aus: Transkriptionsdokument des Heimatvereins Reinhardtsgrimma e.V.

3o Kliembt, Johann Gottlob: Topographie des Dorf und Ritterguths Ebersbach bey Görlitz nebst beygefügter Chronik, Ebersbach 1803, Folie $13 \mathrm{v}-14 \mathrm{r}$ Digitalisat der SLUB Dresden unter: http://digital. slub-dresden.de/id168969713X/31, S. 31-32 .

31 SächsHStA, 10505, Nr. 521, Kauf des Rittergutes ReinstA, 10505, N. 521, Kauf des Rittergutes Reinhardtsgrimma durch Johanna Joachime CharBauliche Verä Reinhardtsaginiert.

Koch 1999, S. 393-394

Wener, Hans; Kurt, Horst: Forstvermessung un Karten, Berlin 1991, S. 10. Zur Forstvermessung, zu Forstakten und Forstkarten: Biele, Gunter: Forstakten - wichtige Quellen für den Vermessungstechniker, Teil 1, in: Sächsisches Archivblatt, H. 02/2017 Dresden 2017, S. 10-11.

Forstcharte vom Ritterguth Reinhardtsgrimme Aufgenommen im Jahr 1807, Verfasser unbekannt, Dresden, Landesamt für Denkmalpflege Sachsen (LfDS), Plansammlung Inv.-Nr. LfDS-PS-1978-284.

35 SächsHStA, 10505, Nr. 253, Bauliche Veränderungen in Reinhardtsgrimma, 1801-1809. Schreiben übe Arbeiten am Schloss und Park an Friedrich Ludwig Ernst von Bülow, 1801

36 Siehe Matrikelbuch der Kirche zu Reinhardtsgrimma: Eintragung d. Pfarrers Johann Gottlieb Holfert (1785-1818) vom 11.07.1793, aus: Transkriptionsdokument des Heimatvereins Reinhardtsgrimma e.V.

37 Die Nutzung von Lärchen als bedeutsame Baumarten ist auch in Maxen bei der Andersen-Laurvertreten. Diese pflanzte der dänische Dichter und Schriftstler Hans Christin Andersen irgenhöndig Schifter auf einer Spazierfahrt 1844 mit Friederike Serre (Kreperin: Threrch wiederum als Bezugspunkt war so bedeutsam, dass un 1907 aufgrund des steigenden Fremdenverkehrs ei Aussichtsturm encthet werden sollte (SachsHStA, 10505, Nr. 445, Beitrag des Rittergutes Reinhardtsgrimma zum Bau eines Turms auf dem Großen Wilischberg, 1907) ganges. Spuren einer bürgerlichen Praktik 1780 1850, Wien 1996, S. 14-15.

25 Rosseaux, Ulrich: Freiräume - Unterhaltung, Ver gnügen und Erholung in Dresden 1694-1830 erschienen in der Reihe: Norm und Struktur - Studien zum sozialen Wandel in Mittelalter und Früher Neuzeit,Band 27, Köln 2007, S. 237.

26 Ebd.

27 SächsHStA, 12884 Karten und Risse, Schrank 04 Fach 047, Nr. 20-2p: Aus-Messung des Guhts Rein-
Schuhmann, August: Vollständiges Staats-, Postund Zeitungslexikon von Sachsen,Band 3: Friedrichswalde bis Herlachsgrün, Zwickau 1816, S. 457 458.

Gersdorf, Ernst Gothelf: Codex diplomaticus Saxoniae regiae (CBD),Band II-1, Urkunde 74, Leipzig 1864, S. 71. Vgl. Eichler, Ernst; Walther Hans: Histo- 
risches Ortsnamenbuch von Sachsen,Band 1, A-L, Berlin 2001, S. 357-358.

40 In einen Zusammenhang mit dem Ritter $\mathrm{d}$ Grymme stellte man den Grimmstein schriftlich bereits ab 1816 (Schuhmann 1816, S. 457-458.). Eine ausführliche Erklärung der Geschehnisse findet sich als nächstes erst bei Poenicke 1856, S. 163. Aufgegriffen wird die Sage immer wieder, unter anderem hier: Schmidt, Otto Eduard: Reinhardtsgrimma Ein Ort und ein Schloß abseits der großen Heerstraße, Sonderabdruck des Sächsischen Heimatschutzes Dresden, Jahrgang 1941, S. 4.

41 Poenicke 1856, S. 164; sowie Schmidt, 1941, S. 4.

42 Goethe, Johann Wolfgang von: Wahlverwandtschaften,Band I, Tübingen 1809, S. 9-11/ 50-52/ 59-60./ 125, online unter: http://www. deutschestextarchiv.de/book/view/goethe_wahlverw01_1809, Stand: 11.01.2021.

43 SächsHStA, 10505, Nr. 527, Die von Hans Georg von Osterhausen beschehene Abtretung der Jgdgerechtigkeit auf Reinhardtsgrimmschen Holzungen und Flurt auf Reinardsginmschen Holzungen und Huren an Churfurst Georg 1., 1788-1856, unpaginiert. Darin liegt ein Kaubrief von 157, , in dem bereits Friedrich fürsten abtritt.

4 SächsHStA, 10505, Nr. 253, Bauliche Veränderungen in Reinhardtsgrimma 1804-1806.

45 LfDS, Plansammlung, Forstcharte vom Rittergut Reinhardtsgrimme 1807, Inv.-Nr. LfDS-PS-1978-284. B- $\mathrm{u}^{3}$ : »Thiergarten« am Unterhof.

46 Krünitz, Johann Georg: Oekonomische Encyklopedie oder allgemeines System der Staats-, Stadt-, Haus- u. Landwirtschaft 1773-1858,Band 121, Berlin 1812, S. 679-680, siehe Krünitz online: http://www. kruenitz1.uni-trier.de/, Stichwort: >Rehgarten Stand: 25.01.2021.

47 Vgl. Beitrag Gottschalk: Artikel zum Schlossgarten Reinhardtsgrimma, Kapitel zum Sentimentalen Landschaftsgarten um 180o, Abschnitt >Voliere und Wildgarten

48 Bülow, Jacob Friedrich Joachim von; Bülow, Paul von: Familienbuch der von Bülow, Berlin 1858, S. 128 .

49 Arends, Martin: Zum Lebenslauf Georg Conrad Ruschenbuschs, online unter: http://www.arendi de/Win-Family/pero2837.htm, Stand: 28.01.2020.

o Merkel, Carl: Topografisch-Statistische Beschrei-

bung des Königreichs Sachsen,Band 1, Pulsnitz 1822 S. $365-366$.

51 LfDS, Plansammlung, Forstcharte vom Ritterguth Reinhardtsgrimme 1807, Inv.-Nr. LfDS-PS-1978-284. Nebenalleen lagen am langen Weg sowie am We nach dem Saubad.

52 Ebd., Nummer B-b4 (schwer lesbar).

53 Auf dem Entwurfsplan für den Schlosspark 1891 is die ehemalige Gärtnerwohnung nun als Forsthau bezeichnet (LfDS, Plansammlung, Inv.-Nr. 2018-98, Entwurfsplan für die Neugestaltung des Schlossparks, Max Bertram). Besagte "Gärtner-Wohnung ist in der Forstcharte von 1807 mit der Bezeichnung 04 am Unterhof (B) markiert. Ein erneuter Umbau geschah in den Jahren 1927/28 (siehe: SächsHStA, 10505, Nr. 391, Bauliche Veränderungen Forsthaus, 1927/28)

Wild, Cristian Gottlob: Interessante Wanderungen durch das sächsische Ober-Erzgebirge, Freyberg 1809, S. 156-161. Hier wird der präzise durchdachte, oft grausame Erfindungsreichtum der Vogeljagd detailliert beschrieben.

5 Gebauer, Heinrich: Die Volkswirtschaft im Königreiche Sachsen. Historisch, geografisch und statistisch dargestellt,Band 1, Dresden 1893, S. 413-414.

6 Bundesamt für Naturschutz (Hg.): Naturschutz und Biologische Vielfalt, Heft 47 - Heimat und Naturschutz. Die Vilmer Thesen und ihre Kritiker, Bonn 2007

Umfangreiche Schonzeiten und aus dem Jagdrech gestrichene Vogelarten werden 1888 erstech deutschlandweit festrelegt Siehe: Gesetz, betreffend den Schutz von Vügeln, in Deytsches Reichsestz-

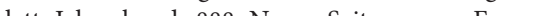
blatt, Jahresband 1888, Nr. 13, Seite 111-114, Fassung

$\mathrm{Ab}$ wann sich die Krähenhütte an diesem Standor befand, ist allerdings unklar. Erste Hinweise erhalten wir 1875 durch Flurbezeichnungen im Flurbuch (SachsHStA, 10505, Nr. 35, Flurbuch 1875). Ihr
genauer Standort findet sich dann im Freiberger Menauer Standort findett von 1876 . Meilenblatt von 1876.

59 Krünitz,Band 46, S. 475-476.
60 Hellmann, August: Über die Nützlichkeit der Krähenhütten, in: Cabanis, Jean (Hg.): Journal für
her Ornithologie. Ein Zentralorgan für die gesamte Ornithologie - zugleich Organ der deutschen Ornithologen-Gesellschaft, Dritter Jahrgang, Cassel 1855, S. 439-442.

LfDS, Plansammlung, Forstcharte vom Ritterguth Reinhardtsgrimme 1807, Inv.-Nr. LfDS-PS-1978-284. Müller, Gerhart: Zwischen Müglitz und Weisseritz. Ergebnisse der heimatkundlichen Bestandsaufnahme im Gebiet von Dippoldiswalde/ Glashütte, erschienen als: Werte der deutschen Heimat,Band 8 Berlin 1964, S. 73. Ebenso: Stephan, Bärbel: Thorvaldsens Aufenthalt im Juni des Jahres 1841 in der valdsens Aufenthalt im Juni des Jahres 1841 in de sächsischen Haupt- und Residenzstadt Dresden und auf dem Landschloß Maxen, in: Sachsisch Heimatblatter, Heft 6/ 1994, S. 338-339. Vgl. auch: Becher sach Handbuch der deutschen Kulturdenkmäler,Band 1 München 1996, S. 751.

München 1996, S. 751.
Bechter; Fastenrath; Dehio-Vereinigung 1996, S 751. Hier wird widersprüchlich zum Dokument aus
(5) 751. Hier wird widersprüchlich zum Dokument aus
der Turmkugel des Schlosses Reinhardtsgrimma vom 23.06.1843 (Verfasser: Pfarrer Paul Konstantin matsverein Rein hardtsgrimma e.V. (Hg.): Grimmsches Heimatblat, Heft Nr. 04, Dezember 2009, S. 9-10.) behauptet, dass Schenke und Schießhaus beide 1810/181 errichtet wurden. Das Turmkugeldokumen schreibt das Schielshaus Georg Conrad Ruschenbusch zu. Es ist vermutlich zwischen 1816 und 1843 entstanden (siehe dieser Beitrag: Die Landschaftsverschönerung unter Ruschenbusch, Abschnitt: Erweiterung der Buschhäuser)

64 SächsHStA, 10505, Akte Nr. 34: A - Unbewegliche Inventar bei dem Rittergute Reinhardtsgrimma 1874, Fol. 90.

65 LfDS, Plansammlung, Forstcharte vom Ritterguth Reinhardtsgrimme 1807, Inv.-Nr. LfDS-PS-1978-284 Die Verbotssäule erklärte vermutlich nur das Zutrittsverbot der Lehmgrube (in Forstkarte: , Lehmkeute $)$ ); siehe auch: Flurkarte 1809, (Erstelle unbekannt), Eigentum der Staatlichen Fortbildungsstätte Landwirtschaft, Signatur 2/399, Foye des Schlosses Reinhardtsgrimma.

66 Siehe SächsHStA, 10505, Nr. 222, Die Erbauung der Drescherhäuser auf dem Rittergute Reinhardtsgrimma betr. und derselben Vererbung 1798 LPDS, grimma betr. und derselben Vererbung 1798; LfDS, Plansannlung, Fortcharte vom Ritterguth Reinheuts Dentsce 137. Gegend nung, 1586-1634, Datensatz 90011272, Aufnahme-

67 Brückner, Johann Jakob; Günther, Christian Augus: Pitoreskische Reisen durch Sachsen oder Naturschönheiten Sächsischer Gegenden - Auf eine gesellschaftlichen Reise gesammelt. Reise durch die Meisnischen Lande mit 12 Landschaften, Heft 3 Leipzig 1803, S. 51-52.

68 Schiffner, Albert; Schumann, August: Vollständige Staats-, Post, und Zeitungslexikon von Sachsen,Ban 9: Rehbocksberg bis Sachsen, Zwickau 1822, S. $84-85$

69 Vgl. Becker, 1799, S. 2-3. Außerdem: Racknitz, Joseph Friedrich von: Briefe über die Kunst an eine Freundin, Leipzig 1795, VI. Brief, S. 104. Eine detaillierte Darstellung findet sich im Beitrag Gottschalk: Schlossgarten Reinhardtsgrimma, im Kapitel zum Sentimentalen Landschaftsgarten, Abschnit: Bedeutung und gartenkünstlerische Einordnung.

70 Schiffner; Schumann 1822, S. 85

71 Ebd., S. 85-86.

72 Lindau, Wilhelm Adolph: Rundgemählde der Gegend von Dresden,Band 2, Dresden 1822, S. 145 146.

73 SächsHStA, 10505, Nr. 250, Kauf- und Pachtverträge über das Rittergut Reinhardtsgrimma, 1788-1856, unpaginiert.

74 Ruschenbuschs Werdegang in Reinhardtsgrimm konnte nicht gesichert belegt werden. Hinweise auf seine Ankunft 1802 in Reinhardtsgrimma stammen aus dem Internet-Portal von Martin Arend "Ahnenforschung in Westfalen \& Lippe« (http:// www.arendi.de/Win-Family/pero2837.htm, Stand 26.01.2021). Seine Hochzeit mit Friederike Julian Christiane von Bülow findet gesichert Erwähnun im Dokument aus der Turmkugel des Schlosse Reinhardtsgrimma vom 23.06.1843. Hinweise au seine bereits davor angetretene Position als Gutsverwalter stammen aus der Sachsischen Zeitung (Grießbach, Karin: Heimatverein spürt Gutsherrn nach, Ausgabe vom 11.04.2009; sowie Herz, Franz Mit Küssen zum Gutsbesitzer, Ausgabe vom 27.12.2005). Die beiden Artikel beziehen sich auf Interviews mit Norbert Schulz vom Heimatverein Reinhardtsgrimma und Anneliese Flasche - Enkelin von Otto Röhringer, Besitzer der Buschhausschänke Anfang des 20. Jahrhunderts.

SächsHStA, 10505, Nr. 36, Grundbuch 1865 - ein 列 gemeinsam im Schloss.

Dokument aus der Turmkugel des Schlosses Reinhardtsgrimma vom 14.07.1886, Verfasser: Pfarre Rudolf Bernhard Hoffmann. Dieser beschreibt, was sich seit der Niederschrift des letzten Dokuments 1843 im Ort getan hat.

Siehe Priddat, Birger: Le concert universel. Physiokratie - eine Transformationsphilosophie des 18. Thd , Marburg 2001 S. 8-9: und Immler, Hans: Natur in der ökonomischen Theorie, Teil 2, Opladen 1985, S. 295-296. Vgl. auch Krepelin; Thränert 2011 S. $57-58$

78 Kötzschke, Rudolf: Ländliche Siedlung und Agrarwesen in Sachsen, Remagen/ Rhein 1953, S. 39-4O

9 Kötzschke 1953, S. 40-41.

(1751-1786) war Professor der Naturgeschichte und Okonomie an de Universität Leipzig; siehe Kötzschke 1953, S. 43.

1 Johann Riem (1730-1807) war ab 1785 Sekretär au Lebenszeit der Leipziger Ökonomischen Societät, siehe Alicke, Gerhard: Johann Riems Wirken in ökonomischen Sozietäten der Spätaufklärung, Dissertation, Mannheim 2015, S. 60-61.

82 Der Mediziner und Agrarreformer Albrecht Thae (1752-1828) gilt als Begründer der Agrarwissenschaften. Er war 1784 Mitglied der Königlich-Kurfürstlichen Hannoverschen Landwirtschaftsgesellschaft, beschäftigte sich ausführlich mit de englischen Landwirtschaft und hielt 1810-1819 Vorlesungen an der Berliner Universität.

83 Johann Christian Schubart (1734-1787) war deutscher Landwirt und Agrarreformer. Seine Pionierrolle in der Nutzung des Klees als Futterpflanze ist umstritten, trotzdem förderte er den Kleeanbau in der Landwirtschaft nachhaltig.

84 Diepenbrock, Wulf; Ellmer, Frank; Léon, Jens: Ackerbau, Pflanzenbau und Pflanzenzüchtung. Stuttgart 2016, S. 33-35; Kötzschke 1953, S. 43.

85 SächsHStA, 10505, Nr. 250, Verschiedene Pachtverträge (1788-1856). Kaufvertrag 1830

86 Merkel 1822, S. 368

7 SächsHStA, 10505, Nr. 309, Wirtschaftsrechnunge 1842

88 Ebd., Nr. 35, Flurbuch 1875.

Ebd., Nr. 13, Leute- und Gespannbuch 1892-1893 Einträge für im Mai transportierte Lebensmitte, darunter auch aus Blattern gepresste Futterriege Alle Bestandteile der Pflanze finden so Verwendung.

Ebd., Nr. 184, Obstwirtschaft 1875-1876.

91 Merkel 1822, S. 366

Ludwig, Jorg: Wissen - Wolle - Wandel. Merino- 
schafzucht und Agrarinnovation in Sachsen im 18. und 19. Jahrhundert, Halle (Saale) 2016; siehe auch Schulze, Eberhardt: Die berühmte Sächsische Schafzucht, online: https://www.sachsen-lese.de/index. php?article_id $=430$, Stand: $21.03 \cdot 2020$.

93 SächsHStA, 10505, Nr. 541, Erbregister über das Rittergut Reinhardtsgrim [...] des Wohl Edlen Gestrengen Herrn Hanß von Osterhausen auf Reinhardtsgrimm, Ober- und Niederlockwitz auch Nickern, Churfürstl. Sächs. Ober-Cammer und Bergrath zu Dresden Anno 1624

94 Merkel 1822, S. 366

95 SächsHStA, 10505, Nr. 78, Schafwollproben eines "Zeitstähr" (I. Classe).

96 Siehe Becker 1792, S. 1; dazu auch: Krepelin. Thränert 2011, S. 67-68.

97 Ein Beispiel dafür stellt dieses Bild dar: Dohna, Umrissradierung (braun laviert), Adrian Zingg, um 180o, Staatliche Kunstsammlungen Dresden - SKD online, Inv.-Nr. A 130459

98 Becker 1799, S. 6-7.

99 Siehe Dokument aus der Turmkugel des Schlosses Reinhardtsgrimma vom 23.06.1843; sowie: Sachsen Kirchengalerie, Fünfte Abteilung, Dresden 1840, S. 100; Entwurf: Aufriss der Hofgebäude der Alten Schaferei, Federzeichnung farbig laviert, Zeichner: Mauermeister Johann Gottlieb Adam, 1837, LfDS,
Plansammlung, ohne Inv.-Nr..

Makowski, Ivonne: Jahreskalender des Landesamtes für Denkmalpflege Sachsen, Dresden 2018, Blat September 2018.

101 Beilage zur Allgemeinen Zeitung No. 339, Ausgabe vom 04.12.1836, Abschnitt Deutschland, Tübingen 1836

102 Poenicke 1856, S. 164.

103 Bei »Sachsens Kirchen-Galerie« (auch: »Alte Sächsische Kirchengalerie «) handelt es sich um eine Beschreibung zahlreicher sächsischer Orte sam historischer Entwicklung, Kirchen- und Kirchinventarbeschreibung sowie Nennung der Pfarrer und Lehrer. Angefügt wurden jeweils Lithografien sämtlicher Kirchen eines Kirchortes innerhalb der Ortsbebauung und Landschaft; aufgenommen von verschiedenen Zeichnern. Entstanden in den verschiedenen Zeich 1837-1848, wurde sie herausgegeben vom Verleger
Hermann Schmidt in Dresden.

104Vgl. Köhler, Marcus Richard: «Thinking himself the greatest gardener in the World". Johann Busch (1725-1795) - Pflanzenhändler und Hofgärtner Katharina II. von Rußland, Dissertation, Berlin 1997. Münchhausen war Initiator des frühen Landschaftsgartens Schwöbber. Veltheim war Initiator des Landschaftsgartens Harbke, wobei Du Roi dort Aufseher über die Pflanzungen war.

05 Laufer, Johannes; Steinsiek, Peter-Michael: Quellen zur Umweltgeschichte in Niedersachsen vom 18. bi zum 20. Jahrhundert. Ein thematischer Wegweise durch die Bestände des Niedersächsischen Landesarchivs, Göttingen 2012, S. 464

106Schiffner, Albert: Beschreibung von Sachsen und der Ernestinischen, Reussischen und Schwarzburgi- schen Lande, Stuttgart 1840, S. 416

Dokument aus der Turmkugel des Schlosses Reinhardtsgrimma vom 23.06.1843.

Bechter; Fastenrath; Dehio-Vereinigung 1996, S. 751. Krepelin; Thränert 2011, S. 234.

Geller, Hans: Franz und Ferdinand Pettrich. Zwe sächsische Bildhauer aus der Zeit des Klassizismus, Dresden 1955, S. 101-102.

10 Ebd., $\mathrm{S} 102$.

11 Vgl. Schroeter, Bernhard: Für Burschenschaft und Vaterland. Festschrift für den Burschenschafter und Studentenhistoriker Peter Kaupp, Jena 2006, S. 73-74.

12 Ebd.; Meurer, Christian: Die Haager Friedenskonferenz,Band 1, München 1905, S. 58 siehe auch: Wikipedia, Artikel "Lützowsches Freikorps", online unter: https://de wikipedia or / wiki/ korps", online unter. Htps.//de.wikipedia.org/wiki/

Schroeter 2006, S. 74.

Cherbor Vom Kriegshaufen zum Massenheer, in: Grundkur S. S. 161. Carl Theodor Kor

Niemann, August: Militär-Handlexikon, Stuttgart 1877, S. 345.

16 Die Befreiungskriege mobilisierten Emigranten aus Tirol, eine Vielzahl an Studenten, Bürgern und Revierförstern. Auch in Reinhardtsgrimma solle 1813 zwei Männer verschwunden sein (Tinius 1956). Nach der Schlacht bei Dresden (August 1813) kam es zu einem Truppenrückzug nach Maxen und einem heftigen Gefecht bei Dohna (Venturini, Carl: Rußands und Deutschlands Befreiungskriege von der Franzosen-Herrschaft unter Napoleon Bonapart 1812-1815. Zweiter Theil, Krieg in Deutschland 1813 Leipzig 1816, S. 356).

17 Die Verbindung von Romantik, Krieg und Jägerkompanie demonstriert auch Joseph von Eichendorffs Gedicht "Der Jäger Abschied « (1810), in dem sich die Jäger sentimental vom Heimatwald verabschieden, um ihren Treuschwur abzuleisten.

18 Bärnighausen, Hendrik; Çoban-Hensel, Margitta: Joseph Friedrich Freiherr von Racknitz (1744-1818), seine Darstellung und Geschichte des Geschmocks der vorïlichsen VOlkern und in Ausstathngsdero Projtiche Schlosser, Burgen und (17in/1793), in :

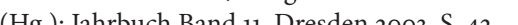
(Hg.): Jahrbuch,Band 11, Dresden 2003, S. 42.

Zur Lehrerschaft Pettrichs: Allgemeine Deutsche Biografie,Band 25, Leipzig 1887, S. 543. Zum Entwur Thormeyers sowie zur Ausführung Kühns: Bech
Fastenrath; Dehio-Vereinigung 1996, S. 201.

20 Zeichnung über Ausführung zweier Kugelessen und Einrichtung von Wohnräumen auf dem sog. Buschhause für Herrn Hauptm. Aster, Federzeichnung, Zeichner: Otto Röllig, 1874, Plansammlung LfDS, Inv.-Nr. LfDS-PS-125-63. Dazu: Dokument aus de Turmkugel des Schlosses Reinhardtsgrimma vom 23.06.1843.

121 Die Schießanlage bei Lauenstein im Müglitztal gehörte zur durch Kurfürst Moritz gegründeten Schützengilde und führte ein jährliches Scheibenschießen durch. 1823 wurde auch dort ein Schieß haus mit Tanzsaal, Orchester und Gesellschaftszimmern im Tal erbaut (Poenicke 1856, S. 167-168.)

122 LfDS, Plansammlung, Zeichnung über Ausführung zweier Kugelessen und Einrichtung von Wohnräumen auf dem sog. Buschhause für Herrn Hauptm. Aster, Federzeichnung, Zeichner: Otto Röllig, 1874 Inv.-Nr. LfDS-PS-125-63.

123 SächsHStA, 10505, Akte Nr. 34: A - Unbewegliche Inventar bei dem Rittergute Reinhardtsgrimm 1874, Fol. 87-89.

124 Zur Abreise Bertel Thorvaldsens aus Maxen (vermutl. nach Leipzig), in: Nauhaus, Gerd (Hg.) Robert Schumann Tagebücher,Band II, 1836-1854 Frankfurt/Main 1987, S. 169-170. Thorvaldsen Anreise erfolgte spätestens am 19.06.1841, siehe Brief König Christian VIU, von Dänemark an Bete Brief Konig Chrstan VII. von Danemark an Bertel Thias: Thorvate

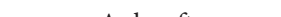
S. 338-339

26 Schiffner 1840, S. 416. Außerdem zur Brauere: Ungewitter, F. H. (Name unbekannt): Neuste Erdbeschreibung und Staatenkunde oder geographischstatistisch-historisches Handbuch,Band 1, Dresden 1858, S. 294.

127 SächsHStA, 12884 Karten und Risse, Schr. 04, F. 04 Nr. 20-2p: Aus-Messung des Guhts Reinhardtsgrüm. f. Fritz Mangolts [Erben], 1614/ 1628.

128 SächsHStA, 10505, Nr. 251: Kostenanschlag für noch fertigzubauende Gebäude, 1811

129 Stephan 1994, S. 339

130 Nauhaus, Gerd (Hg.): Robert Schumann Tagebücher,Band III, 1837-1847, Frankfurt/Main 1982, S. 280 und 282 .

131 Hugo, Albert (Hg.): Jagd-Zeitung, Ausgabe Nr. 23, vom 15.12.1869, Abschnitt ,Kleine Jagdgeschichten Wien 1869

132 Neumann, Hannes: Die deutsche Turnbewegung in der Revolution 1848/49 und in der amerikanischen Emigration, in: Ausschuss deutscher Leibeserziehe (Hg.): Beiträge zur Lehre und Forschung
Leibeserziehung,Band 32, Stuttgart 1968, S. 7-11.

133 Ebd., S. 11-12.

133 Ebd., S. 11-12.

135 Ebd., S. 51-52

136 Heimatverein Reinhardtsgrimma e.V.(Hg.) Grimmsches Heimatblatt, 34. Ausgabe, Juni 2017, S. 9-11.

137 Festzeitung zur Turnhallenweihe des Turnverein Reinhardtsgrimma, Ausgabe vom 1.-3. Mai 1926, S. 2, rechte Spalte. Der Autor dankt an dieser Stell Witold Donath und Norbert Schulz (Heimatverein Reinhardtsgrimma) für die Bereitstellung der Informationen.

138 Regensburger Zeitung, Ausgabe No. 199, vom 22.07.1862, Abschnitt iNachlese, Regensburg 1862. 39 Sächsische Constitutionelle Zeitung, Ausgabe No.
155, vom 09.07.1862, Abschnitt ,Königreich Sachsen`, Dresden 1862

SachsHStA, 10505, Akte Nr. 34: A - Unbewegliches Inventar bei dem Rittergute Reinhardtsgrimma 1874, Fol. 90.

(20)elin; Thranert 2011, S. 87-88.

44 Schiffner 1840, S. 416.

Karl Gottfried Traugott Faber (1786-1863) war seit 1820 Mitglied der Dresdner Kunstakademie. Er legte das Hauptaugenmerk in den 1840er/5oer Jahren auf Zeichnungen sowie auf sachliche und realistische Darstellungen (Saur Verlag Leipzig ( $\mathrm{Hg}$.): Allgemeines Künstlerlexikon,Band 36, München/ Leipzig 2003, S. 43).

1460enicke 1856, S. 163. Familie äre ans bekannte Spazierden der Gedanke nahe, dass eigentlich mehr Künstle die Landschaft durchstreift haben sollten. Zwar war
die Vermählung des bürgerlichen Försters Georg Conrad Ruschenbusch mit von Bülows Tochter eine Mesalliance, jedoch sollte dieser Umstand nicht in einem Zerwürfnis mit den Kunstmäzenen Serre und Majorin Serre waren Bürgerliche.

Dokument aus der Turmkugel des Schlosses Reinhardtsgrimma vom 23.06.1843.

Auszug aus einem Brief von Margarethe Schulz, geb. Aster, an ihren Bruder Georg Aster (1865-1932) Oberleutnant aus Dresden vom 20.03.1929, transkribiert von Arnold Streit, Bonn 2010, transkribiert in: Heimatverein Reinhardtsgrimma e.V.: Ausstellung zu Georg Conrad Ruschenbusch im Schloss Reinhardtsgrimma, o. J.

150 Krepelin; Thränert 2011, S. 41.

151 Becker 1799, S. 105.

153 Krepelin; Thränert 2011, S. 43.

154 Grimm 1922, Sp. 1667.

Agronomische Zeitung. Organ für die Interessen der gesamten Landwirtschaft, Ausgabe No. 24, vom 11.06.1866, Abschnitt `Kleine Zeitung - > Landwirtschaftliche Berichtes, Leipzig 1866, in: Agronomische Zeitung, Sammel-Bd. 21, Leipzig 1866, S. 381.

156 Mittheilungen der Ökonomischen Gesellschaft im Königreiche Sachsen 1874-75, Dresden 1875, S. 22. In einer Diskussion vom 01.01.1872 wird Aster als Vorsitzender genannt. 57 Ebd., S. 4-5.

158 Ebd., S. 20

SächsHStA, 10505, Nr. 47, Ausgabenbuch Arbeitslöhne, Juli 1874 - Mai 1879. Henkes Nachfolger wa ab spätestens 1887 der Revierförster Heidrich. Ein Akte listet um 1887 das Inventar des Forsthauses auf, welches von Förster Heidrich bewohnt wird (SächsHStA, 10505, Nr. 26, Register über das bewegliche Inventar des Rittergutes Reinhardtsgrimma, ab 1874). Unter Senfft von Pilsach wurde schließlich 
ab spätestens 1924 Revierförster Kurt Edmund Hetze eingestellt. In einer Akte liegt der Dienstvertrag zwischen der Gutsherrschaft und dem genannten Förster (SächsHStA, 10505, Nr. 384, Jagd- und Forstangelegenheiten, 1913-1924).

6oBericht über die 24. Versammlung des sächsischen Forstvereins gehalten zu Zittau am 28., 29. und 30 . Juni 1877, in: Jahresbericht des Sächsischen Forstvereins,Band 21-25, Colditz 1876-1879, S. 149.

161 Statuten des Sächsischen Forstvereins, Dresden 1847, ohne Seitenzahlen, online unter: https://digital.slub-dresden.de/werkansicht/dlf/15277/1/, Stand: 11.01.2021.

162 Mittheilungen der Ökonomischen Gesellschaft im Königreiche Sachsen 1875-76, Dresden 1876, S. IV.

163 SächsHStA, 10505, Nr. 35, Flurbuch 1875.

${ }_{164}$ Ebd., Croquis der Fischwässer, Strassen, Wege, Wehre, Obstanlagen u. der Hölzer außerhalb der Schläge des Ritterguts Reinhardtsgrimmas.

165 Dokument aus der Turmkugel des Schlosses Reinhardtsgrimma vom 23.06.1843. Darin wird beschrieben, welche »unvergeßlichen« Gebäude Ruschenbusch ausführte und wie er das Schloss in Stand setzte.

166SächsHStA, 10505, Nr. 73, Ruschenbusch-Statut, S.

67 Reinhardtsgrimma e.V.: Grimmsches Heimatblatt, 34. Ausgabe, Juni 2017, S. 9-1

Müller, Georg: Hans Alexander von Bosse, in: Allgemeine Deutsche Biographie,Band 47, Leipzig 1903, S. 137-138.

69 Über Ludwig Uhland und seinen Prolog: Freie Verwaltung des Nachlasses von Rudolf Steiner, »Biographien und Biographische Skizzen «, S. 324, onlin unter: http://fvn-rs.net/index.php?option=com_ content \&view $=$ article \&id = 616:ludwiguhland\&catid=32:ga-33-biographien-und-biographische-skizzen-1894-\&Itemid=12, Stand 13.01.2021.

17o Siegmund, Andrea: Die romantische Ruine im Landschaftsgarten. Ein Beitrag zum Verhältnis der Romantik zu Barock und Klassik, Würzburg 2002, Romantik

171 Zur Turnsperre, online: https://de.wikipedia.org/ wiki/Turnsperre, Stand: 31.01.2020

72 Müller 1903, S. 137-138.

173 Gern, Alfons: Sächsisches Kommunalrecht, München 2000, S. 10-11.

174 SächsHStA, 10505, Nr. 35: Flurbuch 1875, Croquis von Ober-/ Nieder-Reinhardtsgrimma mit Benennung der Forst-, Wiesen-, Feld- und Plantagenflächen, Angabe der Grenzsteine und Forst-Abtheilungen; siehe auch LIDS, Plansammlung, Forstcharte vom Ritterguth Reinhardtsgrimm 1807, Inv.-Nr. LfDS-PS-1978-28

ericht über die 35 Versammlung des Sächsischen Forstvereins gehalten zu Schwarzenberg, 29.06.-02.07.189o, Freiber 1891, S. 142

6 Deutsche Landwirtschaftsgesellschaft (Hg.): Jahrbuch der Deutschen Landwirtschaftsgesellschaft,Ba nd 6, Teil II - 1891, Berlin 1892, S. 89* der Mitgliederliste.

177 Schreiber, Paul (Hg.): Jahrbuch des königlich sächsischen meteorologischen Institutes für das Jah 1893, Jahrgang XI der neuen Reihe, Chemnitz 1894, S. 14. Messstation Nr. 193 mit einem Jahresniederschlag von $569,9 \mathrm{~mm}$ (siehe S. 32).

178 SächsHStA, 10505, Nr. 339, Bauliche Veränderungen, Reparaturen, Um- und Neubauten auf dem Rittergut Reinhardtsgrimma 1889-1902.

179 SächsHStA, 10505, Nr. 12, Leute- und Gespannbuch 1891-1892. Sowie: Ebd., Nr. 13, Leute- und Gespannbuch 1892-1893.

180Ebd., Nr. 339; Bauliche Veränderungen am Rittergut, 1889-1902. Darin ist das Akkumulatorenhaus samt elektrischer Leitungen aufgeführt. Hinweise zur Elektrifzierung der Landwirtschaft hier Ebd $\mathrm{Nr}$. Elektrifizierung Lon Reinhaft hier: Ebd Anwe, Anwendung der Elektrizität in der Landwirtschaft,
1901.

Tinius, Heinz: Ortschronik Reinhardtsgrimma Reinhardtsgrimma 1956, S. 93. Zum Neubau de Schlottwitzer Straße im Jahr 1900. Zu Straßenbauarbeiten an der Buschhausschänke: SachsHStA, 10505, Nr. 66: Capitel außerhalb des Forstes Rein hardtsgrimma, 1882-1885.

22 Forstmeister August Gödde (Hg.): Neue Jagdzeitung. Mit besonderer Berücksichtigung des JagdBetriebs in West-Deutschland, 1. Jahrgang 1888 Münster 1888, S. 100-103.

3 SächsHStA, 10505, Nr. 66/ 67, Capitel außerhalb de Forstes Reinhardtsgrimma, 1882-1885/ 1885-1887.

4 Ebd., Nr. 339, Bauliche Veränderungen am Rittergut, 1889-1902.

Tinius, Heinz: Ortschronik Reinhardtsgrimma Reinhardtsgrimma 1956, S. 93

186 SächsHStA, 10505, Nr. 92, Adressbuch der Gutsverwaltung 1906.

87 Ebd., Nr. 104, Bau-Rechnung Reinhardtsgrimma, $1907 / 1908$.

188 Ebd., Nr. 445, Bau eines Turms auf dem großen Wilischberg und der Beitrag des Rittergutes Reinhardtsgrimma, Abschrift Antwortschreiben von Maximilian Senfft von Pilsach an Dr. med. Pohl von Pfar Richer vom Verkehrserein Kre Pohl und Umgebung, vom 20.11.1907.

189 SächsHStA, 10505, Nr. 445, Bau eines Turms au dem großen Wilischberg und der Beitrag des Rittergutes Reinhardtsgrimma, Schreiben vom Verkehrsverein Kreischa und Umgebung an Oberst Maximilian Senfft von Pilsach, vom 15.11.1907.

obbd., Nr. 423, Gutsverwaltung in Reinhardtsgrimma, 1907-1913.

1 Ebd., Nr. 233, Bau der Feldscheune und Ausrüstung mit Maschinen, 1927

194 Ebd., S. 98

95 Festzeitung zur Turnhallenweihe des Turnvereins Reinhardtsgrimma, Ausgabe vom 1.-3. Mai 1926.

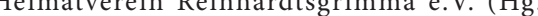

Grimmsches Heimatblatt, 15. Ausgabe, September 2012, Anhang.

97 Ebd., 40. Ausgabe, Dezember 2018, S. 11. Vornam unbekannt.

198 SächsHStA, 12884 Karten und Risse, Schr. 04, F. 047 Nr. 20-2p: Aus-Messung des Guhts Reinhardtsgrüm. f. Fritz Mangolts [Erben, Anmerkung d. Verfassers], $1614 / 1628$

199 Heimatverein Reinhardtsgrimma e.V (Hg.): Grimmsches Heimatblatt, 37. Ausgabe, März 2018, S. 7-8.

201 Eppert, Anja: Röhrsdorfer Grund. Auf den Spuren einer der ältesten Anlagen Sachsens, in: Pückle Gesellschaft e.V. (Hg): Mitteilungen der Pückle Gesellschaft, H. 27, Berlin 2013. Zur Bedeutsankeit der Anlage S. 20.

der Anlage

203Krepelin; Thränert 2011, S. 109-113. Melzer, Stefanie Früh $6 \mathrm{Uhr}$ begaben sich seine churfürstliche Durchlaucht nach der Eremitage ..., in: Jahrbuch der Staatlichen Schlösser, Burgen und Gärten Sachsen 14 (2006), Dresden 2007, S. 173-184.

204Ebd., S. 234.

205Becker 1792, S. 14; siehe auch: Krepelin; Thränert 2011, S. 135-138.

206Krepelin; Thränert, S. 136-136.

207Maier-Solgk, Frank; Greuter, Andreas: Landschaftsgärten in Deutschland, München 2009, S. 26.

208Erworben durch Major Friedrich Anton Serre (17891863) im Jahr 1819. Siehe dazu: Königliche Akademie der Wissenschaften München (Hg.): Allgemeine Deutsche Biographie,Band 34, Leipzig 1892 S. 40-41. Nach seinem Tod blieb es im Besitz seine Gattin Friederike Serre (1800-1872) bis zu dere Tod 1872. Siehe dazu: Brockhaus, Friedrich Arnold: Unsere Zeit. Deutsche Revue der Gegenwart, Leipzig 1872, S. 646, online unter: https://archive org/ stream/unserezeitoofolggoog \#page/n663/ mode/2up, Stand: 21.01.2021.

209Bolze, Lothar: Serres und ihre Freunde, Maxen 2000, S. 6 und 163 .

Anton Serres Innovationen und seinem sozialem Engagement: Bolze, Lothar: Anton Serre, in: Institut für Sächsische Geschichte un Volkskunde e.V. (Hg.): Sächsische Biografie, online unter: https://saebi.isgv.de/biografie/Anton_Serre (1789-1863), Stand: 28.01.2021.

212 Ebd., sowie Heimatverein Reinhardtsgrimma e.V Leben und Wirken des Georg Conrad Ruschenbusch, unveröffentlichte Ausstellungstafeln (in Kooperation mit Nachfahren der Familie).

213 Krepelin; Thränert 2011, S. 39.

214 Ebd., S. 211-212.

215 Siehe Lungkwitzer Herrenhof - Gesamtplan de Anwesens, Verfasser unbekannt, Federzeichnun 1701/1715 (Deutsche Fotothek, SLUB Dresden, Aufn.-Nr.: df_hauptkatalog_0120190), online unter: http://www.deutschefotothek.de/documents obj/30119246. Datiert auf 1715 von der SLUB. Wahrscheinlicher ist nach dem schlichten Zeichenst und dem Planstempel eine Entstehung in der zweiten Hälfte des 18. Jh.

Heinrich, Bernd: Johann Gottlob Quandt in Dittersbach, in: Rat der Gemeinde Dürrröhrsdorf-Dittersbach (Hg.): Johann Gottlob von Quandt, Dürrröhrsdorf-Dittersbach 1985, S. 26.

217 Ebd., S. 28.

219 Maaz, Bernhard: Die Fresken auf der Schönen Höhe, in: Rat der Gemeinde Dürrröhrsdorf-Dittersbach (Hg.): Johann Gottlob von Quandt, Dürrröhrsdorf-Dittersbach 1985, S. 45.

220Krepelin; Thränert 2011, S. 232-233.

221 Bärnighausen; Çoban-Hensel 2003, S. 41

222 Ebd., S. 42

223 Schiffner; Schumann 1822, S. 195-198.

24 Koch 1999, S. 376-383.

225 Schiffner; Schumann 1822, S. 196-197.

26 Racknitz, Joseph Friedrich von: Briefe über die Kunst an eine Freundin, Dresden 1792, in: Koch 1999, S. 393-394.

227 Heimatverein Reinhardtsgrimma e.V.: Ausstellung zu Leben und Wirken des Georg Conrad Ruschenbusch im Schloss Reinhardtsgrimma, o. J., Auszug aus einem Brief von Margarethe Schulz geb. Aster an ihren Bruder Georg Aster (1865-1932), Oberleutnant aus Dresden vom 20.03.1929, transkribiert vo Arnold Streit, Bonn 2010

Festzeitung zur Turnhallenweihe des Turnverein Reinhardtsgrimma, Ausgabe vom 1.-3. Mai 1926, S.

229 Krepelin; Thränert 2011, S. 37. Das Kapitel behandelt neue Legitimationsstrategien des Adels.

Wie im Bezug auf das Reichsvogelschutzgesetz un den Vogelfang unter von Bülow besprochen. Sieh dazu: Bundesamt für Naturschutz (Hg.): Naturschutz und Biologische Vielfalt, Heft 47 - Heimat und Naturschutz. Die Vilmer Thesen und ihre Kritiker, Bonn 2007.

231 Rüenauver, Uta: Zeitgenössische Dichter und die Romantik. Die Poetisierung der Welt, Deutschlandfunk Kultur, Beitrag vom 30.08.2019.

232 Eichendorff, Joseph von: "Man hat die Welt wie ei mechanisches, von selbst fortlaufendes Uhrwerk sich gehörig zurechtgestellt«, in: Eichendorff, Joseph von.: Der deutsche Roman des 18. Jahrhunderts in seinem Verhältnis zum Christenthum, Leipzig 1851 S. 81.

Vgl. Bartsch, Annika und Schmidt, Jacob (Un Jena): Romantik 2.0 als progressive Bewältigungsstruktur der Moderne, in: Blog Modell Romantik 17.05.2017, http://www.modellromantik.uni-jena.de/ index.php/2017/05/17. Siehe auch: Krejci, Walter (Treffpunkt-Philosophie): Romantik 2.o. Warum wir uns wieder nach ihr sehnen sollen, Beitrag vom 13.08.2017, online unter: http://treffpunkt-philosophie.de/romantik-2-o-warum-wir-uns-wiedernach-ihr-sehnen-sollen/2/ (Zugriff am: 13.01.2021). 